\title{
Lattice Frequencies and Rotational Barriers for Inorganic Carbonates and Nitrates From Low Temperature Infrared Spectroscopy
}

\author{
R. A. Schroeder, ${ }^{1}$ C. E. Weir, and E. R. Lippincott ${ }^{2}$
}

(May 29, 1962)

\begin{abstract}
Infrared absorption spectra of inorganic nitrates and carbonates have been obtained on single crystals at room temperature, under liquid nitrogen refrigeration and under liquid helium refrigeration. Diffuse absorption observed in the room temperature spectra between about $1400 \mathrm{~cm}^{-1}$ and $700 \mathrm{~cm}^{-1}$ is resolved under liquid helium refrigeration into a large number of bands not attributable to fundamentals or combinations of fundamental frequencies of the anions. Almost all of these bands are readily interpreted as summation bands of fundamental frequencies with successive levels of a librating oscillator. The libration is considered to represent a planar torsional oscillation of the anion about the trigonal axis. The librational frequency depends in part on the crystal structure and on the ions. In a given material the librational frequency as determined from successive bands is reasonably constant. In the substances studied the librational frequency varied from about $15 \mathrm{~cm}^{-1}$ to $30 \mathrm{~cm}^{-1}$.

Band limits observed in the spectra are interpreted as representing rotational energy barriers. These barrier heights are approximately $200 \mathrm{~cm}^{-1}$ with some dependence on the crystal structure and the ions involved. Barrier heights calculated from a cosine potential function agree reasonably well with the observed barriers for the cubic and calcite structures. Similar calculations have not been made for other structures studied because of doubtful assignments or unknown structural details. In particular, spectra of the aragonite structures are remarkable in detail and complexity, and have not been analyzed. However, the details of these and all other spectra studied appear to involve similar phenomena.
\end{abstract}

\section{Introduction}

Free rotation of atomic groups in the solid phase was suggested initially by Pauling in 1930 [59] ${ }^{3}$. A number of reports appeared subsequently presenting evidence for free rotation in solids $[5,25,32$, $39,40,41,65]$. In general, the experimental evidence presented consisted chiefly of plausible interpretations of X-ray structure determinations of various solid phases in the ammonium salts and in metal nitrates and carbonates. It was argued that essentially free rotation of the nonspherical ion would be necessary to produce a NaCl-type structure which was required by the $\mathrm{X}$-ray data from these salts. In other structures containing nitrate and carbonate ions free rotation of the ion about the trigonal axis was proposed to satisfy the X-ray data. It has been argued more recently that a disoriented arrangement of the nonspherical ions would also satisfy the diffraction data without the necessity for free rotation $[45]$.

Completely unambiguous evidence of rotation in solids has been sought actively. The question has been pursued with an increasing number of experimental techniques being brought to bear such as $\mathrm{X}$-ray studies $[6,22,45,68]$, specific heat measure-

1 Present address, University of Southwestern Louisiana, Lafayette, La.

2 Consultant to the Mineral Products Division, National Bureau of Standards. Present address, Dept. of Chemistry, University of Maryland, College Park, Md. 3 Figures in brackets indicate the literature references at the end of this paper. ments [48], infrared spectroscopy [34, 35, 74, 75], Raman spectroscopy $[9,10,11,12,25,36,42,43$, $44,55,62,63,64]$, nuclear magnetic resonance $[3,4,16,28]$, and neutron diffraction $[18,31,49,50$, 53]. In each of these fields the literature is extensive and the references cited are not exhaustive but are confined to the inorganic materials of interest here. Almost without exception, all studies agree that free rotation does not take place at ordinary temperatures. However, they conclude that hindered rotation, i.e., a torsional oscillation or libration does take place with potential barriers sufficiently low that disordering may occur near room temperature. The only exceptions appear to be in $\mathrm{NH}_{4} \mathrm{I}$ where there is evidence [61, 72] from heat capacity and infrared data that the $\mathrm{NH}_{4}{ }^{+}$rotates about an $\mathrm{N}-\mathrm{H}-\mathrm{I}$ axis above $75^{\circ} \mathrm{K}$, and in a recent report [18] of free rotation in KCN based on neutron diffraction studies. The present ideas suggest librating ions are able to surmount the barriers at a rate sufficiently great to satisfy the $\mathrm{X}$-ray structure requirements. In effect the findings substantiate the suggestions advanced by Frenkel in 1943 [23] who opposed Pauling's rotation hypothesis and proposed instead torsional oscillation with a finite disordering rate.

Harmonic librations are lattice modes and might be detected by Raman or infrared spectroscopic studies. The frequencies expected for these modes cannot be predicted without knowledge of the potential energy function describing the potential barrier. Although 
the rotational frequencies of the free ion can be calculated readily it is only possible to predict that the frequency of the restricted harmonic librator must be greater than that for the free rotator. Low frequency shifts have been found in the Raman spectra of inorganic solids for which there is independent evidence of anion or cation libration [for example, preceding references on Raman spectra]. Certain Raman lines have been attributed to frequencies arising from harmonic libration modes; however, there is no assurance that these represent the fundamentals rather than overtones or combinations. There is also no conclusive evidence for harmonic libration in the infrared spectra of solids, although Hexter [34, 35] has proposed that certain complex high frequency overtone and combination bands in the $3000 \mathrm{~cm}^{-1}$ to $5000 \mathrm{~cm}^{-1}$ region of carbonates and nitrates arise from libration combinations. Early reststrahlen studies [51] have shown the existence of low frequency infrared bands whose exact origin is unknown. These bands have been widely attributed to lattice vibrations of an unspecified nature.

This paper will present evidence for libration in the infrared spectra of anhydrous metal nitrates and carbonates. These substances have been the subject of infrared studies since the early work of Schaefer, Bormuth, and Matossi [66] and the spectra are believed to be well understood insofar as the assignments of the six fundamental vibrations of the free nitrate and carbonate ions $[30,33,38]$ are concerned. However, the strong overtone and combination bands and their complexity have been the source of recent studies $[29,34,35]$. The very intense and obviously complex band containing the antisymmetric stretching band has also been of concern [52]. Newman and Halford $[57,58]$ observed in the infrared spectra of crystalline $\mathrm{Pb}\left(\mathrm{NO}_{3}\right)_{2}$ and $\mathrm{TlNO}_{3}$ bands that were not attributable to fundamentals of the anions. They were assigned to sum and difference bands of the symmetric stretching vibration and a low lying $\left(30 \mathrm{~cm}^{-1}\right)$ lattice mode. Recently Gross and Shultin [26] studied $\mathrm{Ba}\left(\mathrm{NO}_{3}\right)_{2}$ and $\mathrm{Pb}\left(\mathrm{NO}_{3}\right)_{2}$ with similar results and succeeded in resolving several combination bands. Both of these studies used low temperatures (liquid nitrogen temperature) to improve the resolution. A careful examination of the pioneering spectra given by Schaefer, Bormuth, and Matossi [66] on the crystalline carbonates shows clear evidence of weak bands in the frequency range containing the fundamentals. In this early work some attempt was made to explain these bands as sum and differences between fundamentals or between fundamentals and lattice frequencies reported from reststrahlen experiments, but with only partial success.

Recent studies in this laboratory of the effect of high pressure on the infrared spectra of crystalline nitrates and carbonates showed the sum and difference modes previously reported in the heavy metal nitrates and produced evidence for additional bands of this type at elevated pressures. These observations motivated a serious study of the combination bands at $1 \mathrm{~atm}$ in an attempt to understand the behavior at elevated pressures.
It is obvious that extensive combinations involving sum and difference bands between a lattice fundamental of the order of $30 \mathrm{~cm}^{-1}$ and the internal fundamentals of the anion found between $700 \mathrm{~cm}^{-1}$ and $1500 \mathrm{~cm}^{-1}$ will produce such a complex overlapping band structure as to make analysis extremely difficult. If the spectrum were simplified by removing the difference bands through cooling as suggested by Hornig [38] the fact that $30 \mathrm{~cm}^{-1}$ levels are involved would require very low temperatures. Simple calculations showed that at the temperature of liquid nitrogen, large numbers of ions would be in upper states when the levels are spaced $30 \mathrm{~cm}^{-1}$ apart. At the temperature of liquid helium, however, almost all of the ions would be in the ground state. This report presents data on the room temperature and on the low temperature - liquid nitrogen and liquid helium temperature -infrared spectra of "thick" (about 0.010 in.) crystals of metal nitrates and carbonates. The spectra are interpreted in terms of librations of the anions.

\section{Experimental Method}

\subsection{Apparatus}

Most infrared spectra were recorded on a commercial double-beam spectrometer using $\mathrm{NaCl}$ prisms. To permit the use of small thick crystals the spectrometer was equipped with a microfocusing unit employing reflecting optics. This unit was modified for use with the spectrometer and further' to permit introduction of the tip of a Dewar into the focal region. The modified unit produced a focal spot 0.060 to $0.080 \mathrm{in}$. in diameter within a working: space $1 \frac{1}{8}$ in. wide. Approximately 45 to 50 percent of the normal energy was available with the microfocus unit. Only a single unit was available, and this increased the path length of the specimen beam by about $18 \mathrm{in}$. over the path length of the reference beam. Therefore, complete compensation for water vapor and carbon dioxide was not achieved. Weak bands for these materials appeared in all spectra near $1700 \mathrm{~cm}^{-1}, 2350 \mathrm{~cm}^{-1}$, and $3500 \mathrm{~cm}^{-1}$. These regions were not of particular interest in the data but caution was exercised in interpreting weak bands near these frequencies.

The overtone and combination region at frequencies above $1700 \mathrm{~cm}^{-1}$ was studied on a double beam spectrometer using a grating to provide greater resolution in the higher frequency region. This unit was equipped with a reflecting microfocus unit in both beams to provide for better compensation. Weak bands, particularly in the 3500 $\mathrm{cm}^{-1}$ region, indicated incomplete compensation.

The low temperature equipment was constructed to utilize an available commercial Dewar. This was a triple-wall stainless steel unit open at the bottom to permit access to the tip of the innermost liquid container. The central wall comprised a radiation shield that extended well below the liquid reservoir. A specimen holder was fabricated from a $1 / 2$ in. diam bar of copper. The bar was approxi- 
mately 2 in. long, threaded at the top end to screw tightly into the tip of the liquid reservoir and machined down at the bottom end to give a flat plate $1 / 2$ in. square times $1 / 8$ in. thick. The length of 2 in. was necessary to permit specimens mounted in the flat bottom plate to be positioned in the focal spot of the rather large ellipsodial focusing mirror. The specimens were mounted over holes 0.060 in. in diameter drilled in the flat plate. Five holes were drilled in two rows, the top row containing three holes, the bottom row two. Holes were located $1 / 8 \mathrm{in}$. apart and holes in the two rows were staggered so that a single hole could be brought into the focal spot with no stray radiation through the adjacent holes. Each hole was counterbored from each side of of the plate to a diameter of $1 / 8$ in. and of such depth that a flat web of copper approximately $1 / 32$ in. thick remained in the center of the plate. Counterboring permitted entry of the highly convergent cone of radiation and afforded a relatively shallow well in which the crystals were mounted. The Dewar was closed with a brass housing which enclosed the copper bar and was equipped with two $\mathrm{NaCl}$ windows located opposite the flat plate on the bottom of the copper bar. Vacuum closure between the housing and the outer wall of the Dewar was accomplished satisfactorily with a rubber O-ring seal. The restricted working space between the ellipsoidal mirrors required miniaturization and although considerable clearance between brass housing and copper bar was provided, it did not prove feasible to extend the radiation shield around the copper bar inside the housing. Attempts to insert such a shield invariably resulted in a thermal short circuit produced by nonuniform contraction of the inner container or the radiation shield assembly on cooling. Some radiation protection was provided by wrapping the copper bar with bright aluminum foil. The Dewar was evacuated through a cutoff valve by means of an oil diffusion pump backed up by a mechanical pump. The complete Dewar assembly was rigidly mounted in a rack equipped with guides and adjusting screws to permit controlled motion in three perpendicular directions. This mount was essential to afford rapid, controlled centering of the small holes in the equally small focal spot.

Five crystals, each covering a single hole, were studied in a single experiment. The small crystals required ( $1 / 8 \mathrm{in}$. in diameter) were generally available from reagent bottles or crystal fragments. Crystals were selected for clarity and shape, one reasonably flat surface being required. They were then filed down to fit snugly against the $1 / 32$ in. web at the bottom of the $1 / 8 \mathrm{in}$. wells, and were cemented into place against the web and the walls of the well with a low temperature resin. All crystals were mounted on the same side of the web and in use this side was turned away from the incident radiation. This arrangement minimized heating of the crystals by unused radiation and eliminated problems arising from absorption by the adhesive. Crystals were checked for thickness while in place by their spectra; if too thick, they were thinned in the center by using water or dilute acid. In these studies estimated crystal thicknesses ranged from

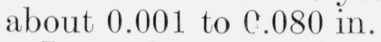

In a given experiment spectra were recorded at room temperature and, following exhaustive evacuation of the Dewar, were recorded at liquid nitrogen temperature. If the runs at liquid nitrogen temperature proved successful, liquid helium was introduced into the Dewar immediately after removing the liquid nitrogen and the final spectra were then recorded. In an ordinary experiment with approximately 1 liter of liquid helium in the Dewar, the rate of boil-off of the helium was sufficiently low to provide cooling for at least $4 \mathrm{hr}$ with the energy input supplied by the spectrometer and the normal environment. This period was more than sufficient to obtain the spectra of the five specimens. Following an experiment the crystals were found to be still firmly cemented in place and, although generally fractured by thermal contraction or the stresses produced by the adhesive, appeared to be in good thermal contact with the copper. Each cooling cycle appeared to produce further fracturing which tended to increase scattering losses and reduce transmission. Thus it was found to be desirable, wherever possible, to obtain all spectra on a single cooling cycle.

In these experiments it was not considered feasible to attempt to measure the temperature of the small crystal specimens. The temperature of the flat copper strip was measured in a typical experiment and with liquid nitrogen in the Dewar a value of $86^{\circ} \mathrm{K}$ was obtained while with liquid helium the temperature was found to be $27^{\circ} \mathrm{K}$. These temperatures represented the temperature of the copper bar at a point as far from the coolant as possible, measured with a gold-cobalt alloy-copper thermocouple [54]. The actual temperature of a crystal might have been higher because of the energy flux from the focal spot, with the temperature being determined by the absorption, the specific heat, the thermal conductivity of crystal and cement, and the thermal barriers between crystal and cement and copper, or lower because of the thermal energy introduced by the thermocouple leads. On the other hand the thermal path was very short and the crystal was nearly surrounded by the cold copper strip. In several spectra of interest the difference band between the symmetric stretching mode and a level of the order of $30 \mathrm{~cm}^{-1}$ was identified. This band in effect represented a thermometer built into the spectrum and observations showed that the difference band, although somewhat reduced in intensity, was still very prominent at the temperature of liquid nitrogen. With liquid helium in the Dewar, however, the difference band was effectively missing. This result may be taken as evidence that the temperature of the crystal was sufficiently low to remove all difference modes involving energies of $30 \mathrm{~cm}^{-1}$ or more. The removal of difference bands was the primary objective of cooling and the result showed that, irrespective of the absolute temperature of the crystal, the resulting spectra could be interpreted in terms of the fundamentals 
and their summation bands only. In tabulating the spectra the temperatures will be described as liquid nitrogen temperature and liquid helium temperature with the clear understanding that the temperatures of the crystals may differ appreciably from the boiling temperatures of these liquids.

\subsection{Materials Studied}

The following nitrates were studied: $\mathrm{NaNO}_{3}$, $\mathrm{KNO}_{3}, \mathrm{RbNO}_{3}, \mathrm{CsNO}_{3}, \mathrm{TlNO}_{3}, \mathrm{AgNO}, \mathrm{Sr}\left(\mathrm{NO}_{3}\right)_{2}$, $\mathrm{Ba}\left(\mathrm{NO}_{3}\right)_{2}$, and $\mathrm{Pb}\left(\mathrm{NO}_{3}\right)_{2}$. Of these all except $\mathrm{RbNO}_{3}, \mathrm{CsNO}_{3}$, and $\mathrm{TINO}_{3}$ were reagent grade chemicals of high purity. These three materials were recrystallized from aqueous solution at $55{ }^{\circ} \mathrm{C}$ to effect further purification and to prepare suitable crystals. This technique was used by Newman and Halford [58] to prepare large $\mathrm{TINO}_{3}$ crystals. Suitable crystals for the other materials were obtained from the substances as received.

The following carbonates were studied: $\mathrm{MgCO}_{3}$, $\mathrm{CaCO}_{3}, \mathrm{SrCO}_{3}, \mathrm{BaCO}_{3}, \mathrm{PbCO}_{3}, \mathrm{FeCO}_{3}$, and $\mathrm{MnCO}_{3}$. These were all natural minerals obtained in large crystals. The materials and their sources are as follows:

$\mathrm{MgCO}_{3}$-magnesite origin uncertain (large clear crystals)

$\mathrm{CaCO}_{3}$ - calcite - Brazil (large clear crystals)

$\mathrm{SrCO}_{3}$ - strontianite - Argyll, Scotland (large translucent crystals)

$\mathrm{BaCO}_{3}$ - witherite - Lancashire, England (large translucent crystals)

$\mathrm{PbCO}_{3}$ - cerrusite - Southwest Africa (large clear crystals)

$\mathrm{FeCO}_{3}$ - siderite-Roxbury, Conn. (opaque masses, obviously impure)

$\mathrm{MnCO}_{3}$-rhodochrosite-Kusatuni Kaga, Japan (opaque-large crystals)

$\mathrm{CaCO}_{3}$ - aragonite - Cianciano, Sicily (large translucent crystal).

Spectrochemical analyses were performed on all carbonates except the $\mathrm{CaCO}_{3}$ (aragonite). Aside from trace impurities the following metallic impurities were found in quantities up to a maximum of 1 percent. $\mathrm{MgCO}_{3}-\mathrm{Fe}$; $\mathrm{CaCO}_{3}$ (calcite)-none; $\mathrm{SrCO}_{3}-\mathrm{Ca} ; \mathrm{BaCO}_{3}-\mathrm{Sr} ; \mathrm{PbCO}_{3}$-none; $\mathrm{MnCO}_{3}$ - $\mathrm{Ca}, \mathrm{Fe}$, $\mathrm{Mg} ; \mathrm{FeCO}_{3}-\mathrm{Mg}, \mathrm{Mn}$,Si. The impurities except in the cases of $\mathrm{MnCO}_{3}$ and $\mathrm{FeCO}_{3}$ appear to be of negligible importance. Inspection of the infrared spectra indicates no evidence for the strongest fundamentals of the major contaminant.

The materials studied fall into the following five classes at room temperature.

(1) calcite type- space group $\mathrm{D}_{3 \mathrm{~d}}^{6}-\mathrm{NaNO}_{3}, \mathrm{MgCO}_{3}$, $\mathrm{CaCO}_{3}$ (calcite), $\mathrm{MnCO}_{3}$, and $\mathrm{FeCO}_{3}[71]$;

(2) aragonite type space group $\mathrm{V}_{\mathrm{h}}^{16}-\mathrm{KNO}_{3}, \mathrm{CaCO}_{3}$ (aragonite), $\mathrm{SrCO}_{3}, \mathrm{BaCO}_{3}$, and $\mathrm{PbCO}_{3}$ $[7,8,17,71,79]$;

(3) hexagonal space group $\mathrm{C}_{3 \mathrm{v}}^{2}-\mathrm{CsNO}_{3}, \mathrm{RbNO}_{3}$ $[19,20,21,60,76]$;

(4) orthorhombic - space group uncertain $\mathrm{TlNO}_{3}, \mathrm{AgNO}_{3}[37,71]$;

(5) cubic space group $\mathrm{T}_{\mathrm{h}}^{6}-\mathrm{Sr}\left(\mathrm{NO}_{3}\right)_{2}, \mathrm{Ba}\left(\mathrm{NO}_{3}\right)_{2}$, $\mathrm{Pb}\left(\mathrm{NO}_{2}\right)_{2}\lceil 711$.
Specific heat data are available for most of these substances between room temperature and lower temperatures which range from 55 to $13^{\circ} \mathrm{K}$ with no reports of any structural changes. $\mathrm{CaCO}_{3}$ (calcite), $\mathrm{CaCO}_{3}$ (aragonite), $\mathrm{SrCO}_{3}$, and $\mathrm{BaCO}_{3}$ were studied by Anderson down to $55^{\circ} \mathrm{K}$ [1]. Anderson also has reported data down to $55^{\circ} \mathrm{K}$ for $\mathrm{MgCO}_{3}, \mathrm{PbCO}_{3}$, $\mathrm{MnCO}_{3}$, and $\mathrm{FeCO}_{3}$ [2]. The data on $\mathrm{CaCO}_{3}$ (aragonite) have been extended down to $23{ }^{\circ} \mathrm{K}$ by Gunther [27] with no observed transitions. Latimer and Ahlberg have studied $\mathrm{Ba}\left(\mathrm{NO}_{3}\right)_{2}$ [46] and $\mathrm{TINO}_{3}$ [47] down to about $16{ }^{\circ} \mathrm{K}$ while Nernst and Schwers [56] have reported data on $\mathrm{CaCO}_{3}$ (calcite) to a temperature of $22^{\circ} \mathrm{K}$. Shomate and Kelley [67] investigated $\mathrm{Ba}\left(\mathrm{NO}_{3}\right)_{2}$ to $53{ }^{\circ} \mathrm{K}$ and similar data were given to $13^{\circ} \mathrm{K}$ for $\mathrm{AgNO}_{3}$ by Smith, Brown, and Pitzer [69]. Finally, data down to $15^{\circ} \mathrm{K}$ were obtained by Southard and Nelson for $\mathrm{KNO}_{3}$ and $\mathrm{NaNO}_{3}$ [70]. In no case were any irregularities in the specific heat curves observed, therefore, no transitions are known to occur between room temperature and the temperatures given. These temperatures may be above the lowest temperature to which the materials were subjected in these studies; however, the specific heat data assure that no transitions occur in the major portion of the temperature range. Low temperature data do not appear to be available for $\mathrm{Sr}\left(\mathrm{NO}_{3}\right)_{2}, \quad \mathrm{~Pb}\left(\mathrm{NO}_{3}\right)_{2}, \quad \mathrm{RbNO}_{3}$, and $\mathrm{CsNO}_{3}$. By analogy with $\mathrm{Ba}\left(\mathrm{NO}_{3}\right)_{2}$ it would be expected that $\mathrm{Sr}\left(\mathrm{NO}_{3}\right)_{2}$ would exhibit a regular low temperature behavior. It would appear much less certain that $\mathrm{Pb}\left(\mathrm{NO}_{3}\right)_{2}$ would behave similarly. The $\mathrm{RbNO}_{3}$ and $\mathrm{CsNO}_{3}$ represent different systems and to resolve the question low temperature $\mathrm{X}$-ray diffraction patterns were obtained on $\mathrm{RbNO}_{3}$ and $\mathrm{CsNO}_{3}$ to $77^{\circ} \mathrm{K}$. The results showed that no structural changes occurred between room temperature and $77^{\circ} \mathrm{K}$. Behavior at temperatures below $77^{\circ} \mathrm{K}$ was not studied.

\subsection{Polarization and Orientation Effects}

The infrared beam underwent at least three reflections in the process of being focused on the crystal studied. Therefore, some uncertainty existed concerning the polarization of the incident beam. To provide a partial answer to the experimental effects to be expected, two specimens from a single crystal of calcite were studied, one cut parallel and the other cut perpendicular to the optic axis. The absorption spectra of these crystals are shown in figure 1. The spectra are displaced vertically to eliminate overlapping. It will be noted that the spectra are similar. Although some major differences in relative intensity are observed in the two spectra, both crystals show essentially the same absorption bands. It is concluded, therefore, that the degree of polarization of the beam is so small that essentially the same absorption spectrum will be shown by randomly oriented, anisotropic crystals.

\section{Results and Discussion}

\subsection{Method of Presentation}

There are a large number of spectra to be presented and discussed and the following pro- 


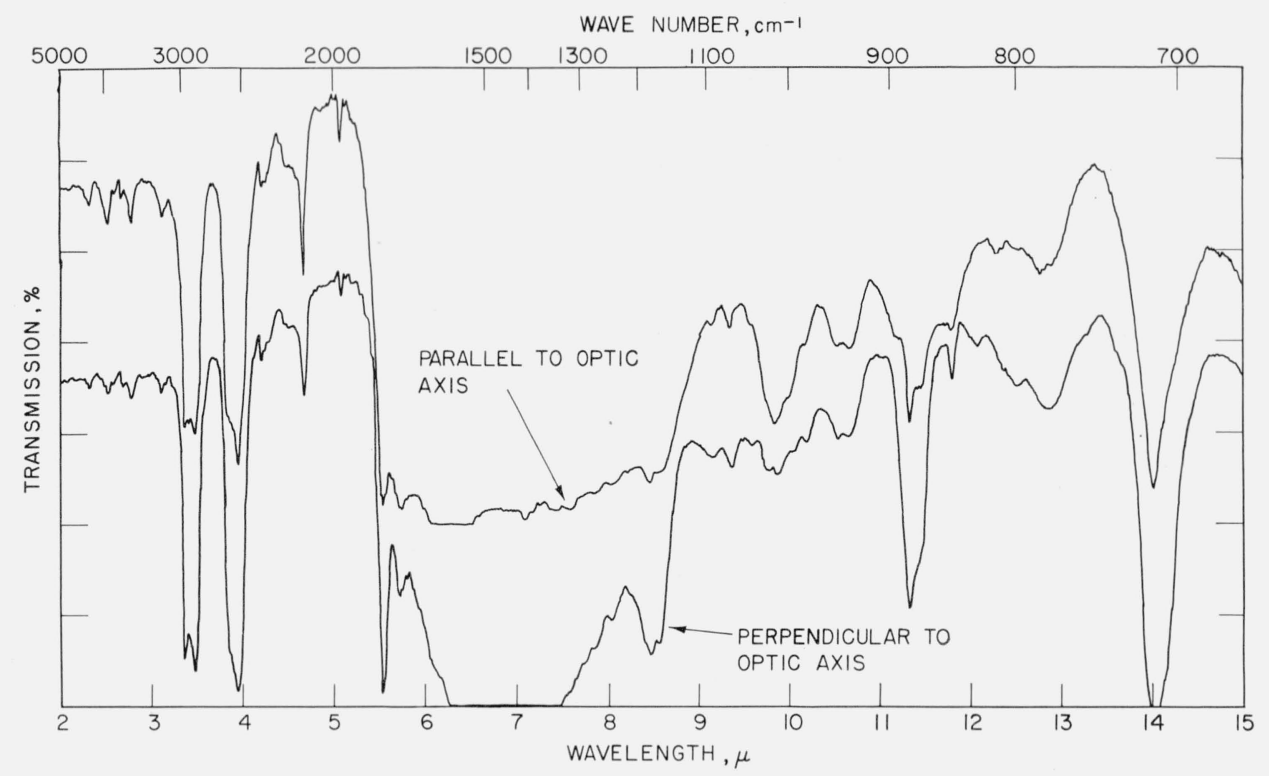

FIGURE 1. Infrared absorption spectra of calcite crystals of different orientations.

cedure is employed: (a) The spectra are subdivided with respect to crystal structure because there appear to be good correlations within a given structure. (b) Spectra are shown for each material studied. For each crystal type except the aragonite type at least one spectrum is shown on an enlarged scale for each of the three temperatures studied. These spectra are given in the same figure but displaced vertically. For other materials of the same crystal type two spectra on a small scale are shown, one at room temperature, and the other at liquid helium temperature. These spectra are drawn on the same figure but displaced vertically. (c) The discussion will also be divided, first according to the vibrations of interest. These sections are then further subdivided according to crystal structure. The major discussion will consist of three parts: first, the fundamentals; second, librations; and third, fundamental overtones and combinations.

\subsection{Fundamental Internal Frequencies}

A discussion of the fundamental internal frequencies for the carbonate and nitrate ions will be given before any additional features of the spectrum are analyzed in terms of lattice modes or combinations. This analysis may be carried out to three stages of approximation for the selection rules applicable to possible infrared transitions. First, the symmetry of the free ion may be assumed, ignoring any effects due to the crystal field symmetry. This assumption would not be expected to be a valid approximation to the actual situation. Second, the site group approximation may be used in which the selection rules for the ions are derived from the symmetry of the site which they occupy in the crystal lattice. In effect the ion is considered as if it were an independent entity possessing the symmetry of the lattice site. This treatment will predict some effects arising from the crystal field symmetry but will not adequately describe those effects due to the interaction of a given ion with its neighbors. Finally the factor group analysis may be considered. This treatment considers the vibrations of the crystal as arising from the motion of the $m$ atoms in the unit cell to give $3 m-3$ fundamentals (including both internal and lattice modes). The selection rules are derived from the factor group symmetry which is isomorphous with the space group symmetry. The factor group analysis will differ from the site group analysis in that coupling of vibrations between ions in different sites is included. Vibrations may show higher degeneracy, may become inactive, or may be repeated several times compared to the results of the site group approximation.

\section{a. Free Ion Approximation}

Free carbonate and nitrate ions are classified in the point group $D_{3 \mathrm{~h}}$. Table 1 gives the spectral activity, symmetry species, types of internal frequencies, and the lattice modes derived from transla-

TABLE 1. Spectral activity for nitrate and carbonate ions of symmetry $\mathrm{D}_{3 \mathrm{~h}}$

\begin{tabular}{|c|c|c|c|}
\hline Species & Activity & $\begin{array}{l}\text { Internal } \\
\text { mode }\end{array}$ & $\begin{array}{l}\text { Lattice modes } \\
\text { derivable from } \\
\text { translation or } \\
\text { rotation }\end{array}$ \\
\hline $\begin{array}{l}\mathrm{A}_{1}^{\prime}{ }^{\prime} \\
\mathrm{A}_{1}^{\prime \prime}, \ldots \\
\mathrm{A}_{2}^{\prime}, \ldots \\
\mathrm{A}_{2}^{\prime \prime} \ldots \\
\mathrm{E}^{\prime}, \ldots \\
\mathrm{E}^{\prime \prime} \ldots \ldots\end{array}$ & $\begin{array}{l}\text { Raman } \\
\text { I.R. R. } \\
\text { I.R.,Raman } \\
\text { Raman }\end{array}$ & 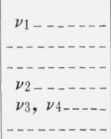 & $\begin{array}{l}\mathrm{L}\left(\mathrm{R}_{z}\right) \\
\mathrm{L}\left(\mathrm{T}_{z}\right) \\
\mathrm{L}\left(\mathrm{T}_{x}, \mathrm{~T}_{y}\right) \\
\mathrm{L}\left(\mathrm{R}_{x}, \mathrm{R}_{y}\right)\end{array}$ \\
\hline
\end{tabular}

I.R. -infrared active; R-Raman active.

$\mathrm{L}(\mathrm{T})$ - lattice mode derivable from translation along $x, y, z$, axis

$\mathrm{L}(\mathrm{T})$-lattice mode derivable from translation along $x, y$, z, axis.

$\mathrm{L}(\mathrm{R})$-lattice mode derivable from rotation about $x, y, z$, axis.
$\nu_{1} \quad$-symmetric stretch; $\nu_{2}$ - out-of-plane bend; $\nu_{3}$ - degenerate antisymmetric $\nu_{1} \quad$ Symmetric stretch; $\nu_{2}$ - out-of-plane ben
stretch; $\nu_{4}$ - degenerate in-plane bend. 
tions and rotations of the free ion. For the free ion, the active fundamentals and their approximate positions are: the out-of-plane bending $\left(\nu_{2}\right)$ observed generally near $850 \mathrm{~cm}^{-1}$; the degenerate antisymmetric stretching $\left(\nu_{3}\right)$ which is usually very intense and observed in the $1400 \mathrm{~cm}^{-1}$ to $1500 \mathrm{~cm}^{-1}$ region; and the degenerate in-plane bending $\left(\nu_{4}\right)$ usually found near $720 \mathrm{~cm}^{-1}$. The symmetric stretching mode $\left(\nu_{1}\right)$ is inactive in the infrared for the free ion approximation but is expected to have a frequency near $1060 \mathrm{~cm}^{-1}$. Translations of the free ion would be infrared active (species $\mathrm{A}_{2}{ }^{\prime \prime}$ and $\mathrm{E}^{\prime}$ ) but the modes derived from rotations of the free ion would be inactive in the infrared spectrum. The frequencies of the lattice modes would be expected to be less than $500 \mathrm{~cm}^{-1}$ and, therefore, unobserved in the present study. However, combinations of these modes with fundamental frequencies would be infrared active and might be observed. Combinations of fundamentals with a number of other lattice modes would be restricted by the $D_{3 h}$ symmetry.

Crystals with the calcite, cubic, hexagonal, and orthorhombic structures show spectra conforming reasonably well with the predictions of the free-ion selection rules insofar as the fundamental internal frequencies are concerned. $\nu_{2}$ and $\nu_{4}$ are always observed in the expected positions although $\nu_{4}$ is occasionally weak in some of the nitrates. $\nu_{3}$ is always observed but with such great intensity that it is not possible to determine whether it is a single or multiple band or even to locate its position with reliability. The symmetric stretching band $\nu_{1}$ is usually not observed as expected or when present is generally weak. The free-ion model must be rejected because it does not adequately describe the complex spectra of the aragonite crystals shown in figures 9 to 15 nor does it permit sufficient flexibility in the selection rules for combinations between internal and lattice modes to explain the elaborate band structure observed in most specta. For example the $\mathrm{D}_{3 \mathrm{~h}}$ selection rules predict that combinations of $\nu_{1}$ with the lattice libration frequency derived from rotation in species $A_{2}^{1}$ should be inactive. For reasons to be discussed later a whole series of such bands are believed to be present in the spectra.

\section{b. Site Group Approximation}

The selection rules for the various crystal structures in the site group approximation may be obtained from the space group symmetry and the tables given by Halford [30] showing the various sites for each space group. In the calcite type crystals of space group $\mathrm{D}_{3 \mathrm{~d}}^{6}$ containing 2 molecules per unit cell, the anions occupy sites of $\mathrm{D}_{3}$ symmetry and the cation's sites of symmetry $\mathrm{C}_{31}$. In the cubic structures of space group $\mathrm{T}_{\mathrm{h}}^{6}$ containing 4 molecules per unit cell the anions must lie on sites with symmetry $\mathrm{C}_{3}$ and the cations on sites of symmetry $\mathrm{C}_{31}$. Similarly in the aragonite structures of symmetry $V_{h}^{16}$ with 4 molecules per unit cell both anions and cations occupy sites of symmetry
$\mathrm{C}_{s}$. The hexagonal and orthorhombic crystals will not be discussed because of uncertainties concerning the space groups. The results of the site group approximation for the selection rules are given in table 2.

TABLE 2. Spectral activity for nitrate and carbonate ions in calcite, aragonite, and cubic structures for the site group approximation

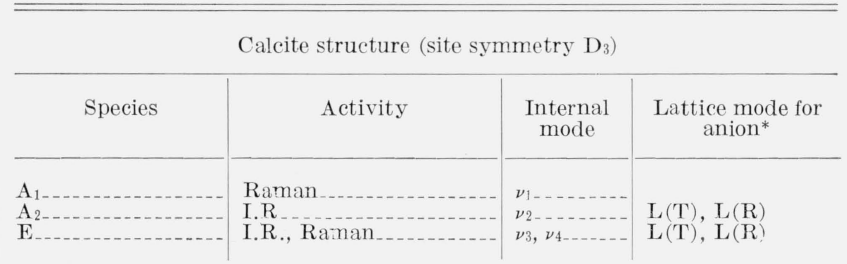

* There are 3 lattice modes of translational origin associated with the cations on sites $\mathrm{C}_{3 \mathrm{i}}$ which are infrared active.

Aragonite structures (site symmetry $\mathrm{C}_{8}$ )

\begin{tabular}{c|c|c|c}
\hline \multicolumn{1}{c|}{ Species } & Activity & $\begin{array}{c}\text { Internal } \\
\text { mode }\end{array}$ & $\begin{array}{c}\text { Lattice mode for } \\
\text { anion* }\end{array}$ \\
\hline $\mathrm{A}^{\prime}$ & $\begin{array}{c}\text { I.R., Raman } \\
\mathrm{A}^{\prime \prime} \ldots\end{array}$ & $\nu_{1}, \nu_{3}, \nu_{4} \ldots$ \\
$\nu_{2}, \nu_{3}, \nu_{4} \ldots$ & $\begin{array}{l}2 \mathrm{~L}(\mathrm{~T}), \mathrm{L}(\mathrm{R}) \\
\mathrm{L}(\mathrm{T}), 2 \mathrm{~L}(\mathrm{R})\end{array}$ \\
\hline
\end{tabular}

* There are 3 lattice modes for the cations on sites of symmetry $\mathrm{C}_{8}$ which are active in both infrared and Raman.

Cubic structures (site symmetry $\mathrm{C}_{3}$ )

\begin{tabular}{|c|c|c|c|}
\hline Species & Activity & $\begin{array}{l}\text { Internal } \\
\text { mode }\end{array}$ & $\begin{array}{l}\text { Lattice mode for } \\
\text { anion* }\end{array}$ \\
\hline & $\begin{array}{l}\text { I.R., Raman } \\
\text { I.R., Raman }\end{array}$ & $\begin{array}{l}\nu_{1}, \nu_{2} \ldots \ldots \\
\nu_{3}, \nu_{4} \ldots \ldots\end{array}$ & $\begin{array}{l}\mathrm{L}(\mathrm{T}), \mathrm{L}(\mathrm{R}) \\
\mathrm{L}(\mathrm{T}), \mathrm{L}(\mathrm{R})\end{array}$ \\
\hline
\end{tabular}

* There are 3 lattice modes associated with the eations on sites of symmetry $\mathrm{C}_{3 \mathrm{i}}$ which are inactive in the Raman but active in the infrared spectrum (species $\mathrm{B}_{\mathrm{u}}$ and $\mathrm{E}_{1 \mathrm{u}}$ ).

Calcite type structures. In the calcite type crystals the selection rules require that $\nu_{2}$ (species $\mathrm{A}_{2}$ ) and $\nu_{3}$ and $\nu_{4}$ (species E) are infrared active while $\nu_{1}$ remains infrared inactive. This prediction agrees with the observed fundamentals but again the selection rules are too restrictive and fail to account for the large number of sum and difference modes believed to be due to lattice modes. As an example, lattice modes of rotational or translational origin in species $\mathrm{A}_{2}$ would be expected to give a series of combination bands with every other band forbidden by the selection rules. This is not believed to be the case.

Aragonite type structures. In these structures the site symmetry $\mathrm{C}_{\mathrm{s}}$ yields selection rules requiring the degenerate stretching and bending modes, $\nu_{3}$ and $\nu_{4}$, to be split and the symmetric stretching mode, $\nu_{1}$, to be active in the infrared spectrum. The outof-plane bending $\nu_{2}$ remains active. The low temperature spectra show that $\nu_{3}$ is split (for example, see spectrum of $\mathrm{SrCO}_{3}$ ). However, there appear to be at least three components of $\nu_{3}$ in $\mathrm{SrCO}_{3}$. This does not agree with the selection rules which predict two components only. Similarly, $\nu_{1}$ is active as predicted but in addition at least one other component 
of $\nu_{1}$ appears to be present which is unaccounted for. Considerations of a similar nature arise regarding $\nu_{2}$ and $\nu_{4}$.

Cubic structures. With the site symmetry $\mathrm{C}_{3}$ the selection rules predict that in addition to $\nu_{2}$ (species A) and $\nu_{1}$ and $\nu_{4}$ (species E) that $\nu_{1}$ (species A) should also be infrared active. Spectra for the cubic crystals show a very weak band in this region which may represent the $\nu_{1}$ vibration.

It is clear that while the site group approximation gives results which are in better agreement with the observations than the free ion approximation, the apparent discrepancies between prediction and observations in the aragonite structures makes the validity of the approximation questionable. The applicability of this treatment has been discussed previously [13] and it has been pointed out that the site group approximation is less applicable to ionic crystals than molecular crystals because of the much stronger coupling in ionic lattices.

\section{c. Factor Group Approximation}

Selection rules for the calcite, aragonite, and cubic crystal types under the factor group approximation are given in table 3 . The internal and lattice frequencies are classified with regard to their respective symmetry species.

TABLE 3.-Factor group selection rules for the calcite, aragonite and cubic structures

\begin{tabular}{l|l|l|l}
\hline \hline Species & Activity & Internal mode & $\begin{array}{c}\text { Lattice } \\
\text { modes }\end{array}$
\end{tabular}

Calcite structure-space group $\mathrm{D}_{3 \mathrm{~d}}^{6} ; 2$ molecules/unit cell; total frequencies-27

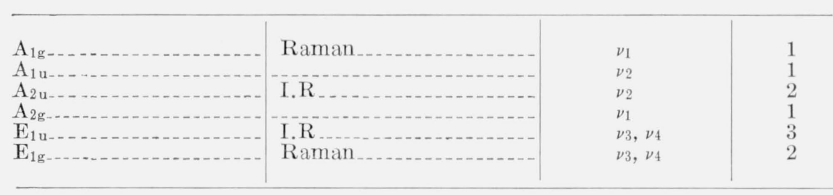

Aragonite structure-space group $\mathrm{V}_{\mathrm{h}}^{16} ; 4$ molecules/unit cell; total frequencies-57

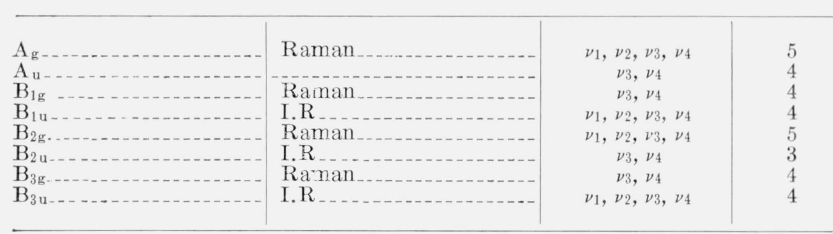

Cubic structure-space group $\mathrm{T}^{9}{ }^{3} 4$ molecules/unit cell; total frequencies-105

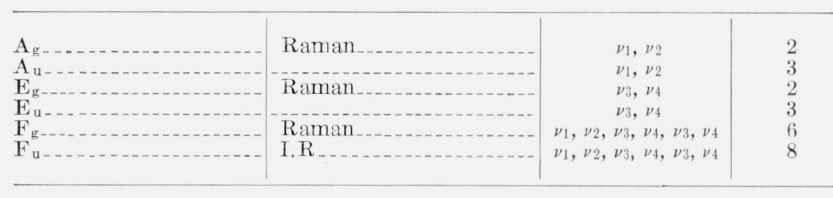

Calcite type structures. For calcite structures, the active modes in the infrared are $\nu_{2}$ (species $\mathrm{A}_{2 \mathrm{u}}$ ), $\nu_{3}$ (species $\mathrm{E}_{1 \mathrm{u}}$ ), and $\nu_{4}$ (species $\mathrm{E}_{1 \mathrm{u}}$ ). The symmetric stretch, $\nu_{1}$, is again inactive. As before, the predictions agree well with the observed funda- mentals. There are now effectively no selection rules governing combinations between fundamentals and lattice modes [78].

Aragonite type structures. In these crystals the selection rules predict that three nondegenerate components of $\nu_{3}$ and $\nu_{4}$ (species $\mathrm{B}_{1 \mathrm{u}}, \mathrm{B}_{2 \mathrm{u}}$, and $\mathrm{B}_{3 \mathrm{u}}$ ) should result from the splitting of the degenerate stretching and bending modes of the free ion. In the $\mathrm{SrCO}_{3}$ spectrum three such bands can be observed at 1362,1445 , and $1522 \mathrm{~cm}^{-1}$. These are sharp, strong, bands and may be taken to represent the three components of $\nu_{3}$. The very strong broad band near $1600 \mathrm{~cm}^{-1}$ is believed to arise from combinations and will be discussed later. Two of the three components of $\nu_{4}$ are found at $701 \mathrm{~cm}^{-1}$ and $711 \mathrm{~cm}^{-1}$ while the third may either be the weaker band near $738 \mathrm{~cm}^{-1}$ or be unresolved from the 701 to $711 \mathrm{~cm}^{-1}$ doublet. The selection rules require $\nu_{1}$ and $\nu_{2}$ to be infrared active in species $\mathrm{B}_{1 \mathrm{u}}$ and $\mathrm{B}_{3 \mathrm{u}}$. The two components of $\nu_{1}$ can be assigned as the two sharp bands observed near $1050 \mathrm{~cm}^{-1}$ and $1072 \mathrm{~cm}^{-1}$ in the low temperature $\mathrm{SrCO}_{3}$ spectra. There are undoubtedly a number of bands, partly unresolved, near the expected position for the two components of $\nu_{2}$. Some of these are undoubtedly lattice combination modes but in any case there appears to be little difficulty in concluding that $\nu_{2}$ consists of at least two components. Similar assignments are possible in the other aragonite type structures. It should be noted that Decius [14, 15] has pointed out that the out-of-plane bending modes in aragonite type crystals are strongly coupled as a result of the proximity of the anions. This coupling produces a splitting of $\nu_{2}$ when isotopic species are involved. The relative intensities involved here, however, appear to be too great to be attributed to the natural abundance of isotopes.

Cubic structures. In the cubic structures the factor group selection rules show that the only active infrared species is $\mathrm{F}_{\mathrm{u}}$ with six triply degenerate internal frequencies and eight triply degenerate lattice modes. The six internal frequencies are derived from $\nu_{1}$ and $\nu_{2}$ and two each from $\nu_{3}$ and $\nu_{4} . \nu_{1}$ is observed very weakly if at all and can hardly be considered as an active fundamental. $\nu_{2}$ can only be assigned near $812 \mathrm{~cm}^{-1}$, its usual position. There may be two components of $\nu_{3}$ but the great intensity of the band prevents any attempts to locate their positions. The splitting of $\nu_{3}$ has been observed in the cubic structures by Couture and Mathieu [10] who studied the Raman spectrum. The two components of $\nu_{4}$ must be considered unresolved in the band near $722 \mathrm{~cm}^{-1}$ in the cubic nitrates.

Some basis must be found for the assignment of the large number of nonfundamental frequencies some of which are very strong. These bands are observed in the low temperature spectra of all the nitrates and carbonates. The factor group treatment forms an adequate basis for assigning these bands as there are in principle no selection rules governing the combinations of lattice modes with internal modes [78]. However, there is no indication of the relative intensities to be expected for sum and difference bands. 


\subsection{Libration-Fundamental Summation and Differ- ence Bands in the $700 \mathrm{~cm}^{-1}$ to $1500^{-1}$ Region}

In this section the large number of bands occurring in the $700 \mathrm{~cm}^{-1}$ to $1500 \mathrm{~cm}^{-1}$ region of the spectrum are discussed. These bands will be interpreted tentatively as combinations between fundamental internal vibrations and a low-lying mode of the order of $20 \mathrm{~cm}^{-1}-30 \mathrm{~cm}^{-1}$. The justification for considering the low frequency mode as a libration fundamental will be given later but the interpretation will be made in accordance with this hypothesis.

The proposed model is shown schematically in figure 2 which assumes an ion on a site of symmetry $\mathrm{C}_{3}$. The potential energy curve for libration is represented by the broken curve on the ground state vibrational level $(n=0)$ and the first excited vibrational level $(n=1)$. The potential energy is assumed to be independent of the vibrational state. In each of the three potential wells there are seven excited librational levels $(J=1-J=7)$ shown. These levels are shown evenly spaced, i.e., anharmonicity corrections are neglected. Transitions between energy states are indicated by the vertical lines. No transitions are indicated between librational levels in the same vibrational state because the energies involved are too low to be of interest here.

At any given temperature transitions in all three potential wells will be similar since the three configurations of the ion are equivalent. With this in mind the three potential minima of figure 2 are utilized to demonstrate the effect of temperature on the resulting spectrum. At very low temperatures where all ions are in the ground state, only summation bands are possible as indicated in the left potential minimum. At intermediate temperatures, in addition to the summation bands shown at the lowest temperature some difference bands arise from the thermal excitation of some ions into the lower librational levels in the ground vibrational level. At still higher temperatures, in addition to the previous transitions, lower energy difference bands arise from thermal excitation to the higher librational levels in the ground vibrational state. Transitions to rotational levels which exist above the potential barriers are not indicated in figure 2. All possible transitions are not shown except at the lowest temperature.

\section{a. Calcite Type Structures}

Many calcite type crystals show spectra which are lacking in detail although there is evidence of unresolved absorption in the region of interest. However, the spectra for $\mathrm{NaNO}_{3}$ shown in figure 3 are most informative. It will be noted that the diffuse absorption between approximately $900 \mathrm{~cm}^{-1}$ and $1050 \mathrm{~cm}^{-1}$ at room temperature (top spectrum), is resolved at liquid helium temperature (lower spectrum) into a series of step like bands located at $913 \mathrm{~cm}^{-1}, 938 \mathrm{~cm}^{-1}, 963 \mathrm{~cm}^{-1}, 991 \mathrm{~cm}^{-1}, 1021 \mathrm{~cm}^{-1}$, $1058 \mathrm{~cm}^{-1}$, and $1071 \mathrm{~cm}^{-1}$. These bands have a nearly uniform separation varying from about $25 \mathrm{~cm}^{-1}$ to $37 \mathrm{~cm}^{-1}$. In the low temperature spectrum other bands are also resolved and the resulting observations are tabulated in table 4 .

TABLE 4. Assignments for $\mathrm{NaNO}_{3}$ at liquid helium temperature for libration combinations

\begin{tabular}{|c|c|c|c|c|c|c|}
\hline Frequency & $\begin{array}{l}\text { Separa- } \\
\text { tion from } \\
\text { funda- } \\
\text { mental }\end{array}$ & Frequency & $\begin{array}{l}\text { Separa- } \\
\text { tion from } \\
\text { funda- } \\
\text { mental }\end{array}$ & Frequency & $\begin{array}{c}\text { Separa- } \\
\text { tion from } \\
\text { funda- } \\
\text { mental }\end{array}$ & $\begin{array}{l}\text { Assign- } \\
\text { ment }\end{array}$ \\
\hline $\mathrm{cm}^{-1}$ & $\mathrm{~cm}^{-1}$ & $\mathrm{~cm}^{-1}$ & $\mathrm{~cm}^{-1}$ & $\mathrm{~cm}^{-1}$ & $\mathrm{~cm}^{-1}$ & \\
\hline $727\left(\nu_{4}\right)$ & & $838\left(\nu_{2}\right)$ & & $1068\left(\nu_{1}\right)$ & & $\nu_{0}$ \\
\hline $747 \mathrm{VW}$ & 20 & $?$ & & $1103 \mathrm{~W}$ & 32 & $\nu_{0}+I$ \\
\hline $778 \mathrm{VW}$ & 51 & ? & & & & $\nu_{0}+2$ \\
\hline $803 \mathrm{VW}$ & 75 & $913 \mathrm{~m}$ & 75 & $1143 \mathrm{VW}$ & 75 & $\nu_{0}+3$ \\
\hline ? & & $938 \mathrm{~m}$ & 100 & $1176 \mathrm{sh}$ & 10 & $\nu_{0}+4 \mathrm{~L}$ \\
\hline ? & & $963 \mathrm{~m}$ & 125 & $1192 \mathrm{~s}$ & 124 & $\nu_{0}+5 \mathrm{~L}$ \\
\hline $880 ?$ & 153 & $991 \mathrm{~s}$ & 153 & $1228 \mathrm{~W}$ & 160 & $\nu_{0}+6 \mathrm{~L}$ \\
\hline $907 \mathrm{sh}$ & 180 & $1021 \mathrm{~s}$ & 183 & $?$ & & $\nu_{0}+7$ \\
\hline $945 \mathrm{sh}$ & 218 & $1058 \mathrm{~s}$ & 220 & ? & & $\nu_{0}+8 \mathrm{~L}$ \\
\hline $960 \mathrm{sh} ?$ & 233 & $1071 \mathrm{vs}$ & 233 & $1311 \mathrm{~s}$ & 243 & cutoff \\
\hline
\end{tabular}

Although they are diffuse and poorly defined at higher temperatures, the $913 \mathrm{~cm}^{-1}-1071 \mathrm{~cm}^{-1}$ series of bands appear to shift by $3 \mathrm{~cm}^{-1}$ to $7 \mathrm{~cm}^{-1}$ between the temperature of liquid nitrogen and that of liquid helium with the larger shifts associated with the higher frequency bands. In the same temperature interval the fundamental $\nu_{2}$ shows no detectable shift and $\nu_{4}$ a shift of at most $1 \mathrm{~cm}^{-1}$. From its temperature dependence and intensity it is believed that the $1071 \mathrm{~cm}^{-1}$ band represents the band limit or cutoff frequency of the series of bands starting at $913 \mathrm{~cm}^{-1}$ rather than the fundamental $\nu_{1}$ which is inactive in all calcite structures. This series of bands may be interpreted as combinations of a mode of frequency $20 \mathrm{~cm}^{-1}-30 \mathrm{~cm}^{-1}$ with $\nu_{2}$. Similarly other bands in the structure may be interpreted as combinations of the same low frequency mode with $\nu_{4}$ and the inactive $\nu_{1}$ fundamental. The cutoff for the series of bands originating from $\nu_{1}$ is believed to be the strong band at $1311 \mathrm{~cm}^{-1}$. The cutoff for the series from $\nu_{4}$ is not apparent but may tentatively be taken as a shoulder appearing at $960 \mathrm{~cm}^{-1}$. The differences between the cutoff frequencies and the respective fundamentals for the three series of bands are 243 $\mathrm{cm}^{-1}\left(\nu_{1}\right), 233 \mathrm{~cm}^{-1}\left(\nu_{2}\right)$, and possibly $233 \mathrm{~cm}^{-1}$ $\left(\nu_{4}\right)$. The bands and assignments are given in table 4 . These data as well as all other tabulated data refer only to observations at liquid helium temperature and include only libration-fundamental summation bands with $\nu_{1}, \nu_{2}$, and $\nu_{4}$. Tabular data are recorded only for reproducible bands and where there is doubt about the existence of a band the recorded frequency is followed by a question mark. The following abbreviations are used in all tables: very weak-vw; weak-w; shoulder - sh; medium$\mathrm{m}$; strong-s; very strong-vs; broad-b. From the tabular data it will be noted that the correlation between the three series is reasonably good. The energy level spacing varies but the apparent variation is estimated to be of the same order of magnitude as the error associated with determining the positions of the weak, frequently broad, combination bands.

Although no combination bands of the $20 \mathrm{~cm}^{-1}$ $-30 \mathrm{~cm}^{-1}$ mode with $\nu_{3}$ are tabulated for any spec- 
VERY LOW INTERMEDIATE

HIGH

TEMPERATURE TEMPERATURE TEMPERATURE

(ONLY SUMMATION

( DIFFERENCE BANDS

BANDS OCCUR)

OCCUR IN ADDITION TO

SUMMATION BANDS)

( ADDITIONAL DIFFERENCE

BANDS OCCUR )

FREE ROTATATION REGION

$\begin{array}{ll}n \quad \\ \\ & 7 \\ & 6 \\ & 5 \\ & 4 \\ & 3 \\ & 2 \\ & 2 \\ & 1 \\ 1 & 0\end{array}$

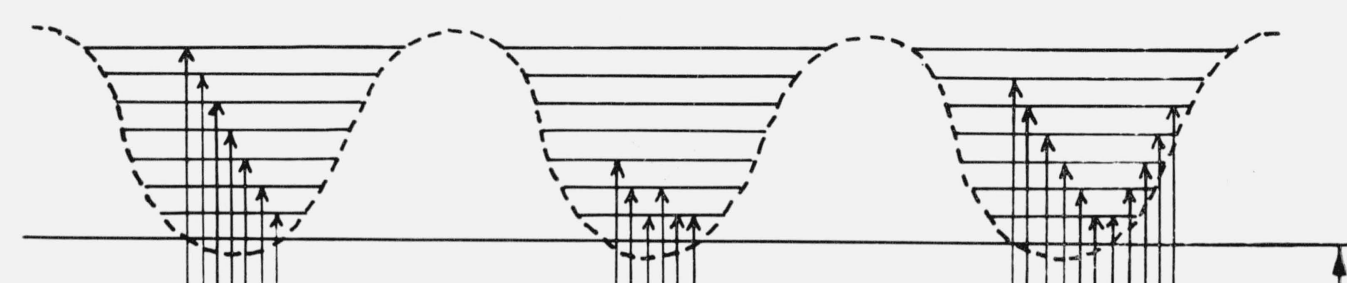

n
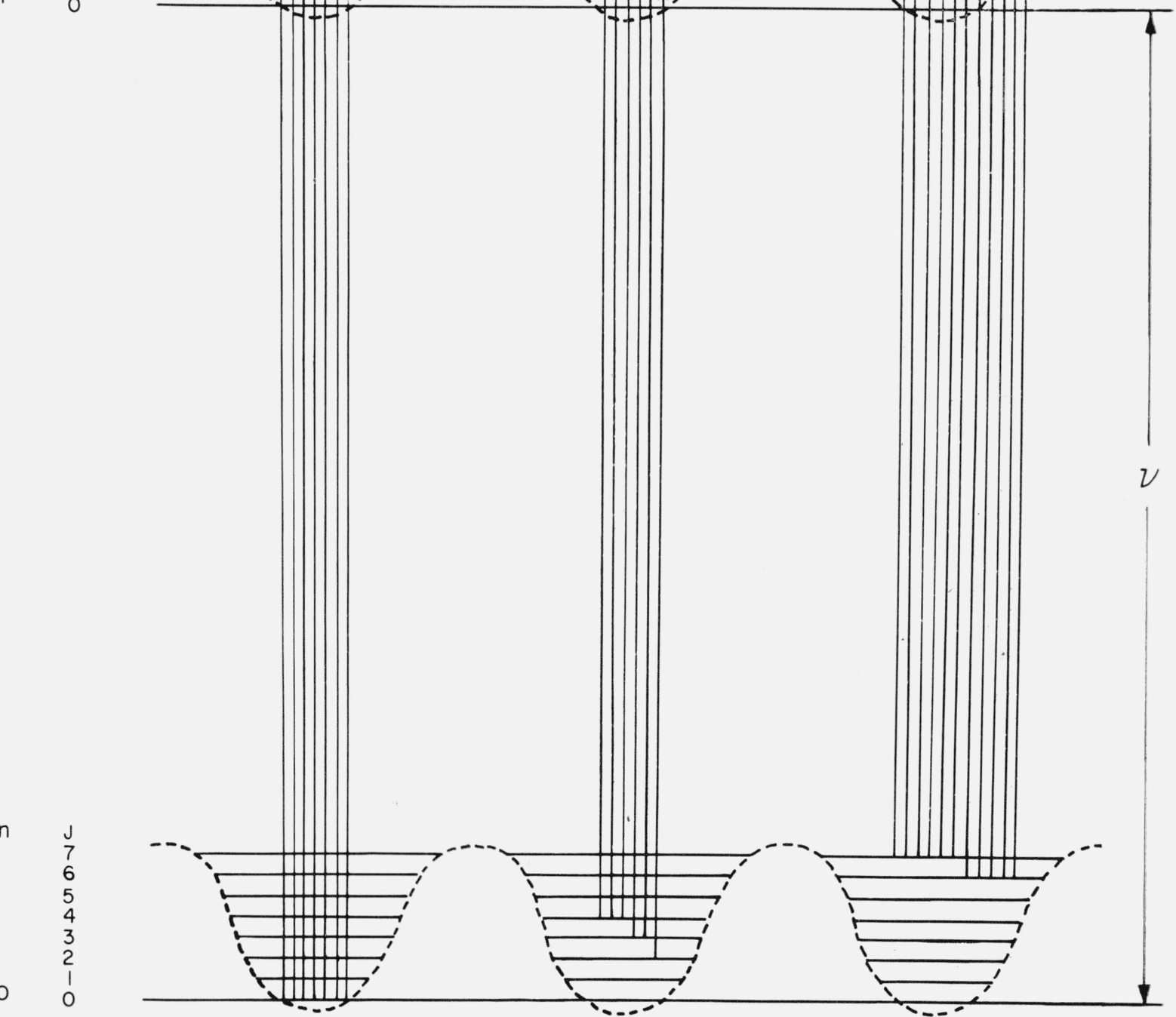

FIgURE 2. Energy level diagram for effect of temperature on libration-vibration combination bands. 


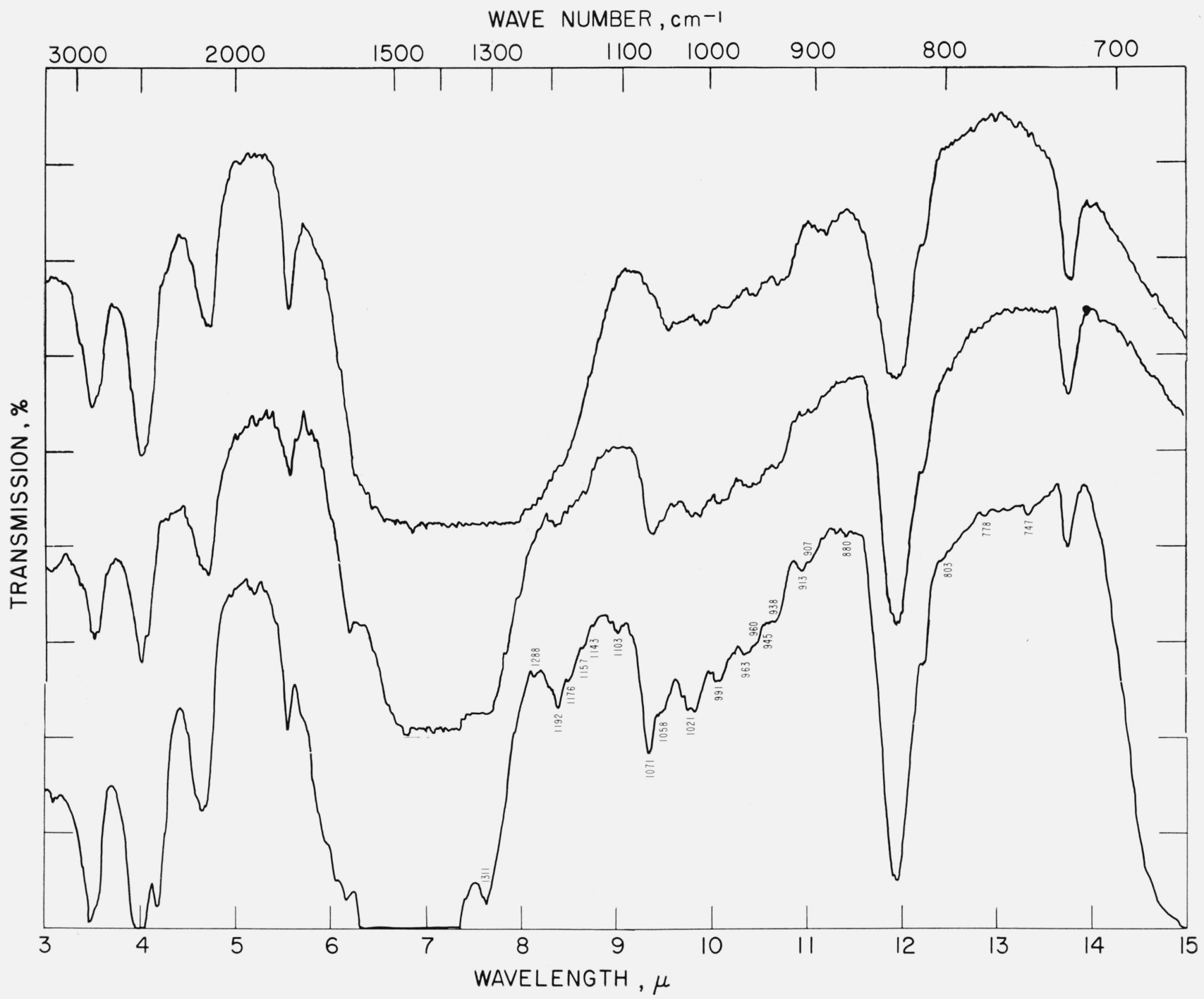

FIGURE 3. Infrared absorption spectra of $\mathrm{NaNO}_{3}$ at room temperature (top), liquid nitrogen temperature (center), and liquid helium temperature (bottom).

trum many instances of summation bands originating from $\nu_{3}$ have been observed. In this frequency region the instrumental dispersion is too low and the intensity of $\nu_{3}$ is usually too great to permit location of combinations with any certainty. Evidence for the existence of combinations with $\nu_{3}$ is indicated by figure 3 and all subsequent figures. The marked increase in transmission of all crystals on the low frequency side of $\nu_{3}$ as the temperature is lowered may be attributed to the elimination of difference bands between $\nu_{3}$ and a low frequency mode at lower temperatures. A corresponding change does not occur on the high frequency side of $\nu_{3}$, where the summation bands would be expected to become stronger at lower temperatures. Furthermore, the rather abrupt increase in transmission observed in most spectra on the high frequency side of $\nu_{3}$ occurs at a frequency which is of the correct order of magnitude for the cutoff for a series of combination bands originating from the fundamental $\nu_{3}$.
Although the assignments given in table 4 account for all bands it cannot be considered completely satisfactory. Several expected bands are missing and the band at $1192 \mathrm{~cm}^{-1}$ is unexpectedly strong. A similar situation will be encountered in all other spectra. All assignments, therefore, are made with some qualifications.

Spectra at room temperature and liquid helium temperature are given for the other calcite structures $\mathrm{MgCO}_{3}, \mathrm{CaCO}_{3}, \mathrm{FeCO}_{3}$, and $\mathrm{MnCO}_{3}$ in figures $4,5,6$, and 7 respectively with tabular data for $\mathrm{CaCO}_{3}$ listed in table 5. Satisfactory resolution of bands was not obtained on any specimen of $\mathrm{MgCO}_{3}$ despite several experiments on crystals of differing thicknesses. The strong band near $1250 \mathrm{~cm}^{-1}$ may represent the $\nu_{1}$ cutoff and that near $1120 \mathrm{~cm}^{-1}$ the $\nu_{2}$ cutoff. A low frequency mode of about $25 \mathrm{~cm}^{-1}$ and a cutoff frequency of approximately $230 \mathrm{~cm}^{-1}$ are indicated on the basis of the several experiments. 


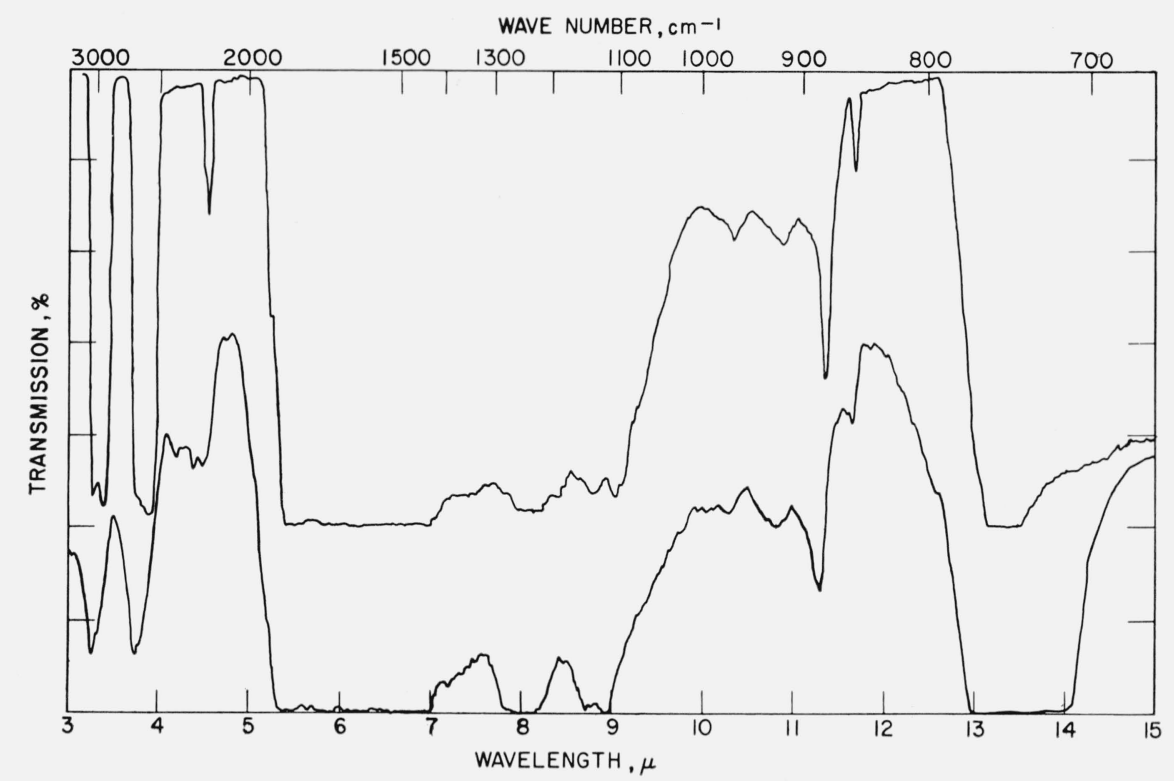

FIGURE 4. Infrared absorption spectra of $\mathrm{MgCO}_{3}$ at room temperature (top) and liquid helium temperature (bottom).

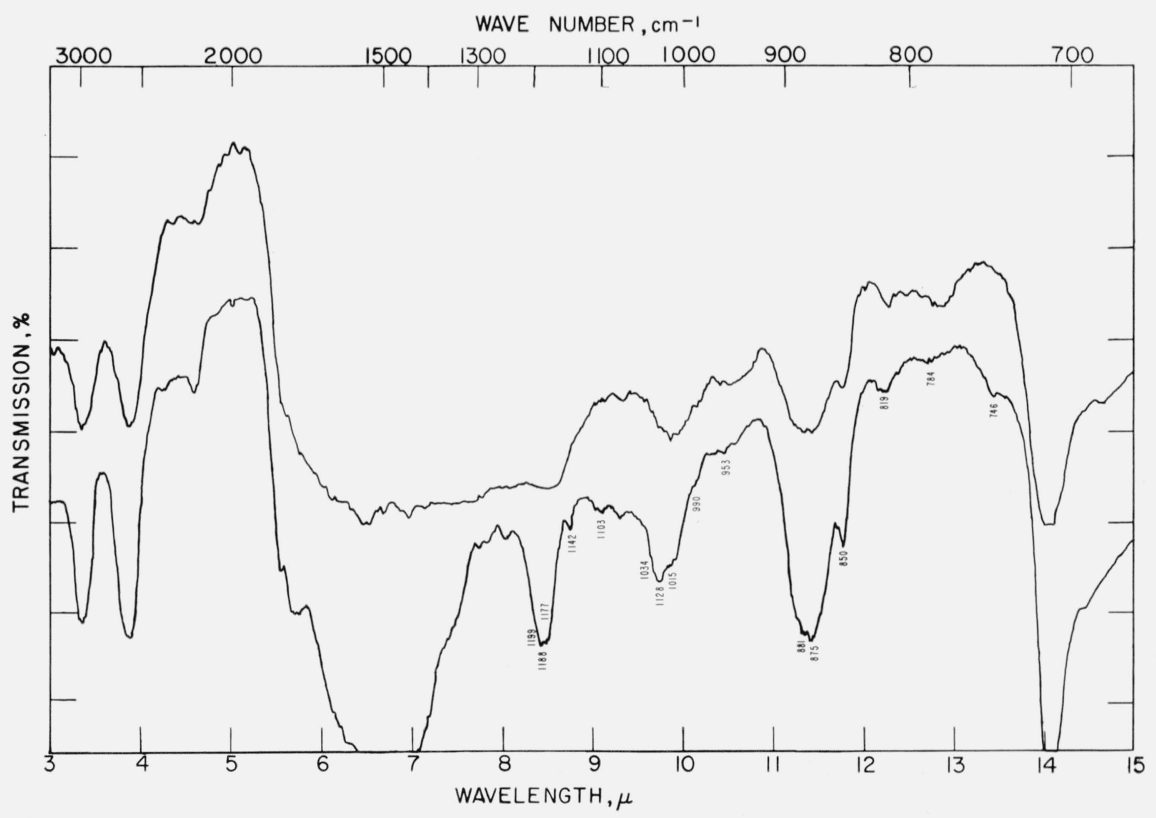

Figure 5. Infrared absorption spectra of $\mathrm{CaCO}_{3}$ (calcite) at room temperature (top) and liquid helium temperature (bottom).

TABLE 5. Assignments for $\mathrm{CaCO}_{3}$ at liquid helium temperature for libration combinations

\begin{tabular}{|c|c|c|c|c|c|c|}
\hline Frequency & $\begin{array}{c}\text { Separa- } \\
\text { tion from } \\
\text { funda- } \\
\text { mental }\end{array}$ & Frequency & $\begin{array}{l}\text { Separa- } \\
\text { tion from } \\
\text { funda- } \\
\text { mental }\end{array}$ & Frequency & $\begin{array}{l}\text { Separa- } \\
\text { tion from } \\
\text { funda- } \\
\text { mental }\end{array}$ & $\begin{array}{c}\text { Assign- } \\
\text { ment }\end{array}$ \\
\hline $\begin{array}{l}\mathrm{cm}^{-1} \\
712\left(\nu_{4}\right) \\
746 \mathrm{~m} \\
784 \mathrm{w} \\
819 \mathrm{~m} \\
850 ? \mathrm{~s} \\
\text { Cutoff } \\
\text { masked } \\
\text { by } \nu_{2}\end{array}$ & $\begin{array}{c}c m^{-1} \\
34 \\
72 \\
107 \\
138 \\
?\end{array}$ & $\begin{array}{c}c m^{-1} \\
881\left(\nu_{2}\right) \\
? \\
953 \mathrm{~W} \\
990 \mathrm{sh} \\
1015 \mathrm{~s} \\
1028 \mathrm{~s} \\
1034 ?\end{array}$ & $\begin{array}{c}c m^{-1} \\
? \\
72 \\
109 \\
134 \\
147 \\
153\end{array}$ & \begin{tabular}{l}
\multicolumn{1}{c}{$\mathrm{cm}^{-1}$} \\
$1070\left(\nu_{1}\right)$ \\
$1103 \mathrm{~W}$ \\
$1142 \mathrm{~m}$ \\
$1177 \mathrm{~s}$ \\
$1186 \mathrm{~s}$ \\
$1199 \mathrm{sh}$ \\
1220
\end{tabular} & $\begin{array}{r}\mathrm{cm}^{-1} \\
\\
33 \\
72 \\
107 \\
116 \\
132 \\
150\end{array}$ & $\begin{array}{l}\nu_{0} \\
\nu_{0}+\mathrm{L} \\
\nu_{0}+2 \mathrm{~L} \\
\nu_{0}+3 \mathrm{~L} \\
\nu_{0}+4 \mathrm{~L} \\
\nu_{0}+5 \mathrm{~L} \\
\text { cutoff }\end{array}$ \\
\hline
\end{tabular}

Tabular data for $\mathrm{CaCO}_{3}$ are given in table 5. A libration frequency of about $35 \mathrm{~cm}^{-1}$ and an average cutoff frequency of about $150 \mathrm{~cm}^{-1}$ are indicated. Three weak bands at $1075 \mathrm{~cm}^{-1}, 1245 \mathrm{~cm}^{-1}$, and $1283 \mathrm{~cm}^{-1}$ are not accounted for by the assignments. Although the band at $1075 \mathrm{~cm}^{-1}$ might be taken as the inactive $\nu_{1}$ fundamental this is not believed to be the case. Raman spectroscopy has located $\nu_{1}$ near $1086 \mathrm{~cm}^{-1}$ and this fundamental is invariably observed as a sharp band in the infrared spectrum when it is active. The band at $1075 \mathrm{~cm}^{-1}$ however, is quite broad. 


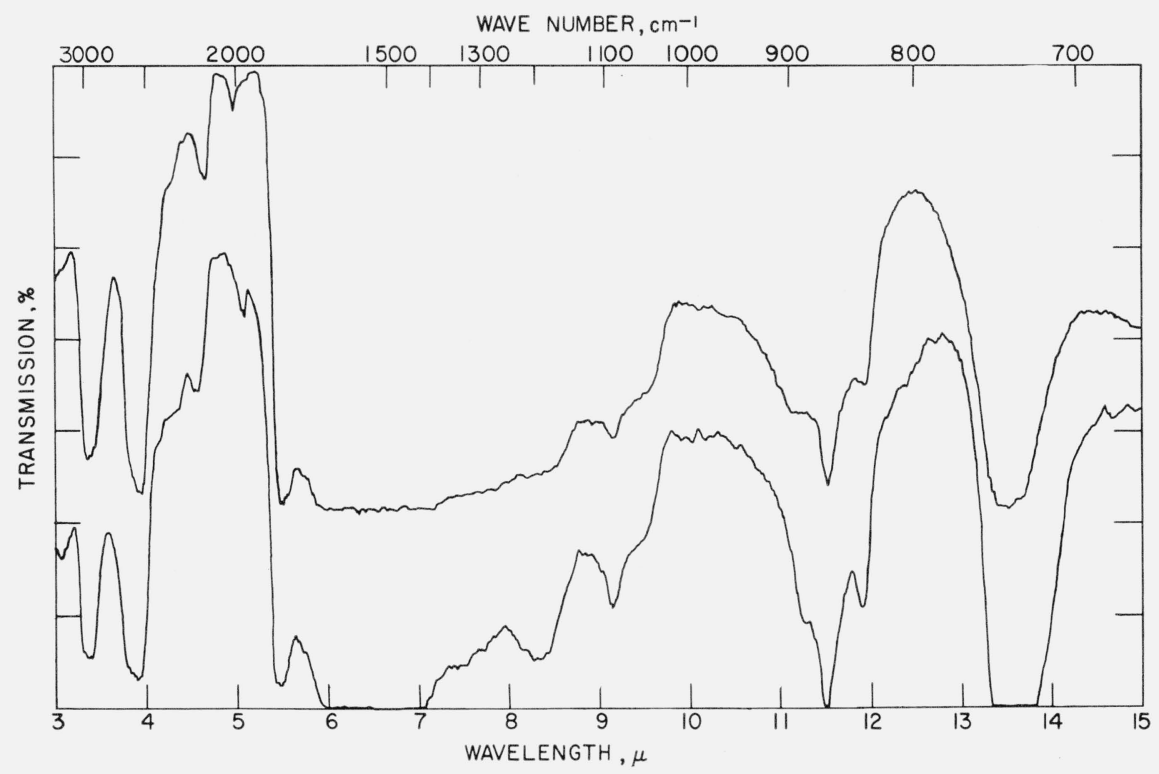

FIGURE 6. Infrared absorption spectra of $\mathrm{FeCO}_{3}$ at room temperature (top) and liquid helium temperature (bottom).

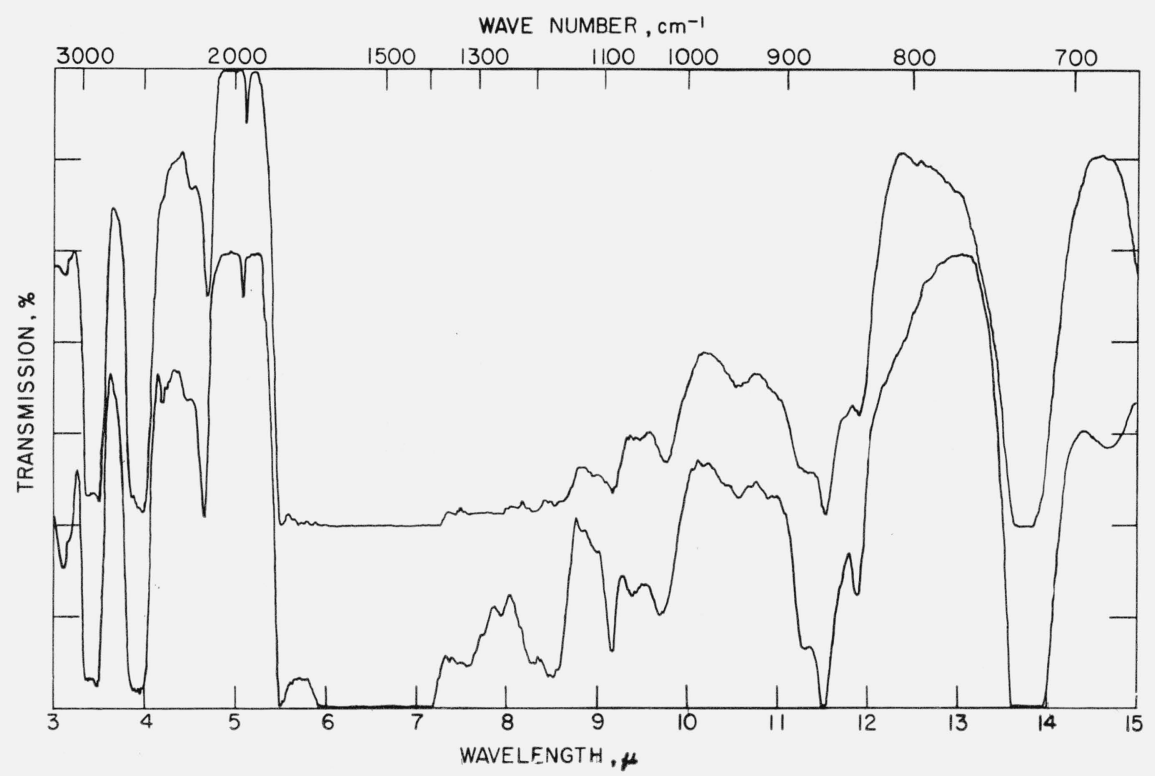

FIgURE 7. Infrared absorption spectra of $\mathrm{MnCO}_{3}$ at room temperature (top) and liquid helium temperature (bottom).

No data are tabulated for $\mathrm{FeCO}_{3}$ and $\mathrm{MnCO}_{3}$ because of the questionable purity of the specimens. As shown by the spectra both materials exhibit the same general absorption pattern as the other calcite structures. Cutoff frequencies are estimated to be $150 \mathrm{~cm}^{-1}$ for $\mathrm{FeCO}_{3}$ and $160 \mathrm{~cm}^{-1}$ for $\mathrm{MnCO}_{3}$ on the basis of tentative assignments. The $\mathrm{MnCO}_{3}$ spectrum which shows much fine structure can be interpreted with a single libration frequency of 15 $\mathrm{cm}^{-1}$ or with two separate frequencies of $30 \mathrm{~cm}^{-1}$.

\section{b. Aragonite Type Structures}

Spectra for two temperatures are given for $\mathrm{SrCO}_{3}$ in figure 8 and the tabular frequencies observed in table 6. Spectra at room temperature and liquid $\mathrm{He}$ temperature and the tabulated frequencies are given in figures $9,10,11$, and 12 , and tables $7,8,9$, and 10 for $\mathrm{CaCO}_{3}$ (aragonite), $\mathrm{BaCO}_{3}, \mathrm{PbCO}_{3}$, and $\mathrm{KNO}_{3}$ respectively. Additional expanded spectra at liquid helium temperatures covering the range from about $1800 \mathrm{~cm}^{-1}$ to $770 \mathrm{~cm}^{-1}$ for $\mathrm{SrCO}_{3}$ and $\mathrm{CaCO}_{3}$ (aragonite) are given in figures 13 and 14 . 
WAVE NUMBER, $\mathrm{cm}^{-1}$



FIGURE 8. Infrared absorption spectra of $\mathrm{SrCO}_{3}$ at room temperature (top) and liquid helium temperature (bottom).

TABLE 6. Observed frequencies for $\mathrm{SrCO}_{3}$ at liquid helium temperature

\begin{tabular}{|c|c|c|c|c|c|}
\hline Frequency & $\begin{array}{l}\text { Separation } \\
\text { from } \\
\text { funda- } \\
\text { mental }\end{array}$ & Frequency & $\begin{array}{l}\text { Separation } \\
\text { from } \\
\text { funda- } \\
\text { mental }\end{array}$ & Frequency & $\begin{array}{l}\text { Separation } \\
\text { from } \\
\text { funda- } \\
\text { mental }\end{array}$ \\
\hline $\left.\begin{array}{l}\mathrm{cm}^{-1} \\
701 \\
711\end{array}\right\} \nu_{4}$ & $\mathrm{~cm}^{-1}$ & $\begin{array}{c}\mathrm{cm}^{-1} \\
863 \nu_{2}\end{array}$ & $\mathrm{~cm}^{-1}$ & $\begin{array}{c}\mathrm{cm}^{-1} \\
1072 \nu_{1}\end{array}$ & $\mathrm{~cm}^{-1}$ \\
\hline $\begin{array}{l}737 \nu_{4} ? \\
803 \mathrm{wb} \\
816 \mathrm{~s} \\
861 \mathrm{sb} \\
879 \mathrm{sb} \\
900 \mathrm{~s}\end{array}$ & $\begin{array}{r}36 ? \\
92 ? \\
105 ? \\
150 ? \\
168 ? \\
189 ?\end{array}$ & $\begin{array}{l}908 \mathrm{vw} \\
913 \mathrm{mb} \\
937 \mathrm{mb} \\
967 \mathrm{sb} \\
995 \mathrm{vw} \\
1008 \mathrm{vw} \\
1042 \mathrm{~W} \text { sh } \\
1050 \mathrm{~m}\end{array}$ & $\begin{array}{r}45 \\
50 \\
73 \\
104 \\
132 \\
145 \\
179 \\
187\end{array}$ & $\begin{array}{l}1108 \mathrm{vW} \\
1147 \mathrm{vb} \\
1165 \mathrm{vb} \\
1200 \mathrm{~W} \\
1230 \mathrm{~W} \\
1256 ? \mathrm{~W} \\
1261 ? \mathrm{~W}\end{array}$ & $\begin{array}{r}36 \\
75 \\
93 \\
128 \\
158 \\
184 \\
189\end{array}$ \\
\hline
\end{tabular}

TABLE 7. Observed frequencies for $\mathrm{CaCO}_{3}$ (aragonite) at liquid helium temperature

\begin{tabular}{|c|c|c|c|c|c|}
\hline Frequency & $\begin{array}{l}\text { Separation } \\
\text { from } \\
\text { funda- } \\
\text { mental }\end{array}$ & Frequency & $\begin{array}{l}\text { Separation } \\
\text { from } \\
\text { funda- } \\
\text { mental }\end{array}$ & Frequency & $\begin{array}{l}\text { Separation } \\
\text { from } \\
\text { funda- } \\
\text { mental }\end{array}$ \\
\hline $\left.\begin{array}{c}c m^{-1} \\
701 \\
717\end{array}\right\} \nu_{4}$ & $\mathrm{~cm}^{-1}$ & $\begin{array}{c}c m^{-1} \\
866 \nu_{2}\end{array}$ & $\mathrm{~cm}^{-1}$ & $\begin{array}{c}\mathrm{cm}^{-1} \\
1086 \nu_{1}\end{array}$ & $\mathrm{~cm}^{-1}$ \\
\hline $741 \overline{\mathrm{mb}}$ & $24 ?$ & - & & $\begin{array}{l}1102 \mathrm{~s} \\
1110 \mathrm{sh}\end{array}$ & $\begin{array}{l}16 \\
24\end{array}$ \\
\hline - & & E & & $\begin{array}{l}1121 \mathrm{~m} \\
1133 \mathrm{msh}\end{array}$ & $\begin{array}{l}35 \\
47\end{array}$ \\
\hline & $58 ?$ & & 58 & & $\begin{array}{l}58 \\
62\end{array}$ \\
\hline- & & - & & 1155 wsh & 69 \\
\hline 809? sh & $92 ?$ & $969 \overline{\mathrm{w}}$ & 103 & $\begin{array}{l}1176 \mathrm{sh} \\
1182 \mathrm{w}\end{array}$ & $\begin{array}{l}90 \\
96\end{array}$ \\
\hline - & & $983 \mathrm{~W}$ & 117 & $1201 \mathrm{~m}$ & 115 \\
\hline $839 \mathrm{sb}$ & $122 ?$ & $989 \mathrm{w}$ & 123 & - & \\
\hline $\begin{array}{c}846 ? \mathrm{sb} \\
-\end{array}$ & $129 ?$ & $\begin{array}{c}996 \mathrm{sh} \\
1018 \mathrm{w} \text { sh }\end{array}$ & $\begin{array}{l}130 \\
142\end{array}$ & $1215 \mathrm{~m}$ & 129 \\
\hline- & & - & & $1245 \mathrm{w}$ & 159 \\
\hline $883 \mathrm{sb}$ & $166 ?$ & $1034 \mathrm{~b}$ & 168 & $1254 \mathrm{~W}$ & 168 \\
\hline $\begin{array}{l}903 \mathrm{~b} \\
912 \mathrm{~s}\end{array}$ & $\begin{array}{l}184 ? \\
195 ?\end{array}$ & $\begin{array}{l}1055 \mathrm{wb} \\
1061 \mathrm{~m}\end{array}$ & $\begin{array}{l}189 \\
195\end{array}$ & $\begin{array}{l}1278 \mathrm{sh} \\
1291 \mathrm{mb}\end{array}$ & $\begin{array}{l}192 \\
205\end{array}$ \\
\hline
\end{tabular}




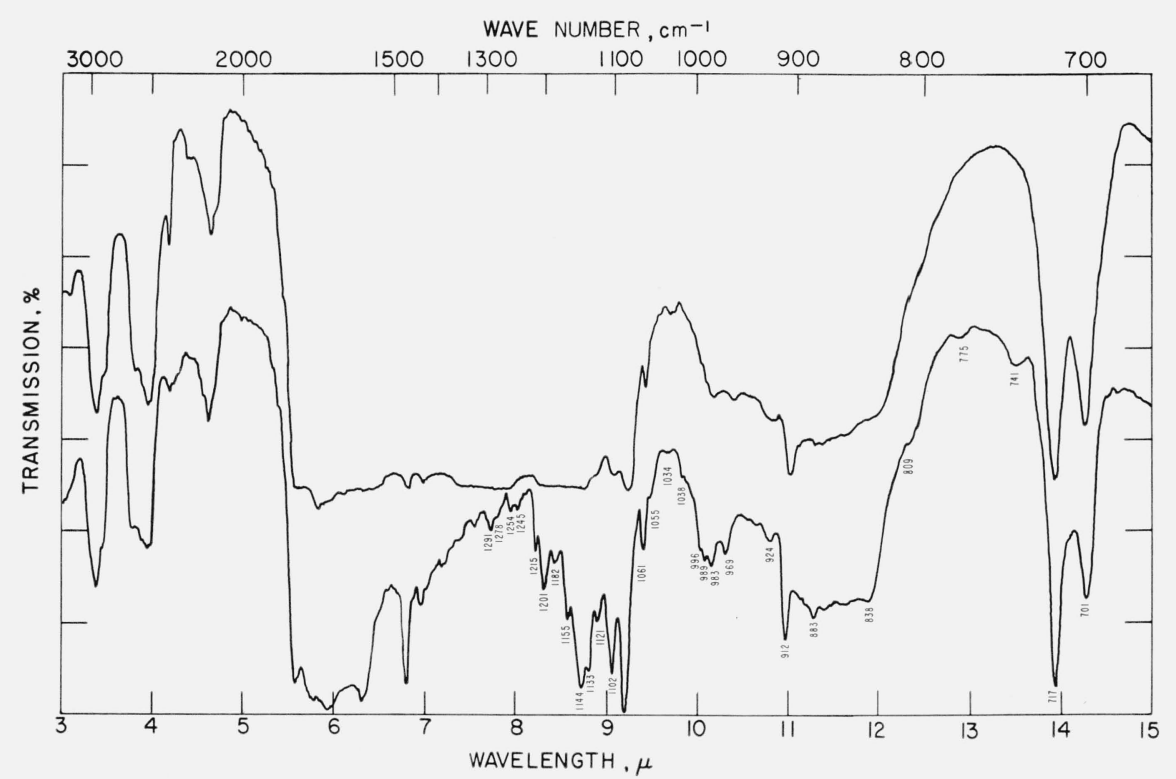

FIGURE 9. Infrared absorption spectra of $\mathrm{CaCO}_{3}$ (aragonite) at room temperature (top) and liquid helium temperature (bottom).

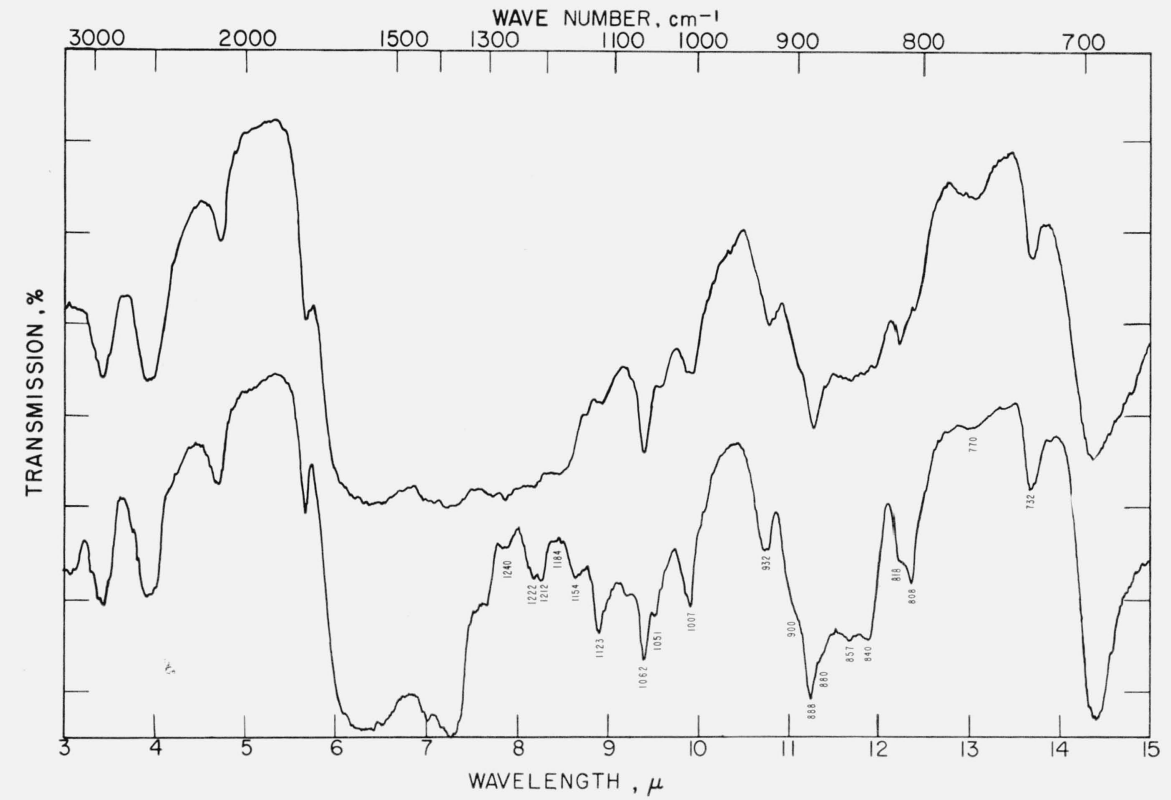

FIGURE 10. Infrared absorption spectra of $\mathrm{BaCO}_{3}$ at room temperature (top) and liquid helium temperature (bottom).

TABLE 8. Observed frequencies for $\mathrm{BaCO}_{3}$ at liquid helium temperature

\begin{tabular}{|c|c|c|c|c|c|}
\hline Frequency & $\begin{array}{l}\text { Separation } \\
\text { from } \\
\text { funda- } \\
\text { mental }\end{array}$ & Frequency & $\begin{array}{l}\text { Separation } \\
\text { from } \\
\text { funda- } \\
\text { mental }\end{array}$ & Frequency & $\begin{array}{l}\text { Separation } \\
\text { from } \\
\text { funda- } \\
\text { mental }\end{array}$ \\
\hline $\begin{array}{l}c m^{-1} \\
694 \nu_{4} \\
732 \mathrm{~m}\left(\nu_{4} ?\right) \\
770 \mathrm{vw} \\
808 \mathrm{~m} \\
818 \mathrm{sh} \\
840 \mathrm{~s} \\
880 \mathrm{sh} \\
888 \mathrm{~s}\end{array}$ & $\begin{array}{c}\mathrm{cm}^{-1} \\
\\
38 \\
76 \\
114 \\
124 \\
156 \\
186 \\
194\end{array}$ & $\begin{array}{c}c m^{-1} \\
857 \nu_{2} \\
900 \mathrm{~m} \\
932 \mathrm{~m} \\
\quad- \\
1007 \overline{\mathrm{m}} \\
1038 \mathrm{w} \mathrm{sh} \\
1051\end{array}$ & $\begin{array}{c}c m^{-1} \\
43 \\
75\end{array}$ & $\begin{array}{l}c m^{-1} \\
1062 \nu_{1} \\
1075 ? \\
1123 \mathrm{~m} \\
1154 \mathrm{~m} \\
1184 \mathrm{vw} \\
1212 \mathrm{~m} \\
1222 \mathrm{~m} \\
\quad-\end{array}$ & $\begin{array}{c}c m^{-1} \\
13 \\
61 \\
92 \\
122 \\
150 \\
160\end{array}$ \\
\hline
\end{tabular}

TABLE 9. Observed frequencies for $\mathrm{PbCO}_{3}$ at liquid helium temperature

\begin{tabular}{|c|c|c|c|c|c|}
\hline Frequency & $\begin{array}{l}\text { Separation } \\
\text { from } \\
\text { funda- } \\
\text { mental }\end{array}$ & Frequency & $\begin{array}{l}\text { Separation } \\
\text { from } \\
\text { funda- } \\
\text { mental }\end{array}$ & Frequeney & $\begin{array}{l}\text { Separation } \\
\text { from } \\
\text { funda- } \\
\text { mental }\end{array}$ \\
\hline $\begin{array}{c}c \mathrm{~m}^{-1} \\
684 \nu^{4} \\
727 \mathrm{~m} \nu_{4} ? \\
734 \mathrm{~m} \nu_{4} ? \\
768 \overline{\mathrm{vw}} \\
788 \mathrm{mb} \\
797 \mathrm{mb} \\
809 \mathrm{wb} \\
818 \mathrm{vw} \\
827 \mathrm{~m} \\
854 \mathrm{sb} \\
877 \mathrm{~s}\end{array}$ & $\begin{array}{c}\mathrm{cm}^{-1} \\
\\
42 \\
50 \\
\\
84 \\
104 \\
113 \\
125 \\
134 \\
143 \\
170 \\
193\end{array}$ & $\begin{array}{l}\mathrm{cm}^{-1} \\
842 \nu_{2} \\
896 \mathrm{w} \text { sh } \\
911 \mathrm{w} \\
- \\
925 \mathrm{w} \text { sh } \\
938 \mathrm{w} \text { sh } \\
958 \mathrm{w} \mathrm{sh} \\
977 \mathrm{w} \mathrm{sh} \\
-\overline{\mathrm{v}} \\
996 \\
1011 \mathrm{vw} \\
1022 \mathrm{wb} \\
1036 ?\end{array}$ & $\begin{array}{r}\mathrm{cm}^{-1} \\
\\
54 \\
69 \\
83 \\
96 \\
116 \\
135 \\
\\
154 \\
169 \\
180 \\
194\end{array}$ & $\begin{array}{c}\mathrm{cm}^{-1} \\
1057 \nu_{1} \\
1082 \mathrm{w} \\
1101 \mathrm{sh} \\
1118 \mathrm{~s} \\
1143 \mathrm{sh} \\
1161 \mathrm{w} \\
-- \\
1187 \mathrm{w} \\
- \\
1228 \mathrm{~m} \\
1234 \mathrm{~m} \\
1257 \mathrm{~m} \mathrm{sh}\end{array}$ & $\begin{array}{r}\mathrm{cm}^{-1} \\
25 \\
43 \\
61 \\
86 \\
104 \\
\\
130\end{array}$ \\
\hline
\end{tabular}




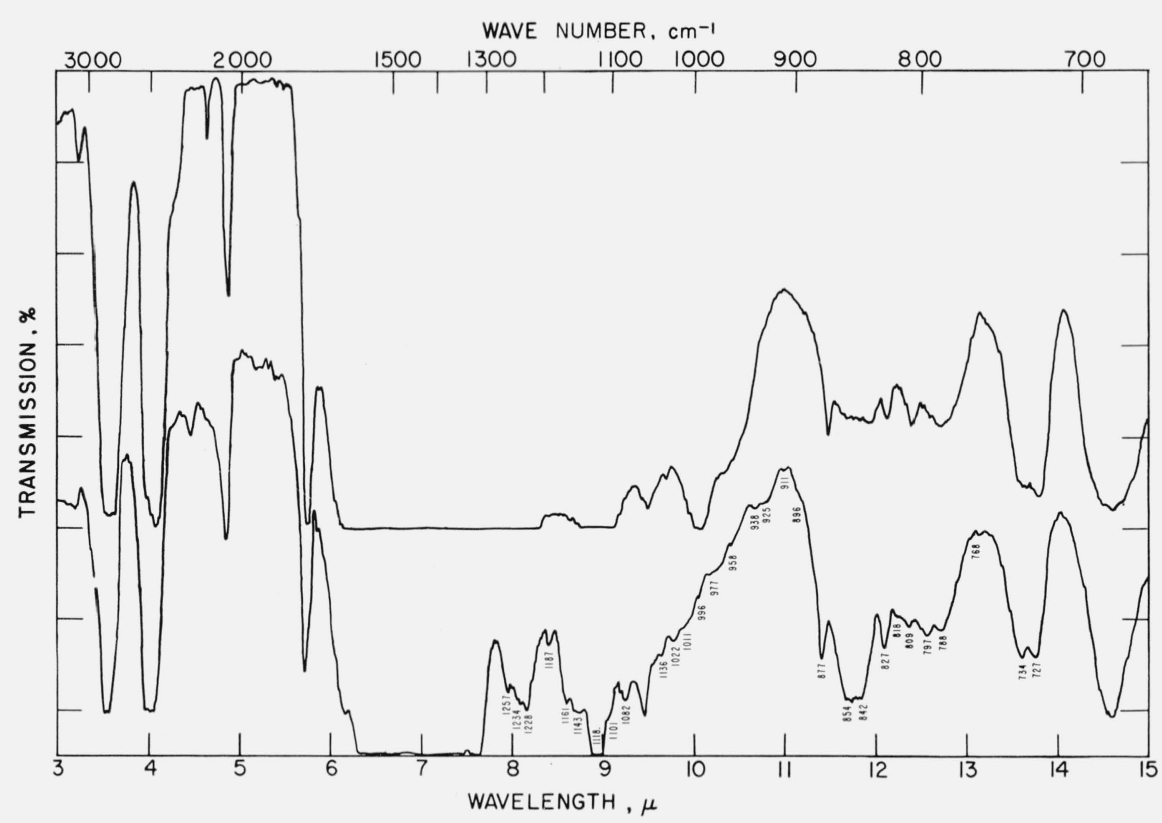

Figure 11. Infrared absorption spectra of $\mathrm{PbCO}_{3}$ at room temperature (top) and liquid helium temperature (bottom).

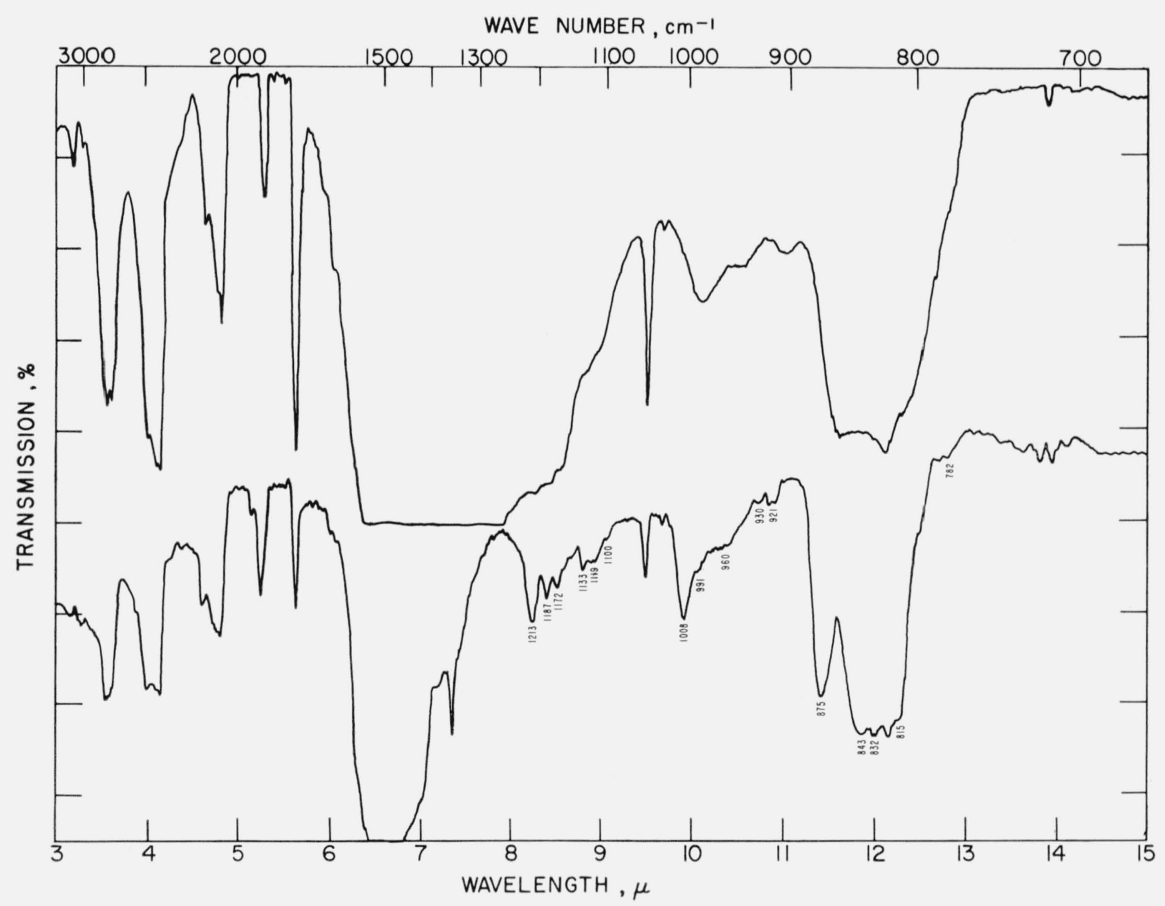

FIGURE 12. Infrared absorption spectra of $\mathrm{KNO}_{3}$ at room temperature (top) and liquid helium temperature (bottom).

Only general observations are given for these spectra. Attempts to analyze the highly complex structure observed in figures 13 and 14 have met with only indifferent success. In part, this is probably the result of the more complex internal fundamental bands observed in these structures which were discussed earlier. At the very least this would produce many overlapping band systems. In part the complexity may arise from further splitting of $\nu_{2}$ from isotope effects first noted by Decius [15] in the aragonites. Finally, there are strong indications that at least two libration frequencies may be involved in these spectra to produce still greater overlapping.

That combination modes are involved is clearly shown by comparing the normal and low temperature spectra. Elimination of the difference modes with $\nu_{1}$ is clearly seen in figures 9,10 , and 11 so that there is little doubt that a liberation frequency of approximately $30 \mathrm{~cm}^{-1}$ is present. Attempts have been 


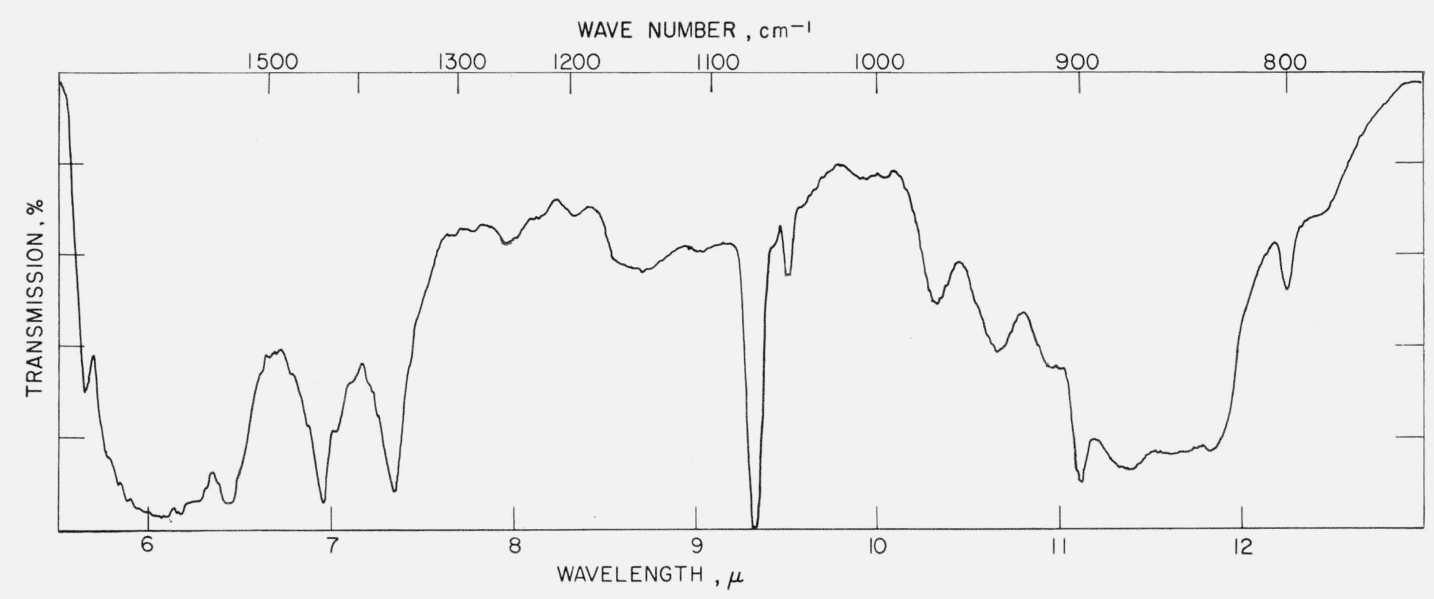

FIGURE 13. Infrared absorption spectrum of $\mathrm{SrCO}_{3}$ at liquid helium temperature (expanded!scale).

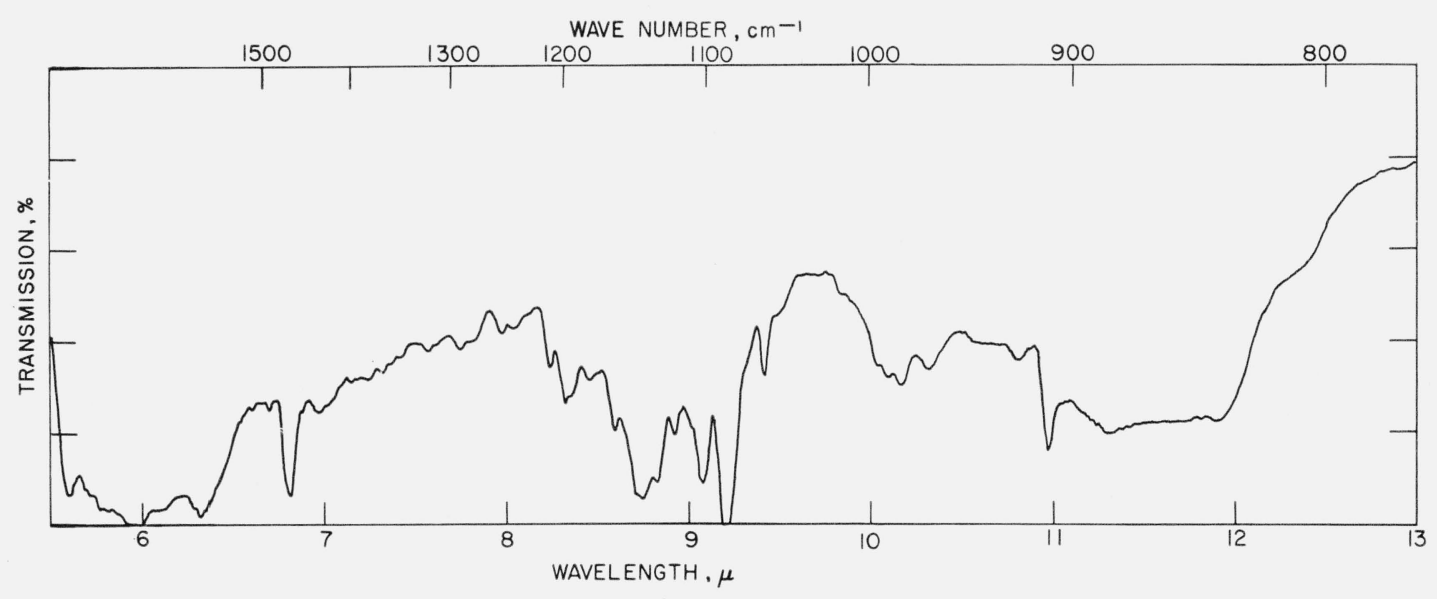

FIGURE 14. Infrared absorption spectrum of $\mathrm{CaCO}_{3}$ (aragonite) at liquid helium temperature (expanded scale).

TABLE 10. Observed frequencies for $\mathrm{KNO}_{3}$ at liquid helium temperature

\begin{tabular}{|c|c|c|c|c|c|}
\hline Frequency & $\begin{array}{l}\text { Separation } \\
\text { from } \\
\text { funda- } \\
\text { mental }\end{array}$ & Frequency & $\begin{array}{l}\text { Separation } \\
\text { from } \\
\text { funda- } \\
\text { mental }\end{array}$ & Frequency & $\begin{array}{l}\text { Separation } \\
\text { from } \\
\text { funda- } \\
\text { mental }\end{array}$ \\
\hline $\begin{array}{l}c m^{-1} \\
714 \nu_{4} \\
782- \\
815- \\
832 \mathrm{~b} \\
843 \mathrm{~b} \\
875 \mathrm{~s}\end{array}$ & $\begin{array}{r}c m^{-1} \\
\\
68 \\
101 \\
118 \\
129 \\
161\end{array}$ & $\begin{array}{c}\mathrm{cm}^{-1} \\
827 \nu_{2} \\
\overline{-} \\
921 ? \mathrm{~b} \\
930 \mathrm{vw} \\
- \\
960 \mathrm{wb} \\
991 \mathrm{w} \mathrm{sh} \\
1008 \mathrm{~s}\end{array}$ & $\begin{array}{r}94 \\
103 \\
133 \\
164 \\
181\end{array}$ & $\begin{array}{c}c m^{-1} \\
1051 \nu_{1} \\
1100 \mathrm{wb} \\
1119 \mathrm{~b} \\
1133 \mathrm{mb} \\
\quad- \\
1172 \mathrm{~m} \\
1187 \mathrm{~m} \\
1213 \mathrm{~s}\end{array}$ & $\begin{array}{c}\mathrm{cm}^{-1} \\
49 \\
68 \\
82 \\
121 \\
136 \\
162\end{array}$ \\
\hline
\end{tabular}

made to correlate bands arising from the various fundamentals in the tabular data. It appears that correlations exist despite the failure to analyze the data.

One outstanding characteristic of the carbonate aragonites is to be found in the very broad, intense band found in the $\nu_{2}$ region. This band completely obscures the ordinarily strong $\nu_{2}$ band found in thin polycrystalline films of these materials [77]. The sharp strong band on the high frequency edge of this absorption complex does not correspond to the usual out-of-plane bending frequency, but may represent the cutoff for a series of liberation modes with $\nu_{4}$.

\section{c. Cubic Type Structures}

The spectra of the cubic nitrates show many bands falling into a regular series that may be assigned to combinations between a harmonic liberation mode and the fundamentals $\nu_{1}, \nu_{2}$, and $\nu_{4}$. Spectra at three temperatures are shown for $\mathrm{Pb}\left(\mathrm{NO}_{3}\right)_{2}$ in figure 15 while similar spectra at two temperatures are given in figures 16 and 17 for $\mathrm{Ba}\left(\mathrm{NO}_{3}\right)_{2}$ and $\mathrm{Sr}\left(\mathrm{NO}_{3}\right)_{2}$ respectively. Assignments at liquid helium temperature are tabulated in tables 11,12 , and 13 . In the spectra it is noted that bands falling between $850 \mathrm{~cm}^{-1}$ and $1250^{-1}$ have relatively large frequency shifts with temperature, while the fundamentals $\nu_{2}$ and $\nu_{4}$ appear to be unaffected by the same temperature change. These bands may be attributed to the combinations of a low lying librational mode with the fundamentals, with the librational mode being relatively temperature dependent through the effect of expansivity on volume. 
WAVE NUMBER, $\mathrm{cm}^{-1}$

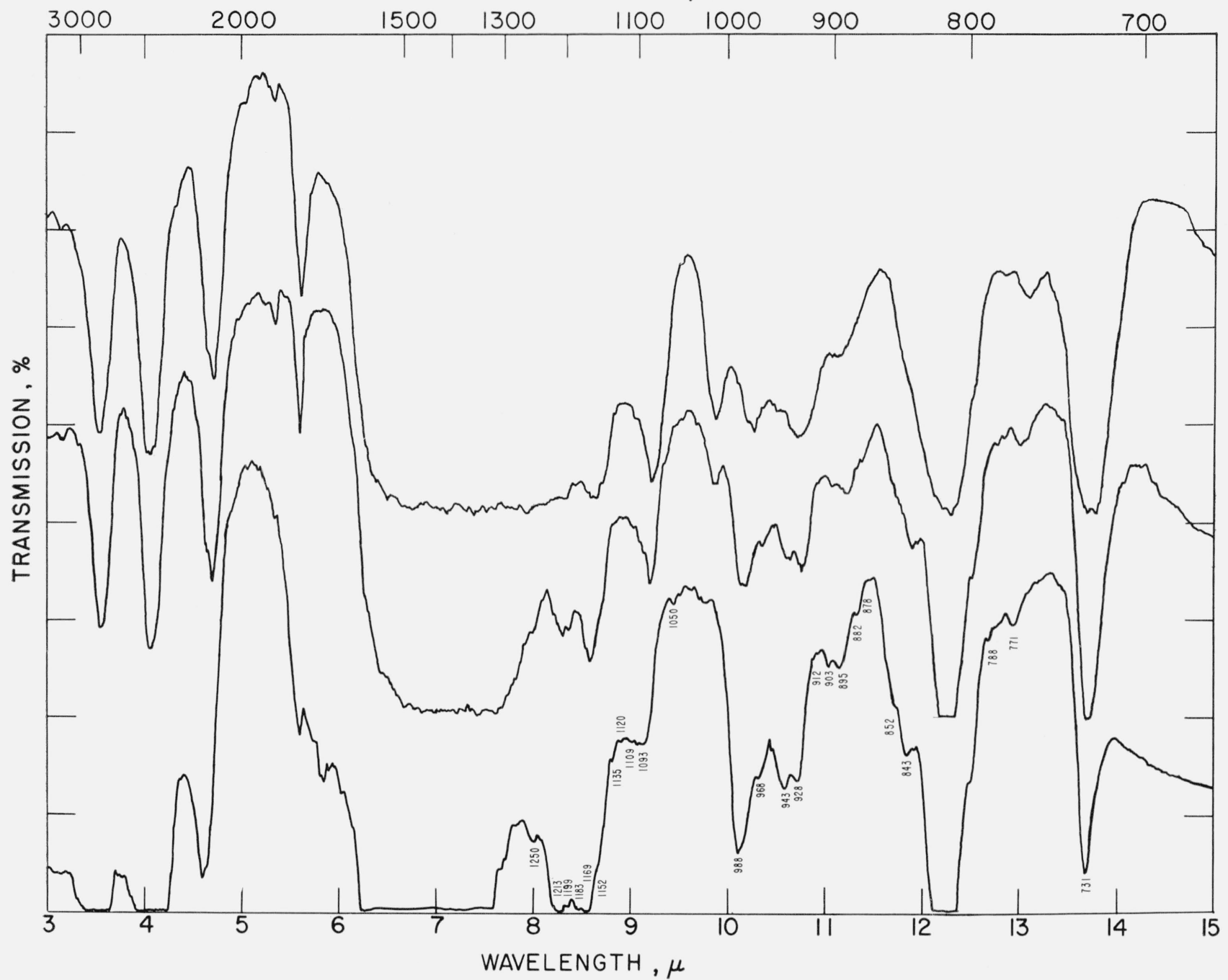

Figure 15. Infrared absorption spectra of $\mathrm{Pb}\left(\mathrm{NO}_{3}\right)_{2}$ at room temperature (top), liquid nitrogen temperature (center), and liquid helium temperature (bottom).

TABLE 11. Assignments for $\mathrm{Pb}\left(\mathrm{NO}_{3}\right)_{2}$ at liquid helium temperature for libration combinations

\begin{tabular}{|c|c|c|c|c|c|c|}
\hline Frequency & $\begin{array}{c}\text { Separa- } \\
\text { tion } \\
\text { from } \\
\text { funda- } \\
\text { mental }\end{array}$ & Frequency & $\begin{array}{l}\text { Separa- } \\
\text { tion } \\
\text { from } \\
\text { funda- } \\
\text { mental }\end{array}$ & Frequency & $\begin{array}{c}\text { Separa- } \\
\text { tion } \\
\text { from } \\
\text { funda- } \\
\text { mental }\end{array}$ & $\begin{array}{l}\text { Assign- } \\
\text { ment }\end{array}$ \\
\hline $\begin{array}{l}\mathrm{cm}^{-1} \\
731 \nu^{4}\end{array}$ & $\mathrm{~cm}^{-1}$ & $\begin{array}{l}\mathrm{cm}^{-1} \\
817 \nu_{2}\end{array}$ & & $\begin{array}{c}\mathrm{cm}^{-1} \\
1058 \nu_{1}\end{array}$ & $\mathrm{~cm}^{-1}$ & $\nu_{0}$ \\
\hline$-\overline{7 \pi 1}$ & & $838 ?$ & 21 & & & $\nu_{0}+\mathrm{L}$ \\
\hline $\begin{array}{l}771 \\
788\end{array}$ & 40 & $852 \mathrm{sh}$ & 35 & $\begin{aligned} 1093 \mathrm{~s} \\
\sim\end{aligned}$ & 35 & $\nu_{0}+2 \mathrm{~L}$ \\
\hline $\begin{array}{c}788 \\
?\end{array}$ & 57 & $\overline{882} \mathrm{~m}$ & 65 & $\begin{array}{c}\approx 1109 \mathrm{VW} \\
1120 ? \mathrm{VW}\end{array}$ & $\begin{array}{l}51 \\
62\end{array}$ & $\begin{array}{l}\nu_{0}+3 \mathrm{~L} \\
\nu_{0}+4 \mathrm{~L}\end{array}$ \\
\hline ? & & - & & $1135 \mathrm{sh}$ & 77 & $\nu_{0}+5 \mathrm{~L}$ \\
\hline$?$ & & $912 \mathrm{vW}$ & 95 & $1152 \mathrm{sh}$ & 94 & $\nu_{0}+6 \mathrm{~L}$ \\
\hline 843 & 113 & $928 \mathrm{~s}$ & 111 & $1169 \mathrm{~s}$ & 111 & $\nu_{0}+7 \mathrm{~L}$ \\
\hline $858 \mathrm{sh}$ & 127 & $943 \mathrm{~s}$ & 126 & $1183 \mathrm{sh}$ & 125 & $\nu_{0}+8 \mathrm{~L}$ \\
\hline $878 \mathrm{sh}$ & 147 & $968 \mathrm{~s}$ & 146 & $1199 \mathrm{sh}$ & 141 & $\nu_{0}+9 \mathrm{~L}$ \\
\hline 895 & 164 & - & & $1213 \mathrm{vS}$ & 153 & $\nu_{0}+10 \mathrm{~L}$ \\
\hline 903 & 172 & $988 \mathrm{vs}$ & 171 & 1220 & 162 & cutoff \\
\hline
\end{tabular}

TABLE 12. Assignments for $\mathrm{Ba}\left(\mathrm{NO}_{3}\right)_{2}$ at liquid helium temperature for libration combinations

\begin{tabular}{|c|c|c|c|c|c|c|}
\hline Frequency & $\begin{array}{l}\text { Separa- } \\
\text { tion } \\
\text { from } \\
\text { funda- } \\
\text { mental }\end{array}$ & Frequency & $\begin{array}{c}\text { Separa- } \\
\text { tion } \\
\text { from } \\
\text { funda- } \\
\text { mental }\end{array}$ & Frequency & $\begin{array}{l}\text { Separa- } \\
\text { tion } \\
\text { from } \\
\text { funda- } \\
\text { mental }\end{array}$ & $\begin{array}{c}\text { Assign- } \\
\text { ment }\end{array}$ \\
\hline $\begin{array}{l}\mathrm{cm}^{-1} \\
722 \nu_{4}\end{array}$ & $c m^{-1}$ & $\begin{array}{l}\mathrm{cm}^{-1} \\
813 \nu_{2}\end{array}$ & $\mathrm{~cm}^{-1}$ & $\begin{array}{r}c m^{-1} \\
1052 \nu_{1}\end{array}$ & $\mathrm{~cm}^{-1}$ & \\
\hline- & & - & & - & & $\nu_{0}+\mathrm{L}$ \\
\hline 765 & 43 & $\overline{866}$ & & $1086 \mathrm{vs}$ & 34 & $\nu_{0}+2 \mathrm{~L}$ \\
\hline$\underset{785 b}{-}$ & 63 & $866 \mathrm{vW}$ & 53 & $\begin{array}{l}1105 \mathrm{~m} \mathrm{sh} \\
1125 \mathrm{~s}\end{array}$ & $\begin{array}{l}53 \\
73\end{array}$ & $\begin{array}{l}\nu 0+3 \mathrm{~L} \\
\nu_{0}+4 \mathrm{~L}\end{array}$ \\
\hline - & & - & & $1139 \mathrm{~s}$ & 87 & $\nu_{0}+5 \mathrm{~L}$ \\
\hline- & & - & & $1156 \mathrm{~s}$ & 104 & $\nu_{0}+6 \mathrm{~L}$ \\
\hline $838 \mathrm{sh}$ & 116 & $931 \mathrm{~m}$ & 118 & $1172 \mathrm{w}$ sh & 120 & $\nu_{0}+7 \mathrm{~L}$ \\
\hline $857 \mathrm{w}$ & 135 & $949 \mathrm{~m}$ & 136 & $1188 \mathrm{sh}$ & 136 & $\nu_{0}+8 \mathrm{~L}$ \\
\hline $876 \mathrm{w}$ & 154 & $969 \mathrm{~m}$ & 156 & $1209 \mathrm{sh}$ & 157 & $\nu_{0}+9 \mathrm{~L}$ \\
\hline $889 \mathrm{sh}$ & 167 & $982 \mathrm{sh}$ & 169 & $1220 ?$ & 168 & $\nu_{0}+10 \mathrm{~L}$ \\
\hline $\begin{array}{l}898 \mathrm{~s} \\
?\end{array}$ & 176 & $\begin{array}{c}993 \mathrm{~s} \\
?\end{array}$ & 180 & $\begin{array}{c}1231 \mathrm{~s} \\
?\end{array}$ & 179 & $\begin{array}{l}\nu_{0}+11 \mathrm{~L} \\
\nu_{0}+12 \mathrm{~L}\end{array}$ \\
\hline $913 \mathrm{~m}$ & 191 & 1004 & 191 & 1245 & 193 & cutoff \\
\hline
\end{tabular}




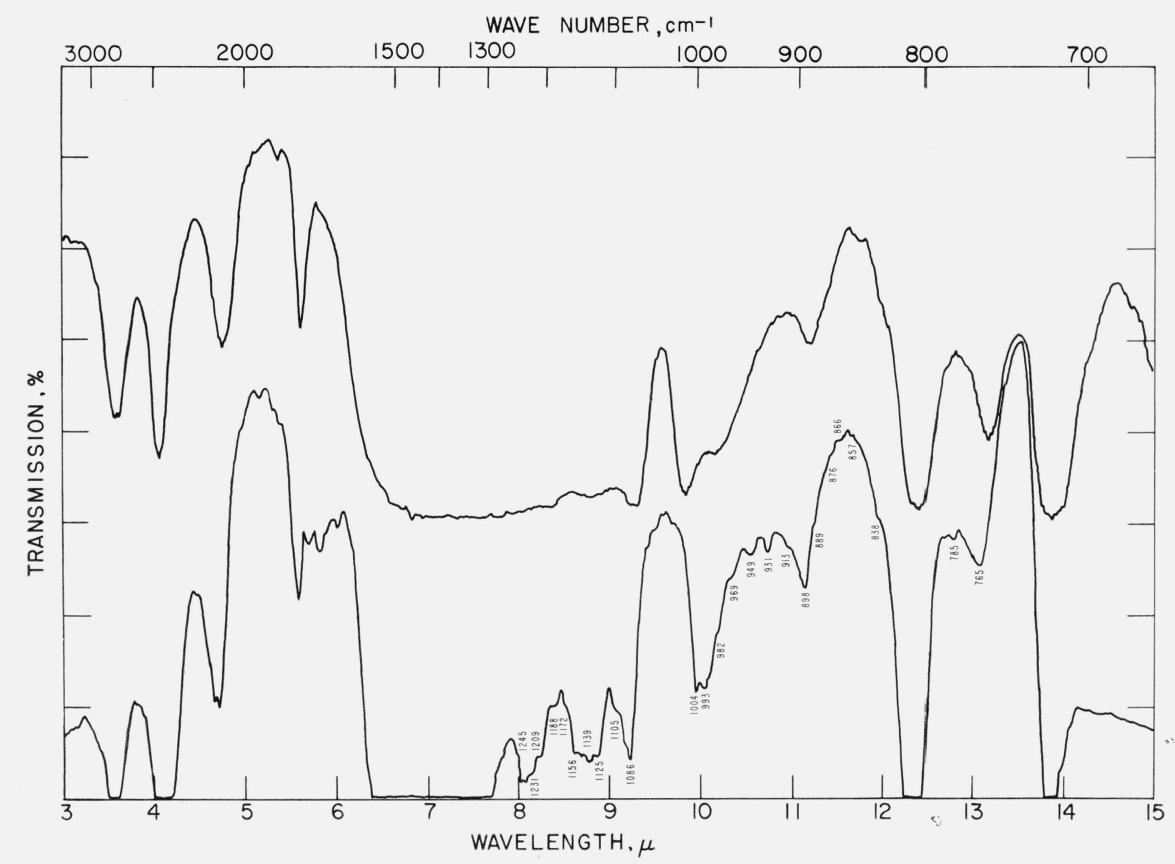

Figure 16. Infrared absorption spectra of $\mathrm{Ba}\left(\mathrm{NO}_{3}\right)_{2}$ at room temperature (top) and liquid helium temperature (bottom).

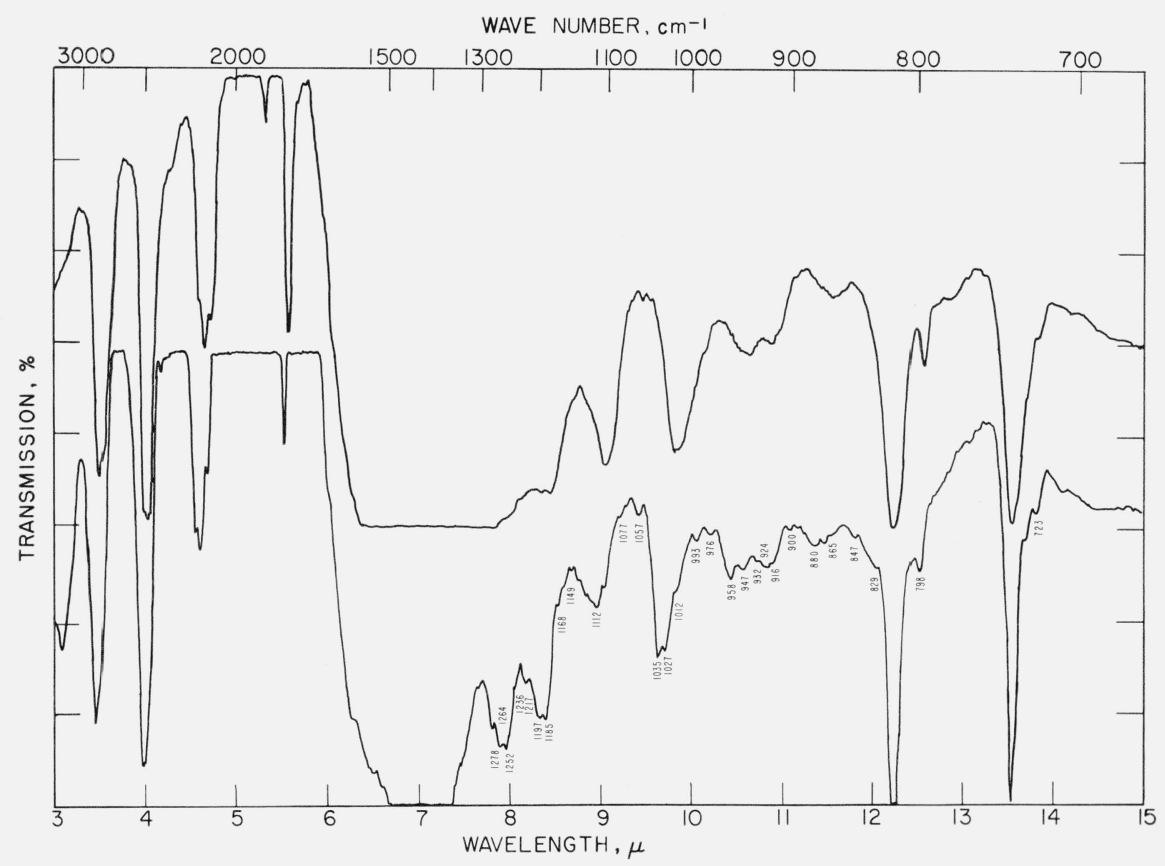

FiguRE 17. Infrared absorption spectra of $\mathrm{Sr}\left(\mathrm{NO}_{3}\right)_{2}$ at room temperature (top) and liquid helium temperature (bottom).

Inspection of the tables shows a rather systematic series of bands arising from each of the fundamentals. In the region between $\nu_{2}$ and the cutoff for the series arising from $\nu_{4}$ the band structure is highly complex. Assignments in this region are not unequivocal as may be seen from the vacancies in the tables. The combination bands are neither sharp nor strong so that errors in positions may easily amount to a few $\mathrm{cm}^{-1}$. With this uncertainty the variation in spacing appears to be of the order of the errors in locating the bands.

The behavior of the two bands located symmetrically on either side of the inactive or very weak $\nu_{1}$ frequency (circa $1050 \mathrm{~cm}^{-1}$ ) provide a convincing argument for the assignments given. These bands are believed to arise from sum and difference tones of the libration and the symmetric stretch. In the room temperature spectra these bands are very 
TABLE 13. Assignments for $\mathrm{Sr}\left(\mathrm{NO}_{3}\right)_{2}$ at liquid helium temperature for libration combinations

\begin{tabular}{|c|c|c|c|c|c|c|}
\hline Frequency & $\begin{array}{c}\text { Separa- } \\
\text { tion } \\
\text { from } \\
\text { funda- } \\
\text { mental }\end{array}$ & Frequency & $\begin{array}{l}\text { Separa- } \\
\text { tion } \\
\text { from } \\
\text { funda- } \\
\text { mental }\end{array}$ & Frequency & $\begin{array}{c}\text { Separa- } \\
\text { tion } \\
\text { from } \\
\text { funda- } \\
\text { mental }\end{array}$ & $\begin{array}{c}\text { Assign- } \\
\text { ment }\end{array}$ \\
\hline $\mathrm{cm}^{-1}$ & $\mathrm{~cm}^{-1}$ & $\mathrm{~cm}^{-1}$ & $\mathrm{~cm}^{-1}$ & $\mathrm{~cm}^{-1}$ & $\mathrm{~cm}^{-1}$ & \\
\hline 754 ? & 16 & $829 \mathrm{sh}$ & 14 & $1077 \mathrm{sh}$ & 20 & $\nu_{0}+\mathrm{L}$ \\
\hline $798 \mathrm{~s}$ & 60 & $?$ & & $1112 \mathrm{~s} \mathrm{~b}$ & 55 & $\begin{array}{l}\nu_{0}+3 \mathrm{~L} \\
\nu_{0}+4 \mathrm{~L}\end{array}$ \\
\hline $829 \mathrm{sh}$ & 91 & $?$ & & $1149 \mathrm{VW}$ & 92 & $\nu_{0}+5 \mathrm{~L}$ \\
\hline $847 \mathrm{w}$ & 109 & $924 \mathrm{~m}$ & 109 & $1168 \mathrm{w}$ sh & 111 & $\nu_{0}+6 \mathrm{~L}$ \\
\hline $865 \mathrm{~W}$ & 127 & & & $1185 \mathrm{~s}$ & 128 & $\nu_{0}+7 \mathrm{~L}$ \\
\hline $880 \mathrm{~m}$ & 142 & ? & & $1197 \mathrm{~s}$ & 140 & $\nu_{0}+8 \mathrm{~L}$ \\
\hline $900 ? \mathrm{VW}$ & 162 & $976 \mathrm{w}$ & 161 & $1217 \mathrm{~m}$ & 160 & $\nu_{0}+9 \mathrm{~L}$ \\
\hline $916 \mathrm{w}$ sh & 178 & $993 \mathrm{~m}$ & 178 & $1236 \mathrm{sh}$ & 179 & $\nu_{0}+10 \mathrm{~L}$ \\
\hline $932 \mathrm{sh}$ & 194 & $1012 \mathrm{sh}$ & 197 & $1252 \mathrm{~s}$ & 195 & $\nu_{0}+11 \mathrm{~L}$ \\
\hline $947 \mathrm{~m}$ & 209 & $1027 \mathrm{sh}$ & 212 & $1264 \mathrm{~s}$ & 209 & $\nu_{0}+12 \mathrm{~L}$ \\
\hline $958 \mathrm{~s}$ & 220 & $1035 \mathrm{vs}$ & 220 & $1278 \mathrm{~m}$ & 221 & cutoff \\
\hline
\end{tabular}

prominent features of the spectra. In $\mathrm{Sr}\left(\mathrm{NO}_{3}\right)_{2}$ the bands appear to be located at $1103 \mathrm{~cm}^{-1}$ and 1029 $\mathrm{cm}^{-1}$ and the difference between these values appears to be four times the librational frequency giving a libration mode of $19 \mathrm{~cm}^{-1}$. In $\mathrm{Pb}\left(\mathrm{NO}_{3}\right)_{2}$ the bands are at $1086 \mathrm{~cm}^{-1}$ and $1012 \mathrm{~cm}^{-1}$ giving $\mathrm{L}=18 \mathrm{~cm}^{-1}$, while in $\mathrm{Ba}\left(\mathrm{NO}_{3}\right)_{2}$ the corresponding values are 1074 $\mathrm{cm}^{-1}, 1015 \mathrm{~cm}^{-1}$ with $\mathrm{L}=15 \mathrm{~cm}^{-1}$. These values of the librational frequency may be lower than the corresponding values given in the tables for liquid helium temperature, but the value of the libration frequency is temperature dependent as shown by the temperature dependence of the libration bands. From figure 15 it will be noted that as the temperature is lowered the summation band located at $1086 \mathrm{~cm}^{-1}$ at room temperature in $\mathrm{Pb}\left(\mathrm{NO}_{3}\right)_{2}$ shifts to about $1088 \mathrm{~cm}^{-1}$ at liquid nitrogen temperature and to approximately $1093 \mathrm{~cm}^{-1}$ at liquid helium temperature. Simultaneously the difference band located at $1012 \mathrm{~cm}^{-1}$ which is very strong at room temperature is reduced to about one-half of this intensity at liquid nitrogen temperature and to a very weak, questionable band at liquid helium temperature. The intensity behavior corroborates the interpretation as a difference band and the low temperature required for its removal is conclusive evidence for a low frequency transition. As mentioned earlier this difference band constitutes a thermometer in the spectrum.

The effect of temperature on the cutoff frequency for combinations with $\nu_{2}$ observed in the same figure appears to result in an increase of the cutoff from $975 \mathrm{~cm}^{-1}$ at room temperature, to $985 \mathrm{~cm}^{-1}$ at liquid nitrogen temperature and to about $988 \mathrm{~cm}^{-1}$ at liquid helium temperature. Simultaneously the cutoff appears to increase in intensity and become noticeably sharper. The effect of temperature on the intensity will be discussed later.

An analagous behavior is exhibited by $\mathrm{Sr}\left(\mathrm{NO}_{3}\right)_{2}$ and $\mathrm{Ba}\left(\mathrm{NO}_{3}\right)_{2}$. It should be noted that the strong 1015 $\mathrm{cm}^{-1}$ band in the room temperature spectrum of $\mathrm{Ba}\left(\mathrm{NO}_{3}\right)_{2}$ does not represent the cutoff for the $\nu_{2}$ series. The $1015 \mathrm{~cm}^{-1}$ band is the $\nu_{1}$ difference mode and is eliminated on cooling. The $\nu_{2}$ series cutoff appears to be represented by the strong shoulder near $980 \mathrm{~cm}^{-1}$ which shifts to $1004 \mathrm{~cm}^{-1}$ on cooling.
In $\mathrm{Sr}\left(\mathrm{NO}_{3}\right)_{2}$ the difference band located near 1015 $\mathrm{cm}^{-1}$ at room temperature appears to be obliterated by the $\nu_{2}$ cutoff which shifts from an unknown position at room temperature to about $1032 \mathrm{~cm}^{-1}$ at liquid nitrogen temperature and to approximately $1035 \mathrm{~cm}^{-1}$ at liquid helium temperature.

As in all other spectra the effect of cooling on $\nu_{3}$ is to produce a marked increase in transmission on the low frequency side of $\nu_{3}$ with an absence of a similar effect on the high frequency side. This is in accord with the elimination of the difference modes $\nu_{3}-n L$ on cooling with no corresponding elimination of the summation bands. The $\nu_{3}$ cutoff is estimated to be of the correct order of magnitude if it is taken at the frequency at which the specimens show transmission on the high frequency side of $\nu_{3}$.

\section{d. Miscellaneous Structure Types}

Data are given here for $\mathrm{TINO}_{3}, \mathrm{AgNO}_{3}, \mathrm{CsNO}_{3}$, and $\mathrm{RbNO}_{3}$. Spectra are given at three temperatures for $\mathrm{TlNO}_{3}$ in figure 18. Spectra for two temperatures are given in figures 19,20 , and 21 for $\mathrm{AgNO}, \mathrm{CsNO}_{3}$, and $\mathrm{RbNO}_{3}$, respectively. The corresponding frequencies are given in tables 14, 15, 16, and 17. In the experiments using $\mathrm{AgNO}_{3}$ difficulties were encountered because of the reaction between the copper bar and $\mathrm{AgNO}_{3}$. Successful runs were obtained by cementing the $\mathrm{AgNO}_{3}$ crystal to a silver strip which was attached to the copper bar. The thermal path for $\mathrm{AgNO}_{3}$ was longer and more doubtful than for any other specimen. However, comparison of the two spectra for the $\mathrm{AgNO}_{3}$ show that considerable cooling was effected.

These spectra contain a wealth of fine structure of which only a portion appears to be explained by the present analysis. There are indications that at least two low frequency libration modes are coupling with the fundamentals giving rise to two overlapping series of bands with two cutoff values. As shown in table 14, half of the bands for $\mathrm{TlNO}_{3}$ can be assigned with a $25 \mathrm{~cm}^{-1}$ libration mode but there are also at least nine unassigned bands.

TABLE 14. Assignments for $\mathrm{TINO}_{3}$ at liquid helium temperature for libration combinations

\begin{tabular}{|c|c|c|c|c|c|c|}
\hline Frequency & $\begin{array}{c}\text { Separa- } \\
\text { tion } \\
\text { from } \\
\text { funda- } \\
\text { mental }\end{array}$ & Frequency & $\begin{array}{l}\text { Separa- } \\
\text { tion } \\
\text { from } \\
\text { funda- } \\
\text { mental }\end{array}$ & Frequency & $\begin{array}{c}\text { Separa- } \\
\text { tion } \\
\text { from } \\
\text { funda- } \\
\text { mental }\end{array}$ & $\begin{array}{c}\text { Assign- } \\
\text { ment }\end{array}$ \\
\hline $\mathrm{cm}^{-1}$ & $\mathrm{~cm}^{-1}$ & $\mathrm{~cm}^{-1}$ & $\mathrm{~cm}^{-1}$ & $\mathrm{~cm}^{-1}$ & $\mathrm{~cm}^{-1}$ & \\
\hline $\begin{array}{l}715 \nu_{4} \\
740 \mathrm{~s}\end{array}$ & & $\begin{array}{l}828 \nu_{2} \\
830 \mathrm{sh}\end{array}$ & 32 & $\begin{array}{l}1044 \nu_{1} \\
1068 \mathrm{sh}\end{array}$ & 24 & $\nu_{0}^{\nu_{0}}+\mathrm{L}$ \\
\hline $140 \mathrm{~S}$ & 20 & $830 \mathrm{sin}$ & 32 & $1090 \mathrm{~m}$ & $\begin{array}{l}24 \\
46\end{array}$ & $\begin{array}{l}v_{0}+\mathrm{L} \\
\text { ? }\end{array}$ \\
\hline $768 \mathrm{sh}$ & 53 & $880 \mathrm{wb}$ & 52 & $\begin{array}{l}1096 \mathrm{~m} \\
1101 \mathrm{sh}\end{array}$ & $\begin{array}{l}52 \\
57\end{array}$ & $\begin{array}{c}\nu_{\circ}+2 \mathrm{~L} \\
?\end{array}$ \\
\hline $791 \mathrm{~m}$ & 76 & $905 \mathrm{w}$ & 77 & $1115 \mathrm{w}$ & 71 & $\nu_{\circ}+3 \mathrm{~L}$ \\
\hline - & & $913 \mathrm{~m}$ & 85 & $1127 \mathrm{vW}$ & $\begin{array}{l}83 \\
94\end{array}$ & $?$ \\
\hline 二 & & $93 \overline{1} \mathrm{w}$ & 103 & $\begin{array}{l}1138 \mathrm{w} \\
1147 \mathrm{~s}\end{array}$ & $\begin{array}{r}94 \\
103\end{array}$ & $\nu_{\mathrm{o}}+4 \mathrm{~L}$ \\
\hline - & & - & & $1150 \mathrm{vs}$ & 106 & \\
\hline - & & 一 & & $1160 \mathrm{sh}$ & 116 & ? \\
\hline 一 & & 一 & & $1168 \mathrm{sh}$ & 124 & ? \\
\hline - & & $956 \mathrm{~m}$ & 128 & $1175 \mathrm{~s}$ & 131 & $\nu_{\circ}+5 \mathrm{~L}$ \\
\hline $850 \mathrm{sh}$ & 145 & $975 \mathrm{~s}$ & 147 & $1193 \mathrm{~b} \mathrm{sh}$ & 149 & \\
\hline $885 \mathrm{~W}$ & 160 & $989 \mathrm{~m}$ & 161 & $1207 \mathrm{~m}$ & 163 & $?$ \\
\hline - & & $1003 \mathrm{~s}$ & 175 & $1224 \mathrm{~m}$ & 180 & $\nu_{\circ}+7 \mathrm{~L}$ \\
\hline - & & $1023 \mathrm{~m}$ & 195 & - & & \\
\hline $922 \mathrm{w}$ & 207 & 1030 & 202 & $1246 \mathrm{~W}$ & 202 & $\nu_{\mathrm{o}}+8 \mathrm{~L}$ \\
\hline $943 \mathrm{sh}$ & 228 & $1054 \mathrm{vW}$ & 226 & $1280 ? \mathrm{sb}$ & 236 & $\nu_{\mathrm{O}}+9 \mathrm{~L}$ \\
\hline $975 \mathrm{~s}$ & 260 & $1080 \mathrm{~m}$ & 252 & $1294 ? \mathrm{~b}$ & 250 & cutoff \\
\hline
\end{tabular}


TABLE 15. Observed frequencies in $\mathrm{AgNO}_{3}$ at liquid helium temperature

\begin{tabular}{|c|c|c|c|c|c|}
\hline Frequency & $\begin{array}{l}\text { Separation } \\
\text { from fun- } \\
\text { damental }\end{array}$ & Frequency & $\begin{array}{l}\text { Separation } \\
\text { from fun- } \\
\text { damental }\end{array}$ & Frequency & $\begin{array}{l}\text { Separation } \\
\text { from fun- } \\
\text { damental }\end{array}$ \\
\hline 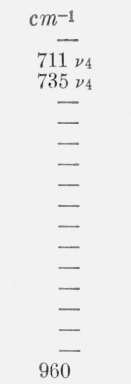 & $\mathrm{cm}^{-1}$ & $\begin{array}{l}c m^{-1} \\
806 \nu_{2} \\
835 \\
- \\
- \\
862 \mathrm{sh} \\
868 \\
\overline{897} \\
909 \\
929 \\
\overline{948} \\
\overline{-} \\
987 \\
1000 \\
1017 \\
1025\end{array}$ & $\begin{array}{c}\mathrm{cm}^{-1} \\
29 \\
\\
56 \\
62 \\
91 \\
103 \\
123 \\
143 \\
\\
181 \\
196 \\
211 \\
219\end{array}$ & $\begin{array}{c}c m^{-1} \\
1046 \nu_{1} \\
1078 \mathrm{~s} \\
1086 \\
1093 \\
1103 \mathrm{~s} \\
1- \\
1122 \mathrm{~m} \\
1136 \mathrm{~m} \\
1150 \mathrm{~m} \\
1164 \mathrm{sh} \\
1179 \mathrm{sh} \\
1195 \mathrm{~m} \\
1214 \mathrm{w} \\
1230 \mathrm{sh} \\
1242 \mathrm{~s} \\
- \\
\text { Obscured? }\end{array}$ & $\begin{array}{c}\mathrm{cm}^{-1} \\
\\
32 \\
40 \\
47 \\
57 \\
76 \\
90 \\
104 \\
118 \\
133 \\
149 \\
168 \\
184 \\
196 \\
\\
\text { cutoff? }\end{array}$ \\
\hline
\end{tabular}

TABLE 16. Assignments for $\mathrm{CsNO}_{3}$ at liquid helium temperature for libration combinations

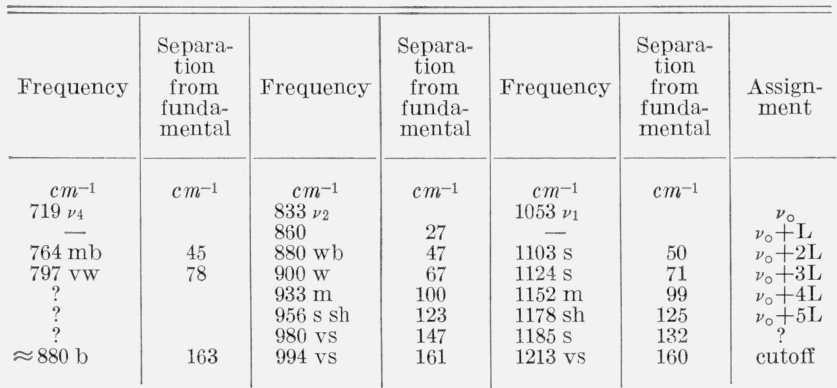

TABLE 17. Assignments for $\mathrm{RbNO}_{3}$ at liquid helium temperature for libration combinations

\begin{tabular}{|c|c|c|c|c|c|c|}
\hline Frequency & $\begin{array}{l}\text { Separa- } \\
\text { tion } \\
\text { from } \\
\text { funda- } \\
\text { mental }\end{array}$ & Frequency & $\begin{array}{l}\text { Separa- } \\
\text { tion } \\
\text { from } \\
\text { funda- } \\
\text { mental }\end{array}$ & Frequency & $\begin{array}{l}\text { Separa- } \\
\text { tion } \\
\text { from } \\
\text { funda- } \\
\text { mental }\end{array}$ & $\begin{array}{l}\text { Assign- } \\
\text { ment }\end{array}$ \\
\hline $\begin{array}{c}\mathrm{cm}^{-1} \\
726 \nu_{4} \\
748 \\
780 \\
793 \mathrm{w} \\
= \\
- \\
\overline{-} \\
866 \mathrm{sh} \\
890 \mathrm{br} \\
\approx 901 \mathrm{~b}\end{array}$ & $\begin{array}{c}c m^{-1} \\
22 \\
54 \\
67\end{array}$ & $\begin{array}{c}c m^{-1} \\
844 \nu_{2} \\
- \\
- \\
928 \mathrm{~m} \mathrm{~b} \\
- \\
950 \mathrm{sh} \\
964 \mathrm{~m} \\
988 \mathrm{~s} \\
1005 \mathrm{~s} \\
1019 \mathrm{~s}\end{array}$ & $\begin{array}{r}76 \\
106 \\
120 \\
144 \\
161 \\
175\end{array}$ & $\begin{array}{c}\mathrm{cm}^{-1} \\
1061 \nu_{1} \\
1084 \mathrm{vW} \\
1111 \mathrm{~s} \\
1126 \mathrm{~s} \\
1140 \mathrm{~s} \\
1153 \mathrm{~m} \\
1170 \mathrm{vW} \\
1186 \mathrm{~W} \\
1206 \mathrm{~s} \\
1232 \mathrm{~s}\end{array}$ & $\begin{array}{c}\mathrm{cm}^{-1} \\
\\
24 \\
51 \\
66 \\
80 \\
93 \\
110 \\
126 \\
146 \\
\\
172\end{array}$ & $\begin{array}{l}\quad \nu_{\circ} \\
\nu_{\circ}+\mathrm{L}_{1} \\
\nu_{\circ}+2 \mathrm{~L}_{1} \\
\nu_{\circ}+2 \mathrm{~L}_{2} \\
\nu_{\circ}+3 \mathrm{~L}_{1} \\
\nu_{\circ}+3 \mathrm{~L}_{2} \\
\nu_{\circ}+4 \mathrm{~L}_{1} \\
\nu_{\circ}+4 \mathrm{~L}_{2} \\
\text { cutoff } \mathrm{L}_{1} \\
\nu_{\circ}+5 \mathrm{~L}_{2} \\
\text { cutoff } \mathrm{L}_{2}\end{array}$ \\
\hline
\end{tabular}

The tabular data for $\mathrm{AgNO}_{3}$ are not assigned. The complexity of the spectrum may be less than that of $\mathrm{TlNO}_{3}$ and it seems that at least two librational modes are required. One peculiarity of the spectrum is the frequent appearance of triplet bands. One libration mode of $30 \mathrm{~cm}^{-1}$ with a cutoff of approximately $220 \mathrm{~cm}^{-1}$ appears reasonably certain.

Although the spectra of $\mathrm{CsNO}_{3}$ and $\mathrm{RbNO}_{3}$ appear to be similar, a somewhat different assignment can be given. A single libration mode of $30 \mathrm{~cm}^{-1}$ and a cutoff of $160 \mathrm{~cm}^{-1}$ is given for $\mathrm{CsNO}_{3}$. A similar assignment for $\mathrm{RbNO}_{3}$ is not obvious. Instead two modes one at $25 \mathrm{~cm}^{-1}$ and the other $30 \mathrm{~cm}^{-1}$ with barriers of $146 \mathrm{~cm}^{-1}$ and $175 \mathrm{~cm}^{-1}$ are indicated. However, it would appear that the $1153 \mathrm{~cm}^{-1}$ band might represent a cutoff not indicated by the assignment. Raman studies [36] show two frequency shifts of $109 \mathrm{~cm}^{-1}$ and $147 \mathrm{~cm}^{-1}$ for $\mathrm{RbNO}_{3}$ both of which are observed in the spectra here. The $147 \mathrm{~cm}^{-1}$ band appears to correspond with one of the cutoff values.

\section{e. Discussion of Raman and Infrared Assignments}

The preceding analyses and assignments of the infrared spectra have been made with a minimum of reference to the considerable literature on the Raman spectra of the carbonates and nitrates (see Introduction). It may be noted that, so far as can be ascertained, the Raman shifts have never been assigned to a series of bands arising from librational motion of the anion about the trigonal axis. Some Raman bands have been assigned to libration perpendicular to this axis. Couture [10] pointed out that the fundamental libration used here should be inactive or at most weakly active in the Raman spectrum. However, analysis shows that the combination bands should be active in the infrared. It may be noted that no shift as low as $30 \mathrm{~cm}^{-1}$ has been reported in the Raman spectra of these materials but Krishnamurti [42] has recently reported that the few shifts obtained by routine Raman studies appear to consist of bands covering a wide frequency range when high resolution and long exposures are employed. He attributed the fine structure to superlattice vibrations.

In the present data the separations between the fundamental and the summation bands can be identified in part with a series of Raman shifts reported for the material of interest. The Raman assignments for these shifts involve individual translational and librational lattice modes. The evidence in favor of the librational assignment as opposed to the translational assignment and vice versa will be summarized here.

The effect of temperature on sum and difference bands of the fundamental $\nu_{1}$ observed in many spectra represents good evidence that a very low lying frequency of the order $20 \mathrm{~cm}^{-1}-30 \mathrm{~cm}^{-1}$ is involved. The additional finding that this frequency represents the separation of a large number of bands in almost all spectra studied is considered to be significant. Furthermore, all structures, both carbonates and nitrates, yield a spectrum in which a frequency difference of the order of $20 \mathrm{~cm}^{-1}-30 \mathrm{~cm}^{-1}$ appears independent of the cation. The materials studied here contain one common factor - a planar anion having trigonal symmetry-and it appears that the recurring frequency difference should be attributed to this source. A librational motion of these anions all of which have essentially the same principal moments of inertia would be expected to occur at a frequency determined largely by the interionic potential forces. There is evidence that the anions are closely packed in these crystals $[45,77]$ and the interionic forces would be of the same general order of magnitude. It appears reasonable to conclude that the low frequency fundamental 


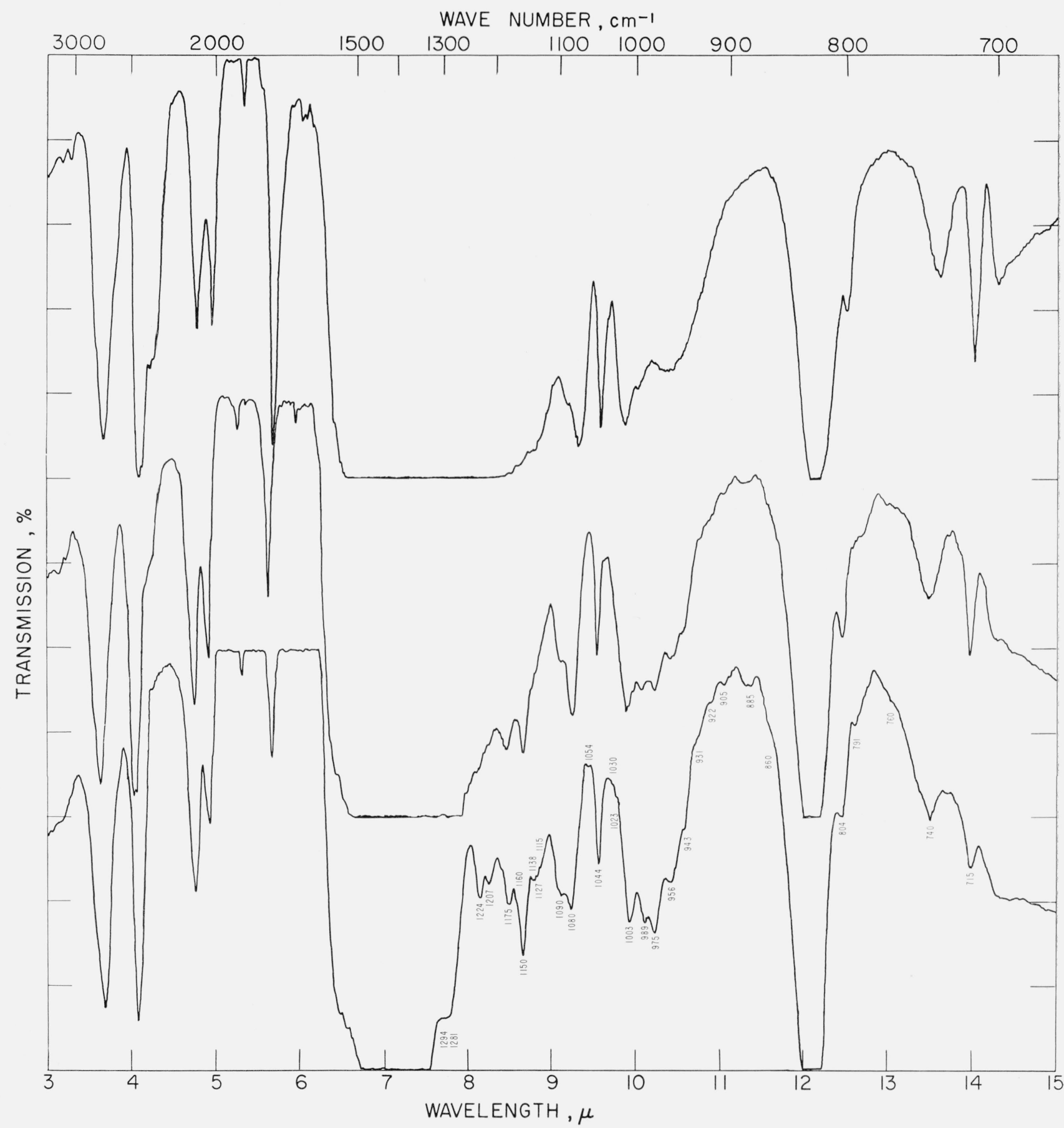

FIgURE 18. Infrared absorption spectra of $\mathrm{TINO}_{3}$ at room temperature (top), liquid nitrogen temperature (center), and liquid helium temperature (bottom).

arises from libration of the anions. The nature of the libration is not apparent and, as noted in the previous discussion, more than one frequency appears to be involved in some instances. However, based on the X-ray and neutron diffraction data previously cited which indicate libration about the trigonal axis, it is concluded that the libration responsible for the $20 \mathrm{~cm}^{-1}-30 \mathrm{~cm}^{-1}$ band spacing is a torsional oscillation about the trigonal axis.
Conversely, the bands observed here could be assigned to a large number of separate translational lattice modes in combination with the fundamentals. However, it seems unlikely that individual translational modes would have frequencies such as to yield a series of bands with uniform spacing. It is even more unlikely that similar series would be produced by such a variety of structures and cations. Therefore, the explanation that individual transla- 


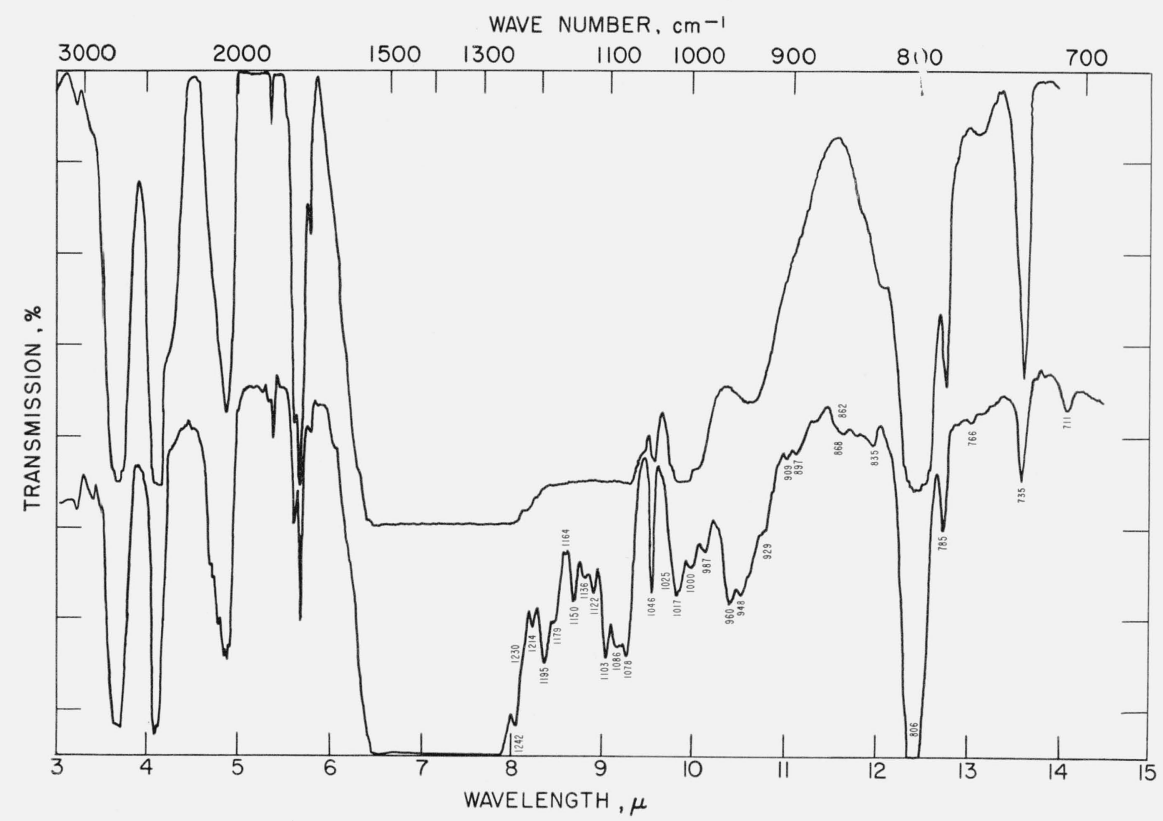

FIgURE 19. Infrared absorption spectra of $\mathrm{AgNO}_{3}$ at room temperature (top) and liquid helium temperature (bottom).

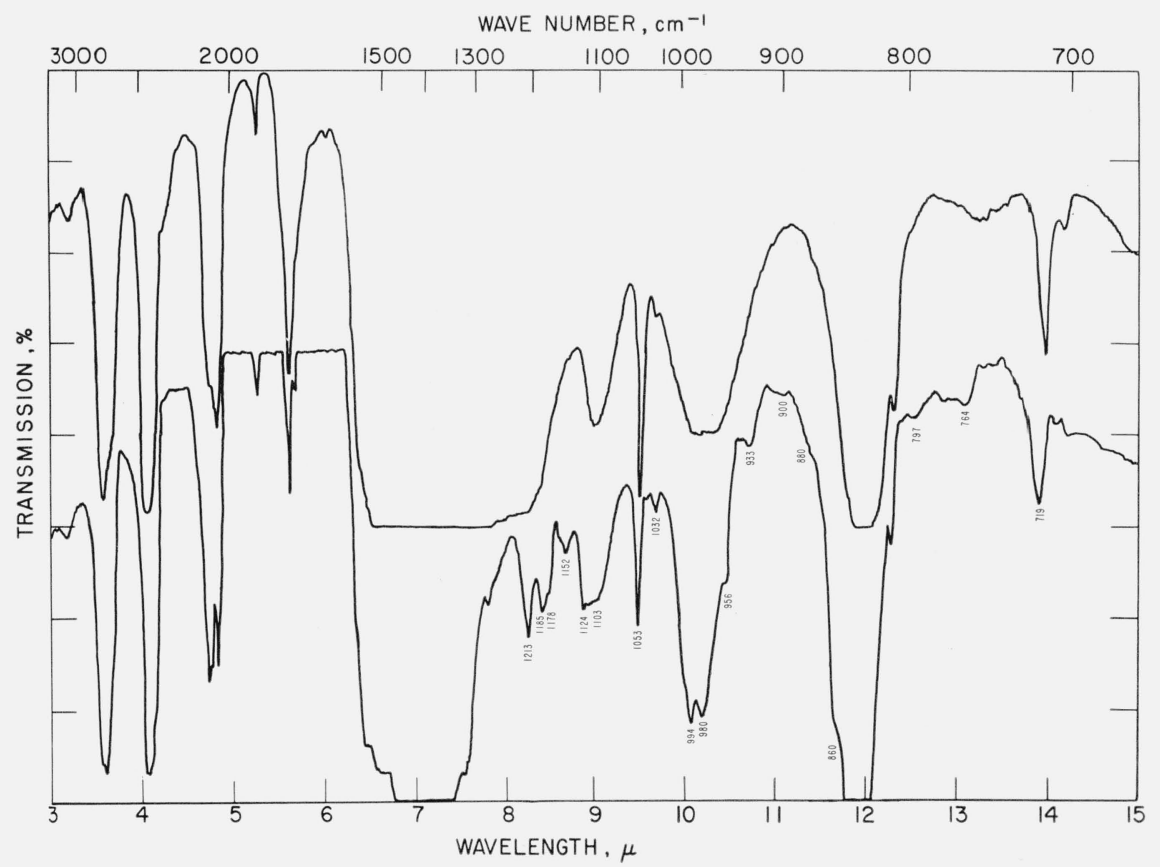

FiguRE 20. Infrared absorption spectra of $\mathrm{CsNO}_{3}$ at room temperature.(top) and liquid helium temperature (bottom).

tional modes are involved must be rejected. However, there remains the possibility that the bands arise from combinations between the fundamental and successive levels of a translational mode of frequency near $30 \mathrm{~cm}^{-1}$. The relative insensitivity of the frequency to the crystal structure and the mass of the cation and the independent evidence for libration makes this interpretation appear doubtful. In addition the band limit or cutoff frequency which is of the same general order of magnitude in all these materials is readily understood in terms of libration. It can be explained with somewhat more difficulty for translation. It appears that the majority of evidence available at this time appears to favor the interpretation of the data in terms of libration. However, it must be emphasized that on the basis of the present evidence, a translational origin for the observed bands cannot be rejected unequivocally.

The effect of temperature on the frequency, intensity, and shape of the summation bands has been noted in the discussion. It is to be expected that the frequencies of the bands involving a lattice mode should be more temperature dependent than 


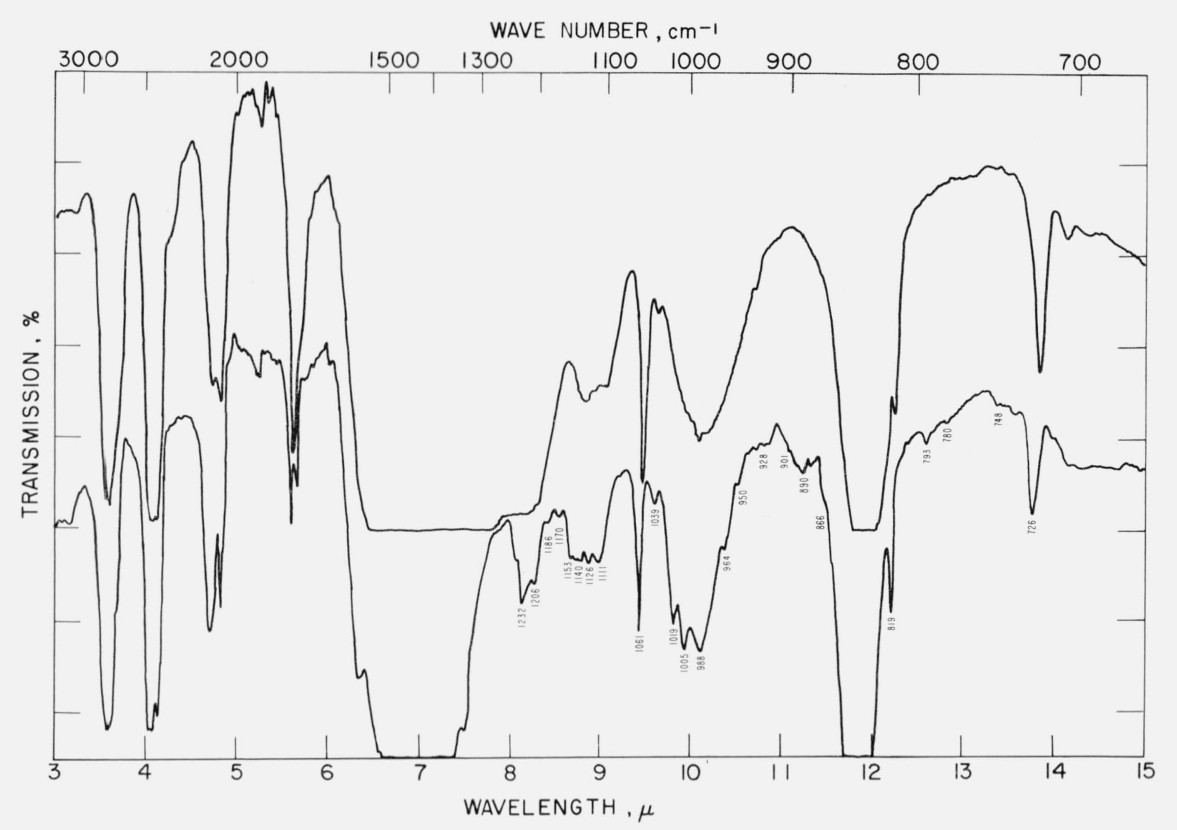

FIGURE 21. Infrared absorption spectra of $\mathrm{RbNO}_{3}$ at room temperature (top) and liquid helium temperature (bottom).

the fundamentals. The lattice frequencies will depend on the interionic forces which are directly affected by the change in volume produced by cooling. If the forces are principally repulsive a shift to higher frequencies would be expected on cooling. This is actually observed. The fundamental internal frequencies have been shown to be rather insensitive to changes in volume. The intensity of the summation bands is expected to increase with decreasing temperature in these experiments. At ordinary temperatures, the higher librational levels are expected to be densely populated because of the low energy involved. As the temperature is lowered the lower levels increase in population at the expense of the higher levels. In absorption the intensity depends on the population of the lower of the two levels involved and, all other factors being equal, intensity should increase markedly as the lower levels become populated. Simultaneously it appears reasonable that the individual librational band widths should decrease.

Translational lattice modes must exist and no attempt has been made to identify these modes which would be active in combination with the fundamentals. However, in every spectrum there appear to be a few bands not falling into a regular sequence which might be assigned in this manner. There are also many unusually strong bands which might be attributed to superposition of a libration and translation combination with the fundamental. Such coincidences would be expected to be of frequent occurrence in a series of close spaced bands and might produce resonance splitting effects. Such splitting may produce the variation in spacing observed in some series of bands.

On the basis of the librational motion the cutoff frequencies are readily interpreted. According to
Lander [45] the oxygen-oxygen interaction between neighboring anions defines the ordering. Spectroscopic data on the nitrates, carbonates, and borates [77] has also been interpreted in this manner. In a given crystal the anion should orient in the potential field in such a position that its oxygen atoms would be at a maximum distance from the neighboring oxygens. This position is not unique, however, as equivalent positions can be obtained by a rotation about the trigonal axis, potential minima being found every $120^{\circ}$ or every $60^{\circ}$ depending on the symmetry of the site. If sufficient energy is available a librating anion can surmount the energy barrier imposed by the repulsive forces of neighboring oxygen atoms and either rotate freely or, on losing energy, take up an equivalent position displaced by $120^{\circ}$ or $60^{\circ}$ from the original position. Therefore the librational bands should terminate at a frequency corresponding to the "free rotation" energy barrier.

No convincing arguments can be offered at this time for the intensity relationships in a series of bands. Hexter and Dows [35] have calculated that higher order combinations of the type postulated here should decrease in intensity exponentially. However, these calculations did not consider the interactions between neighboring ions. It appears reasonable to suppose that libration of the anion produces a change in the electronic charge distribution of the oxygen atoms. It appears likely that the perturbation of the charge distribution increases with increasing amplitude of the oscillation and should reach a maximum at the top of the barrier. What the effect of this change in charge distribution would be on the relative intensities is not clear so that this question cannot be answered at this time.

At the top of the energy barrier the librational modes change rapidly from a vibrational type to a 
rotational type. The intensity of transitions from a state corresponding to the ground vibrational level $(n=0)$ and the ground librational level $(J=0)$ to the upper vibrational level $(n=1)$ and the upper rotational levels (say $J \geqq 10$ ) would be very weak because such transitions are forbidden by rotational selection rules. Therefore if librational transitions below the top of the barrier have appreciable intensity because of electrical anharmonicity a rather sharp cutoff or band limit is indicated. Rotational transitions in addition to being forbidden would be expected to be very weak because of the absence of electrical anharmonicity in rotational motion.

\section{f. Discussion of Libration and Energy Barrier Data}

The observed data on libration frequencies and apparent energy barriers are tabulated in the first two columns of table 18. The libration frequencies listed correspond to maximum values observed for each substance, i.e., average values derived from the lower energy levels. Despite the wide variation in structure it is interesting to note that variations of the absolute values of libration frequency and energy barrier are relatively small. Libration frequencies appear to range from $15 \mathrm{~cm}^{-1}$ to $36 \mathrm{~cm}^{-1}$ and energy barriers from $140 \mathrm{~cm}^{-1}$ to $250 \mathrm{~cm}^{-1}$. No reliable libration frequency was observed from $\mathrm{MgCO}_{3}$ although the probable barrier is listed in table 18 . The barriers tabulated represent the average estimates of the bands assigned as the three cutoff values of the three series of bands arising from combinations with $\nu_{1}, \nu_{2}$, and $\nu_{4}$ which usually agree very well with each other.

Although qualitative arguments for libration have been presented in the previous section it remains to be demonstrated that the observed energy barriers are quantitatively of the correct order of magnitude. The following discussion will be limited to the calcite and cubic structures because of the uncertainties involved in the other structures. In addition only the data for $\mathrm{NaNO}_{3}$ and $\mathrm{CaCO}_{3}$ among the calcite structures will be considered because of doubts concerning the purity of the other materials. Column 3 of table 18 lists approximate anharmonicity cor-

TABLE 18. Collected libration frequencies and energy barriers from infrared spectra at liquid helium temperature

\begin{tabular}{|c|c|c|c|c|}
\hline Material & $\begin{array}{l}\text { Observed } \\
\text { barrier a }\end{array}$ & $\begin{array}{c}\text { Libration } \\
\text { frequency, } \nu_{L}\end{array}$ & $\begin{array}{l}\text { Approximate } \\
\text { anharmonic- } \\
\text { ity correc- } \\
\text { tion }\end{array}$ & $\begin{array}{c}\text { Calculated } \\
\text { barrier b }\end{array}$ \\
\hline $\begin{array}{l}\mathrm{MgCO} \\
\mathrm{CaCO}_{3} \\
\mathrm{FeCO}_{3} \\
\mathrm{MnCO}_{3} \\
\mathrm{NaNO} \mathrm{NO}_{3} \\
\mathrm{Sr}\left(\mathrm{NO}_{3}\right)_{2} \\
\mathrm{Ba}\left(\mathrm{NO}_{3}\right)_{2} \\
\mathrm{~Pb}\left(\mathrm{NO}_{3}\right)_{2} \\
\mathrm{TINO}_{3} \\
\mathrm{AgNO}_{3} \\
\mathrm{CsNO}_{3} \\
\mathrm{RbNO}_{3}\end{array}$ & $\begin{array}{r}c m^{-1} \\
220 \\
152 \\
150 \\
160 \\
238 \\
220 \\
191 \\
167 \\
255 \\
223 \\
161 \\
175,146\end{array}$ & $\begin{array}{c}c m^{-1} \\
\\
36 \\
25 ? \\
25 ? \\
32 \\
20 \\
19 \\
18 \\
25 ? \\
30 ? \\
25 \\
15,30\end{array}$ & $\begin{array}{l}\mathrm{cm}^{-1} \\
1 \\
3 \\
0.5 \\
.5 \\
.5\end{array}$ & $\begin{array}{c}\mathrm{cm}^{-1} \\
162 \\
\\
155 \\
198 \\
179 \\
161\end{array}$ \\
\hline
\end{tabular}

a Experimental values neglecting zero point energy. Approximate correction for zero point energy is $\nu_{L} / 2$.

b Calculated barriers including correction for anharmonicity but neglecting correction for zero point energy. Approximate correction for zero point energy is $\nu_{L} / 2$. rections calculated from the observed frequencies for $\mathrm{CaCO}_{3}$ (table 5), $\mathrm{NaNO}_{3}$ (table 4), $\mathrm{Sr}\left(\mathrm{NO}_{3}\right)_{2}$ (table 13), $\mathrm{Ba}\left(\mathrm{NO}_{3}\right)_{2}$ (table 12), and $\mathrm{Pb}\left(\mathrm{NO}_{3}\right)_{2}$ (table 11). The anharmonicity corrections are observed to much larger for the calcite structures than for the cubic structures. This difference will be discussed subsequently. From the observed libration frequencies and the anharmonic corrections, the potential barrier for rotation may be calculated as follows. form

Assuming a rotational potential energy of the

$$
V=\frac{V_{0}}{2}(1-\cos n \theta)
$$

where $V_{0}$ is the energy barrier, $n$ the number of potential minima in a complete cycle, and $\theta$ the angular displacement from the equilibrium position, the potential barrier can be calculated from the libration frequency through the relationship

$$
\nu_{c}=n \sqrt{\frac{V_{0} h}{8 \pi^{2} c I}} .
$$

In eq (2), $\nu_{c}$ corresponds to the corrected libration frequency, $I$ the moment of inertia of the anion, and the other quantities have their usual significance. The corrected libration frequency is taken as equal to the observed libration frequency plus twice the anharmonic correction [33]. Taking the $\mathrm{C}-\mathrm{O}$ and $\mathrm{N}-\mathrm{O}$ bond lengths to be $1.25 \mathrm{~A}$ and $1.22 \mathrm{~A}$, respectively, and independent of structure [80], the following two relationships for the potential barriers are obtained.

$$
\begin{aligned}
& \text { for carbonates } V_{0}=4.26\left(\nu_{c} / n\right)^{2} \text {. } \\
& \text { for nitrates } V_{0}=4.47\left(\nu_{c} / n\right)^{2} \text {. }
\end{aligned}
$$

In calcite structures the anions occupy sites of symmetry $\mathrm{D}_{3}$ and $n=6$. In the cubic structures the site symmetry is $\mathrm{C}_{3}$ and $n=3$. Using eqs (3) and (4) and the corresponding data from table 18 the barriers were calculated and are given in column 4 of the table. The calculated barriers as tabulated have been corrected for the zero point energy contribution so as to be comparable with the observed values, that is the tabulated values represent the calculated barriers minus $1 / 2$ the libration frequency.

A comparison of observed and calculated barriers shows that except for $\mathrm{NaNO}_{3}$ the agreement is quite encouraging. Inasmuch as the libration frequencies cannot be determined with precision because of the width of the bands, and since a similar error exists in determining the cutoff frequencies, it is considered that the agreement between calculated and observed barriers is probably within the experimental error even in the case of $\mathrm{NaNO}_{3}$. Furthermore the calculated barrier is dependent on the exact shape of the potential energy curve and on the bond distance used. The fact that the observed and calculated barriers are of the same order of magnitude supports the present interpretation of the observed spectra in 
terms of librational oscillations of anions that produce a series of bands terminating in a cutoff frequency which corresponds to the potential barrier for rotation.

The fact that the barriers are of the same order of magnitude implies that in these crystals the forces are of the same nature. This conclusion has been reached previously [77]. The smaller anharmonicity corrections of the cubic salts as compared with those of the calcites are to the expected. In the former there appear to be broader potential wells $(n=3)$ than in the latter $(n=6)$ and the levels are closer $\left(20 \mathrm{~cm}^{-1}\right.$ as compared to $\left.30 \mathrm{~cm}^{-1}\right)$.

It will be noted that the agreement between calculated and observed barriers also implies that the assignments of the individual libration bands is essentially correct. If the data for $\mathrm{CsNO}_{3}$ and $\mathrm{RbNO}_{3}$ are used to calculate barriers it appears most likely that the nitrate ions must occupy sites of six-fold symmetry in these structures. However, similar calculations for $\mathrm{TlNO}_{3}$ and $\mathrm{AgNO}_{3}$ are not possible because of the great uncertainty in assigning the libration bands. From this point of view it is not surprising that the aragonite spectra is so complex because the anions occupy sites of symmetry $\mathrm{C}_{\mathrm{s}}$.

The absolute value of the potential barriers observed requires the conclusion that at ordinary temperatures, i.e., $300^{\circ} \mathrm{K}$, a considerable number of anions have energies in excess of the hindering rotational barrier. If large numbers of anions rotate, it is conceivable that the structure may become unstable. Several phase changes occur in the nitrates at moderate temperatures but the corresponding transitions in the carbonates take place only at relatively high temperatures [45]. There is no obvious correlation between the transition temperature and the height of the energy barrier. It must be concluded, therefore, that the cohesive energy of the crystal lattice is sufficient to accommodate considerable variation in the anion disorder and that the transitions are not caused primarily by the effect of the disordering. Since similar transitions in nitrates and carbonates are separated by several hundred degrees in temperature it appears that the cohesive energy, which is expected to be roughly four times as great in the carbonates, must largely determine the transition temperature. On the basis of the present interpretation most of the carbonate ions would have energies above the rotational energy barriers at temperatures well below the transition temperatures.

\subsection{Overtones and Combinations of Fundamentals}

Inspection of figures 1-21 for the carbonates and nitrates shows that numerous strong bands occur in the range $1700 \mathrm{~cm}^{-1}$ to $3000 \mathrm{~cm}^{-1}$. The prism instrument provided insufficient dispersion and resolution for accurate study of this region. However, the number and strength of the bands indicate that free ion selection rules are not applicable in these crystals. In most spectra two sharp bands are observed, one near $1750 \mathrm{~cm}^{-1}$ and the other much weaker near $1800 \mathrm{~cm}^{-1}$. Without exception these bands are located within a few wave numbers of the positions expected for the combinations $\nu_{1}+\nu_{4}$ and $\nu_{1}+\nu_{2}$, respectively. These bands can be assigned confidently. The other bands cannot.

For further study of this region several spectra were obtained on a grating spectrometer. The spectral regions from $1600 \mathrm{~cm}^{-1}$ to $4000 \mathrm{~cm}^{-1}$ for the liquid helium runs are given in figures $22,23,24$, and 25 for $\mathrm{CaCO}_{3}, \mathrm{KNO}_{3}, \mathrm{BaCO}_{3}$, and $\mathrm{Ba}\left(\mathrm{NO}_{3}\right)_{2}$ respectively. Frequencies of bands identiifable with certainty are listed in tables $19,20,21$, and 22 . The studies showed no appreciable shift of band positions in this region as the temperature was lowered although considerable sharpening of bands occurred at low temperature. Inspection of the spectra shows a very complex band system in this region and no assignments are given. It is particularly noted that in regions in which bands would be expected to correspond to the combinations $\nu_{1}+\nu_{3}$ and $2 \nu_{3}$ the spectra show strong broad bands which appear to contain unresolved structure. Also of interest are the many bands appearing to contain shoulders extending more than $100 \mathrm{~cm}^{-1}$ to higher frequencies. Conversely similar shoulders are missing on the low frequency side. The spectra of $\mathrm{KNO}_{3}$ and $\mathrm{Ba}\left(\mathrm{NO}_{3}\right)_{2}$ are particularly complex in this region. Several triple groups are evident in $\mathrm{Ba}\left(\mathrm{NO}_{3}\right)_{2}$ with components separated by about $30 \mathrm{~cm}^{-1}$ and $40 \mathrm{~cm}^{-1}$. In general this region of the spectra does not offer any evidence to contradict the libration hypothesis and the complexity and broad bands would be expected if there is a libration-fundamental combination involved.

TABLE 19. Overtones and fundamental combinations observed for calcite

\begin{tabular}{|c|c|c|}
\hline Frequencies & Frequencies & Fundamentals \\
\hline $\begin{array}{c}c m^{-1} \\
3935 \mathrm{~m} \\
3735 \mathrm{w} \\
3587 \mathrm{~m} \\
3218 \mathrm{~m} \\
3175 \mathrm{~m} \\
2915 \mathrm{vs}\end{array}$ & \begin{tabular}{l}
\multicolumn{1}{c}{$\mathrm{cm}^{-1}$} \\
$2798 \mathrm{~m}$ sh \\
$2560 \mathrm{vs}$ \\
$2490 \mathrm{~s}$ \\
$2330 \mathrm{mb}$ \\
$2210 \mathrm{mb}$ \\
$2142 \mathrm{~m}$ \\
$1960 \mathrm{~m}$
\end{tabular} & $\begin{array}{c}c m^{-1} \\
\nu_{1}-1070 \\
\nu_{2}-881 \\
\nu_{3}-1460 ? \\
\nu_{4}-712\end{array}$ \\
\hline
\end{tabular}

TABLE 20. Overtones and fundamental combinations observed for $\mathrm{KNO}_{3}$

\begin{tabular}{|c|c|c|}
\hline Frequencies & Frequencies & Fundamentals \\
\hline $\begin{array}{l}c m^{-1} \\
3734 \mathrm{~m} \text { shoulder } \\
\text { to } 3900 \\
3425 \mathrm{~m} \text { shoulder } \\
\text { to } 3550 \\
3103 \mathrm{w} \\
3006 \mathrm{~W} \\
2850 \mathrm{mb} \text { shoulder } \\
\text { to } 2970 \\
2782 \mathrm{mb} \\
2733 \mathrm{~m} \\
2718 \mathrm{sh} \\
2695 \mathrm{~m} \\
2550 \mathrm{mb} \text { shoulder } \\
\text { to } 2610 \\
2485 \mathrm{sb} \\
2422 \mathrm{~m}\end{array}$ & $\begin{array}{l}\quad \mathrm{cm}^{-1} \\
2395 \mathrm{~s} \mathrm{sh} \\
2360 \mathrm{~m} \\
2335 \mathrm{mb} \\
2150 \mathrm{mb} \\
2090 \mathrm{mb} \\
2060 \mathrm{~m} \\
1920 \mathrm{~W} \\
1890 \mathrm{~m} \\
1875 \mathrm{~ms}\left(\nu_{1}+\nu_{2}\right) \\
1762 \mathrm{~s}\left(\nu_{1}+\nu_{4}\right) \\
1745 \mathrm{~m}\end{array}$ & $\begin{array}{c}c m^{-1} \\
\nu_{1}-1051 \\
\nu_{2}-827 \\
\nu_{3}-1420 \\
\nu_{4}-714\end{array}$ \\
\hline
\end{tabular}




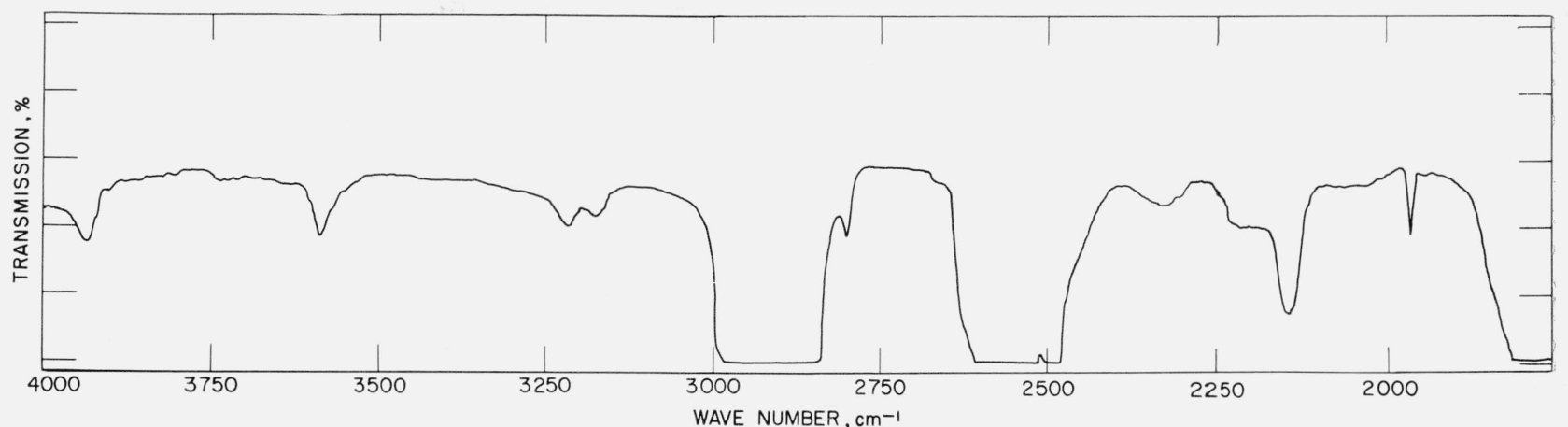

FIGURE 22. Infrared absorption spectrum of $\mathrm{CaCO}_{3}$ (calcite) at liquid helium temperature $\left(1600 \mathrm{~cm}^{-1}\right.$ to $\left.4000 \mathrm{~cm}^{-1}\right)$.

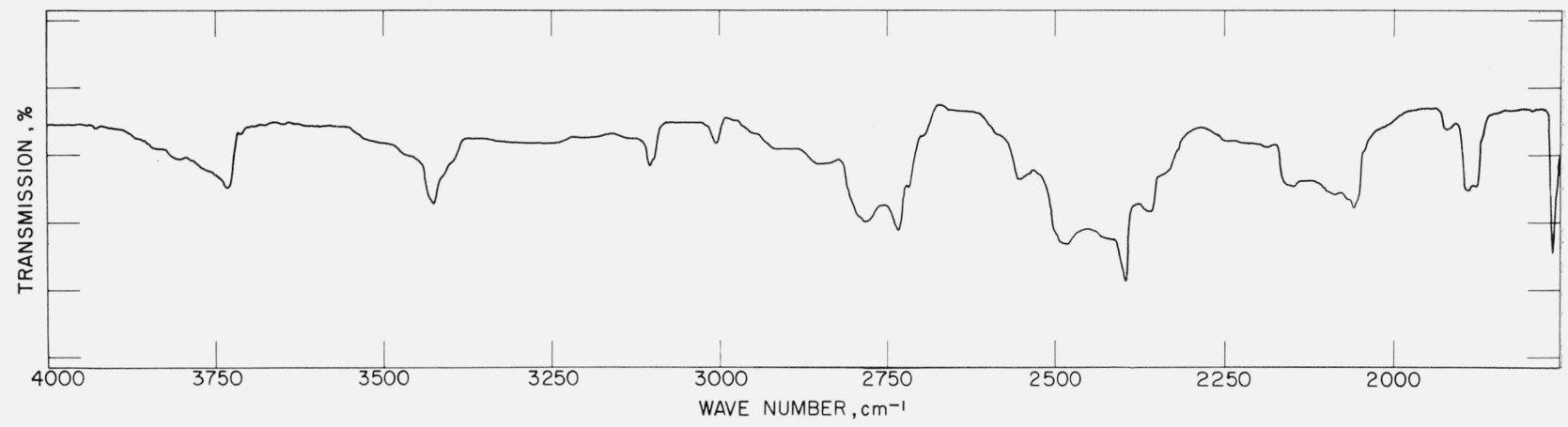

Figure 23. Infrared absorption spectrum of $\mathrm{KNO}_{3}$ at liquid helium temperature $\left(1600 \mathrm{~cm}^{-1}\right.$ to $\left.4000 \mathrm{~cm}^{-1}\right)$.

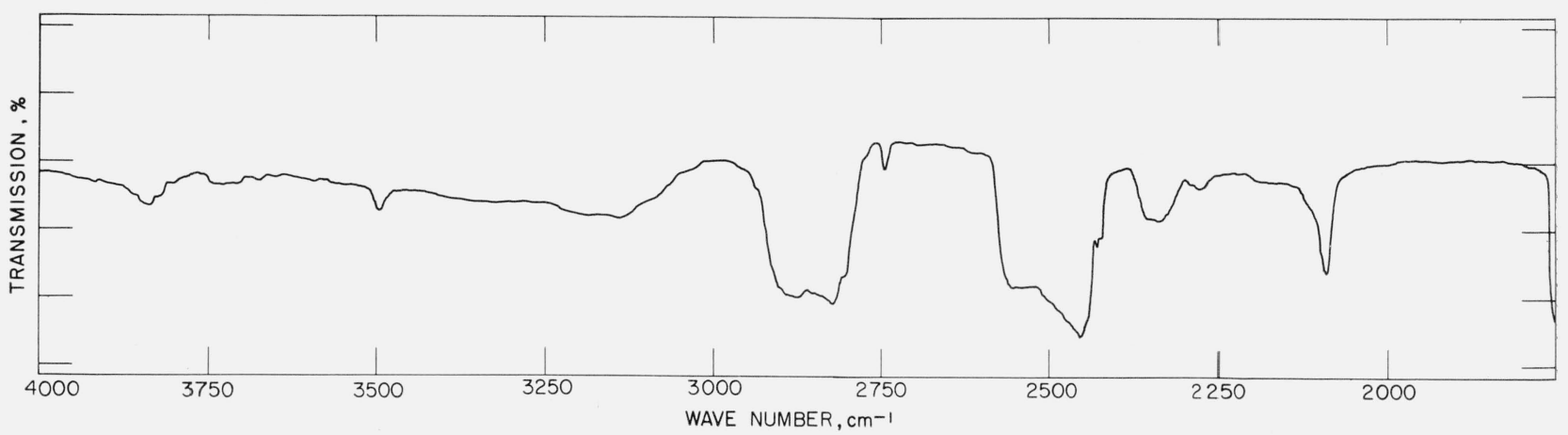

Figure 24. Infrared absorption spectrum of $\mathrm{BaCO}_{3}$ at liquid helium temperature $\left(1600 \mathrm{~cm}^{-1}\right.$ to $\left.4000 \mathrm{~cm}^{-1}\right)$.

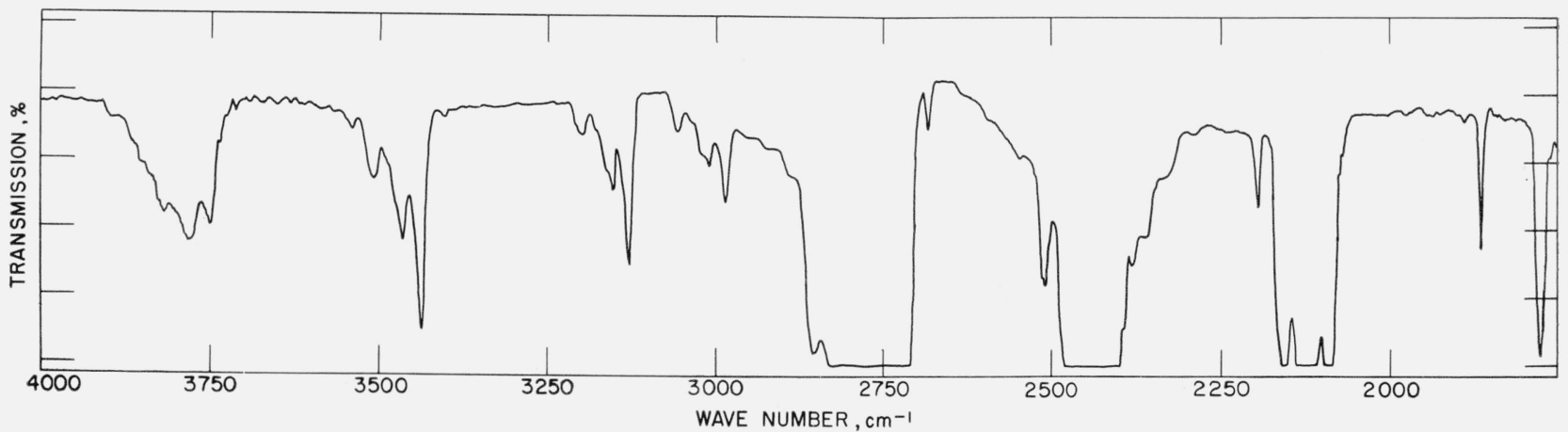

FIGURE 25. Infrared absorption spectrum of $\mathrm{Ba}\left(\mathrm{NO}_{3}\right)_{2}$ at liquid helium temperature $\left(1600 \mathrm{~cm}^{-1}\right.$ to $\left.4000 \mathrm{~cm}^{-1}\right)$. 
TABLE 21. Overtones and fundamental combinations observed for $\mathrm{BaCO}_{3}$

\begin{tabular}{|c|c|c|}
\hline Frequencies & Frequencies & Fundamentals \\
\hline $\begin{array}{l}\mathrm{cm}^{-1} \\
3840 \mathrm{wb} \\
3498 \mathrm{w} \\
2880 \mathrm{sb} \\
2820 \mathrm{~b} \\
2805 \mathrm{sh} \\
2746 \mathrm{w} \\
2550 \mathrm{sb}\end{array}$ & $\begin{array}{l}\quad \mathrm{cm}^{-1} \\
2452 \mathrm{~s} \\
2430 \mathrm{sh} \\
2423 \mathrm{sh} \\
2340 \mathrm{~b} \\
2092 \mathrm{sh} \\
1755 \mathrm{sh}\left(\nu_{1}+\nu_{4}\right) \\
1748 \mathrm{~s} \\
1735 \mathrm{sh}\end{array}$ & $\begin{array}{l}\quad c m^{-1} \\
\nu_{1}-1062 \\
\nu_{2}-857 \\
\nu_{3}-1470 \\
\nu_{4}-732,694\end{array}$ \\
\hline
\end{tabular}

TABLE 22. Overtones and fundamental combinations for $\mathrm{Ba}\left(\mathrm{NO}_{3}\right)_{2}$

\begin{tabular}{|c|c|c|}
\hline Frequencies & Frequencies & Fundamentals \\
\hline $\begin{array}{l}c m^{-1} \\
3817 \\
3780 \mathrm{~s} \\
3750\end{array}$ & $\begin{array}{l}\quad \mathrm{cm}^{-1} \\
2683 \mathrm{~m} \mathrm{sh} \\
2550 \mathrm{~b} \\
2510 \mathrm{~b}\end{array}$ & \begin{tabular}{l}
\multicolumn{1}{c}{$c m^{-1}$} \\
$\nu_{1}-1052$ \\
$\nu_{2}-813$ \\
$\nu_{3}-1400 ?$
\end{tabular} \\
\hline $\begin{array}{l}3508 \\
3465 \mathrm{~s} \\
3435\end{array}$ & $\begin{array}{l}2440 \mathrm{~b} \\
2380 \mathrm{~b} \\
2360 \mathrm{~b}\end{array}$ & $\nu_{4}-722$ \\
\hline $\begin{array}{l}3200 \\
3155 \mathrm{~s} \\
3128\end{array}$ & $\begin{array}{l}2330 \mathrm{~b} \\
2290 \mathrm{~b} \\
2195 \mathrm{~m}\end{array}$ & \\
\hline $\begin{array}{l}3055 \\
3010 \mathrm{~m} \\
2985\end{array}$ & $\begin{array}{l}2156 \mathrm{vs} \\
2120 \mathrm{vs} \\
2090 \mathrm{~s}\end{array}$ & \\
\hline $\begin{array}{l}2885 \mathrm{~W} \\
2855 \mathrm{~s} \\
2770 \mathrm{vS}\end{array}$ & $\begin{array}{l}1863 \mathrm{~m}\left(\nu_{1}+\nu_{2}\right) \\
1775 \mathrm{~S}\left(\nu_{1}+24\right) \\
1620\end{array}$ & \\
\hline
\end{tabular}

\section{Conclusion}

Infrared absorption spectra of inorganic nitrates and carbonates have been obtained on single crystals at room temperature, liquid nitrogen temperature, and liquid helium temperature. The diffuse absorption observed in the room temperature spectra between about $1400 \mathrm{~cm}^{-1}$ and $700 \mathrm{~cm}^{-1}$ is resolved at liquid helium temperature into a series of a large number of bands not attributable to fundamentals or combinations of fundamental frequencies of the anions. Most of these bands are readily interpreted as summation bands of fundamental frequencies with successive levels of a librating oscillator.

This interpretation is supported by the following, experimental observations:

1. The removal of the difference bands with reduction in temperature.

2. The large temperature dependence of the positions of individual bands as compared with that of the fundamentals.

3. The uniformity of the spacing of the individual bands within a given series of bands.

4. The similarity of the separation of the individual members of the separate series of bands from each of the fundamentals $\nu_{1}, \nu_{2}$, and $\nu_{4}$.

5. The agreement in the separation of the band limits or cutoffs assigned from each of the fundamentals $\nu_{1}, \nu_{2}$, and $\nu_{4}$.

6 . The general similarity of the behavior in the vicinity of $\nu_{3}$ with that observed at the other fundamentals, although the individual bands could not be distinguished.
The libration is considered to represent a planar torsional oscillation of the anion about the trigonal axis. The librational frequency appears to be dependent in part on the crystal structure and the ions involved. For a given material the librational frequency as determined from successive bands is reasonably constant. In the substances studied the librational frequency varied from about $15 \mathrm{~cm}^{-1}$ to $30 \mathrm{~cm}^{-1}$.

Observed band limits in the spectra are interpreted as representing rotational energy barriers. These barriers are of the order of $200 \mathrm{~cm}^{-1}$ with the barrier height being dependent on the crystal structure and the ions involved. Barrier heights calculated from a cosine potential function agree reasonably well with the observed barriers for the cubic and calcite structures. Similar calculations have not been made for other structures studied because of doubtful assignments or unknown strucural details. In particular, the spectra of the aragonite structures are remarkable in detail and complexity and have not been analyzed successfully. However, the details of these and all other spectra studies appear to involve similar phenomena.

The question of whether this behavior is restricted to carbonates and nitrates cannot be answered fully. Preliminary studies on other salts at low temperatures indicates that similar band systems may exist. Further experiments are required to answer this question with certainty.

It is apparent that the band structure observed in these studies is not clearly seen in absorption spectra of thin films and polycrystalline specimens. In part, this may be due to the fact that it is customary in most instances to study specimens which do not absorb completely even in the strongest fundamentals and that the combination bands are too weak in comparison with the fundamentals to be observed under these circumstances. However, it would also appear likely that reduction of the crystal size below some minimum value as determined by the lattice mode might effectively eliminate the lattice mode and consequently the combination band. With lattice modes of low frequency the minimum crystal size might be readily attainable and preliminary investigations indicate some experimental evidence of a dimensional effect. Further study on these questions is under way.

The authors are indebted to L. Bolz for obtaining low temperature X-ray data.

\section{Reference}

[1] C. T. Anderson, J. Am. Chem. Soc. 56, 340 (1934).

[2] C. T. Anderson, J. Am, Chem. Soc, 56, 849 (1934).

[3] E. R. Andrew, J. Chem. Phys. 18, 607 (1950).

[4] R. Bersohn and H. S. Gutowsky, J. Chem. Phys. 22, 651 (1954).

[5] J. M. Bijvoet and J. A. A. Ketelaar, J. Am. Chem. Soc. 54, 625 (1932).

[6] P. Chevin, W. C. Hamilton, and B. Post, American Crystallographic Assoc., Boulder, Colo. (July 31, 1961).

[7] M. Y. Colby and L. J. B. LaCoste, Z. Krist. 90, 1 (1935).

[8] M. Y. Colby and L. J. B. LaCoste, Z. Krist. 84, 299 (1933). 
[9] L. Couture, Compt rend. 220, 656 (1945).

[10] L. Couture and J. Mathieu, Ann. phys. 12, 35 (1938).

[11] L. Couture and J. Mathieu, Compt. rend. 225, 1140 (1947).

[12] L. Couture, Compt. rend. 220, 87 (1945).

[13] L. Couture, J. Chem. Phys. 15, 153 (1947).

[14] J. C. Decius, J. Chem. Phys. 23, 1290 (1955)

[15] J. C. Decius, J. Chem. Phys. 22, 1941 (1954).

[16] L. E. Drain, Faraday Soc. Discussions 19, 200 (1955).

[17] D. A. Edwards, Z. Krist. 80, 154 (1931).

[18] N. Elliott and J. Hastings, Acta Cryst. 14, 1018 (1961).

[19] E. Ferrari, A. Sabatini, and P. Orioli, Gazz. chim. ital. 87, 630 (1957)

[20] E. Ferrari, A. Sabatini, and P. Orioli, Ricerca sci. 27, 1557 (1957).

[21] C. Finback and O. Hassel, J. Chem. Phys. 5, 460 (1937).

[22] C. Finback and O. Hassel, Z. physik. Chem. B35, 25 (1937).

[23] J. Frenkel, Acta Physiocochim. 3, 23 (1935)

[24] L. Guilotto and G. Olivelli, J. Chem. Phys. 16, 555 (1948).

[25] G. Glockler, Rev. Mod. Phys. 15, 111 (1943).

[26] E. F. Gross and A. A. Shultin, Sov. Phys. Dokl. 2, 371 (1957).

[27] P. Gunther, Ann. Physik 51, 828 (1916).

[28] H. S. Gutowsky, G. E. Pake, and R. Bersohn, J. Chem. Phys. 22, 643 (1954).

[29] C. Haas and J. A. A. Ketelaar, Physica 22, 1286 (1956).

[30] R. S. Halford, J. Chem. Phys. 14, 8 (1946).

[31] W. C. Hamilton, Acta Cryst. 10, 103 (1957)

[32] S. B. Hendricks, E. Posnjak, and F. Kracek, J. Am. Chem. Soc. 54, 2766 (1932).

[33] G. Herzberg, Molecular Spectra and Molecular Structure, Vol. II, Infrared and Raman Spectra of Polyatomic Molecules, 7th ed., p. 178 (D. Van Nostrand \& Co., New York, N.Y., 1956).

[34] R. M. Hexter, Spectrochim. Acta 10, 291 (1958).

[35] R. M. Hexter and D. A. Dows, J. Chem. Phys. 25, 504 (1956).

[36] J. H. Hibben, The Raman Effect and its Chemical Applications (Reinhold Publ. Corp., New York, N.Y., 1939) pp. 428 and 445.

[37] R. M. Hinde and E. A. Kellett, Acta Cryst. 10, 383 (1957).

[38] D. F. Hornig, J. Chem. Phys. 16, 1063 (1948).

[39] J. Jaffray, Ann. phys. 3, 5 (1948).

[40] J. A. A. Ketelaar and B. Strijk, Rec. trav. chim, 64, 174 (1945).

[41] F. C. Kracek, T. F. W. Barth, and C. J. Kasanda, Phys. Rev. 40, 1034 (1932).

[42] D. Krishnamurti, Proc. Indian Acad. Sci. 46A, 183 (1957).

[43] D. Krishnamurti, Proc. Indian Acad. Sci. 43A, 210 (1956).

[44] R. S. Krishnan, Proc. Indian Acad. Sci. 31A, 435 (1950).

[45] J. J. Lander, J. Chem. Phys. 17, 892 (1949).

[46] W. M. Latimer and J. E. Ahlberg, Z. physik. Chem. 148, 464 (1930).
[47] W. M. Latimer and J. E. Ahlberg, J. Am. Chem. Soc. 54, $1900(1932)$.

[48] A. W. Lawson, Phys. Rev. 57, 417 (1940).

[49] H. A. Levy and S. W. Peterson, Phys. Rev. 86, 766 (1952).

[50] H. A. Levy and S. W. Peterson, J. Chem. Phys. 21, 366 (1953).

[51] T. Liebisch and H. Reubens, Ber. Akad. Wiss. Berlin 198 (1919).

[52] J. Louisfert, Compt. rend. 241, 940 (1955).

[53] G. Lutz, Z. Krist. 114, 232 (1960).

[54] F. A. Mauer, Formation and Trapping of Free Radicals (Academic Press Inc., New York, N.Y., 1960) ch. 5.

[55] T. M. K. Nedungadi, Proc. Indian Acad. Sci. 14A, 242 (1941).

[56] Nernst and Schwers, Ber. Akad. Wiss. Berlin 355 (1914).

[57] R. Newman and R. S. Halford, J. Chem. Phys. 18, 1291 (1950).

[58] R. Newman and R. S. Halford, J. Chem. Phys. 18, 1276 (1950).

[59] L. Pauling, Phys. Rev. 36, 430 (1930).

[60] L. Pauling and J. Sherman, Z. Krist. 84, 213 (1933).

[61] R. C. Plumb and D. F. Hornig, J. Chem. Phys. 21, 366 (1953).

[62] A. K. Ramdas, Proc. Indian Acad. Sci. 37A, 441 (1953).

[63] B. L. Rao, Proc. Indian Acad. Sci. 14A, 48 (1941).

[64] B. S. R. Rao, Proc. Indian Acad. Sci. 19A, 93 (1944).

[65] S. Satoh, J. Sci. Research Inst. 48, 59 (1948).

[66] C. Schaefer, C. Bormuth, and F. Matossi, Zeit. f. Phys. 39, 648 (1926).

[67] C. H. Shomate and K. K. Kelley, J. Am. Chem. Soc. 66, 1490 (1944)

[68] L. A. Siegel, J. Chem. Phys. 17, 1146 (1949).

[69] W. V. Smith, O. L. Brown, and K. S. Pitzer, J. Am. Chem. Soc. 59, 1213 (1937).

[70] J. C. Southard and R. A. Nelson, J. Am. Chem. Soc. 55, 4865 (1933)

[71] Standard X-Ray Diffraction Powder Patterns, NBS Circular 539, Vol. 1-6.

[72] C. C. Stephenson, L. A. Landers, and A. G. Cole, J. Chem. Phys. 20, 1043 (1952).

[73] L. Vegard and L. Bilberg, Norske Videns. Akad. Oslo, 1931-1933.

[74] E. L. Wagner and D. F. Hornig, J. Chem. Phys. 18, 296 (1950).

[75] E. L. Wagner and D. F. Hornig, J. Chem. Phys. 18, 305 (1950).

[76] L. Waldbauer and D. C. McCann, J. Chem. Phys. 2, 615 (1934).

[77] C. E. Weir and E. R. Lippincott, J. Research NBS, 65A, 173 (1961).

[78] H. Winston and R. S. Halford, J. Chem. Phys. 17, 607 (1949).

[79] R. W. G. Wyckoff, Am. J. Sci. 9, 145 (1925).

(Paper 66A5-176) 